\title{
5 Eine erste südosteuropäische Waffen- SS-Division: Die Division „Prinz Eugen“
}

\section{1 Übersicht}

Obwohl Himmler, Berger und Lorenz bereits zwischen 1939 und 1940 eine erste größere Rekrutierungsanstrengung in Rumänien unternommen hatten ${ }^{1}$ und noch während laufender Kriegshandlungen im April 1941 unter den „Volksdeutschen" Jugoslawiens rekrutieren ließen, ${ }^{2}$ begann die eigentliche Aufstellung der SS-Freiwilligen-Gebirgs-Division „Prinz Eugen“ erst ein Jahr später, im Frühjahr 1942. ${ }^{3}$ Bereits ein halbes Jahr früher, am 6. November 1941, hatte aber „Volksgruppenführer“ Josef „Sepp“ Janko Himmler den Vorschlag gemacht, eine nur aus „Volksdeutschen“ bestehende Formation aufzustellen, die es den reichsdeutschen Divisionen erlauben sollte, sich aus dem Banat zurückzuziehen. ${ }^{4}$ Bei dieser Besprechung zwischen Janko, Himmler und „Volksgruppenführer“ Branimir Altgayer wurde schließlich die Aufstellung eines „Banater Regiments“ zur Partisanenbekämpfung beschlossen. ${ }^{5}$ Im Februar 1942 erhielt schließlich Artur Phleps den Auftrag, eine „volksdeutsche“ Division, die als Division „Prinz Eugen“ bekannt werden sollte, aufzubauen. Phleps, selbst ein „Volksdeutscher“ aus Siebenbürgen, mit einer für diese Region typischen Militärkarriere in der k.u.k.- und nach dem Ersten Weltkrieg in der rumänischen Armee, hatte bereits 1941 darum gebeten, sich der deutschen Waffen-SS anschließen zu dürfen. ${ }^{6}$

Die „Prinz Eugen“ war die erste von vier südosteuropäischen Waffen-SS-Divisionen, die bis Sommer 1944 aufgestellt werden sollten. Sie existierte bis zum Kriegsende im Mai 1945. Ihre Aufstellung kann als direkte Folge der ersten großen Niederlagen an der Ostfront gesehen werden: Die gescheiterte Offensive auf Moskau und die durch den russischen Winter 1941/42 verursachten Nachschubprobleme hatten bei den unzureichend ausgerüsteten deutschen Truppen

1 Vgl. Milata, Zwischen Hitler, Stalin und Antonescu, S. 49.

2 Vgl. Casagrande, Volksdeutsche SS-Division, S. 167.

3 Vgl. Mehner, Waffen-SS und Polizei, S. 12, 144, 200 oder auch Heinz Höhne, Der Orden unter dem Totenkopf. Die Geschichte der SS. (Erstausgabe 1967), hier: München: Orbis 2002, S. 437. Die Nummerierung der Waffen-SS-Divisionen erfolgte erst im Oktober 1943. Von diesem Zeitpunkt an ist von der 7. SS-Freiwilligen-Gebirgs-Division „Prinz Eugen“. Vgl. Mehner, WaffenSS und Polizei, S. 200 f.

4 Vgl. Casagrande, Volksdeutsche SS-Division, S. 185.

5 Vgl. Casagrande, Unsere Gegner, S. 166.

6 Vgl. Milata, Zwischen Hitler, Stalin und Antonescu, S. 53 f. und Casagrande, Volksdeutsche SSDivision, S. 189. 
hohe Verluste zur Folge. Durch das Bekanntwerden der Niederlagen stiegen auch die Partisanenaktivitäten in den südosteuropäischen Gebieten an - seit Spätsommer 1942 sogar exponentiell. ${ }^{7}$ Die einsetzenden massenhaften Rekrutierungen von „Volksdeutschen“ für die Waffen-SS sind als direkte Folge dieser veränderten Ausgangslage im Südosten und damit einhergehenden Personalengpässen zu verstehen. ${ }^{8}$ Aus jener ersten südosteuropäischen Division „Prinz Eugen“ rekrutieren sich seit Anfang 1943 auch die Kommandeure für die drei weiteren Balkan-Divisionen, „Handschar“, „Skanderbeg“ und „Kama“. Da „Volksdeutsche“ aus Südosteuropa neben ihren deutschen auch über slawische Sprachkenntnisse verfügten, waren sie für den Aufbau der geplanten muslimischen Divisionen unersetzliche Brückenbauer. ${ }^{9}$

Nicht nur im Banat und in Südserbien, sondern bis weit hinein nach Montenegro, Bosnien und Kroatien stand die „Prinz Eugen“ gegen Partisanen im Einsatz. ${ }^{10}$ Bereits bei ihren ersten Einsätzen gingen ihre Divisionsangehörigen brutal gegen Zivilisten vor. ${ }^{11}$ Die „Prinz Eugen“ gilt nach heutigem Kenntnisstand als besonders grausam und hinterließ in den Gebieten Südosteuropas eine Spur der Gewalt und Zerstörung. ${ }^{12}$ Ganze Dörfer wurden durch sie ausgelöscht, tausende Zivilisten erschossen.

Die Tatsache, dass Einheiten der „Prinz Eugen“ für zahlreiche Kriegsverbrechen verantwortlich sind, darf aber nicht darüber hinwegtäuschen, dass viele der Divisionsangehörigen nicht freiwillig der Waffen-SS beigetreten waren, sondern für deutsche Interessen instrumentalisiert wurden, wie der Zeitzeuge Friedrich Binder 1979 rückblickend feststellte. ${ }^{13}$ Auch Schmidhuber gab in Kriegsgefangenschaft sarkastisch zu Protokoll:

7 Vgl. Janko, Weg und Ende der deutschen Volksgruppe, S. 212; Schmider, Jugoslawischer Kriegsschauplatz, S. 1015.

8 Berhard R. Kroener, Die personellen Ressourcen des Dritten Reiches im Spannungsfeld zwischen Wehrmacht, Bürokratie und Kriegswirtschaft 1939-1942, in: Kroener, Bernhard R.; Müller, Rolf-Dieter; Umbreit, Hans, Organisation und Mobilisierung des deutschen Machtbereichs, hg. vom Militärgeschichtlichen Forschungsamt Potsdam, Das Deutsche Reich und der Zweite Weltkrieg, Bd. 5/1, Stuttgart: Deutsche Verlags-Anstalt 1988, S. 891-894.

9 Vgl. Zaugg, Albanische Muslime, S. 227. So verstanden Albaner aus Kosovo und umliegenden Gebieten meistens Serbisch bzw. Türkisch, für die übrigen Albaner musste zuerst von Deutsch auf Serbisch und dann von Serbisch auf Albanisch übersetzt werden. Vgl. von Pistor an Vopersal, ohne Datum, BArchF, N756/182b.

10 Vgl. beispielsweise Schmider, Partisanenkrieg, S. 449.

11 Vgl. Schmider, Partisanenkrieg, S. 444. Vgl. auch Schmider, Jugoslawischer Kriegsschauplatz, S. 1030.

12 Vgl. Sundhaussen, Waffen-SS in Kroatien, S. $194 \mathrm{f}$.

13 Wittmann, Anna M., Mutiny in the Balkans: Croat Volksdeutsche, The Waffen-SS and Motherhood, S. 255. 
Die Bezeichnung ,Freiwilligen'-Geb.Div. erhielt die Division vom Reichsführer SS, Heinrich Himmler, nicht etwa weil die deutschen Männer des Banats als Einzelne sich freiwillig zur Truppe meldeten, sondern weil der Führer der deutschen Volksgruppe, Dr. Sepp Janko, sich freiwillig erbat, den Propaganda- und Organisationsapparat der Volksgruppenführung einzusetzen, um die Aufstellung der Division zu ermöglichen. ${ }^{14}$

Die Diskussionen über die Schuldzuweisungen und die damit einhergehende Frage nach Freiwilligkeit und Zwang halten im Falle aller hier vorgestellten Waffen-SS-Divisionen bis heute an. Erhellend ist in diesem Zusammenhang Anna Wittmanns Aussage, die mit Bezug auf George Stein und Hans-Werner Schuster schreibt, die Brutalität der Kriegführung sei kein Spezifikum der „volksdeutschen“ Zusammensetzung der Division „Prinz Eugen“ gewesen, sondern integraler Bestandteil deutscher Kriegführung bei der Partisanenbekämpfung im Allgemeinen. ${ }^{15}$ Damit hat sie sicherlich recht, denn blickt man nach Osteuropa, zeigt die Brutalität deutscher Truppen im so genannten „Vernichtungskrieg“" gegen die Sowjetunion ähnliche Ausmaße. ${ }^{16}$

Doch trotz dieses Umstands scheinen in einigen Dörfern auch alte Rechnungen beglichen worden zu sein. Und auch die ethnische Zusammensetzung der Dorfbevölkerung dürfte beim Grad der Radikalität eine Rolle gespielt zu haben. ${ }^{17}$ Mit Blick auf die „Prinz Eugen“ und die doch sehr unterschiedlichen Darstellungen sind aber weder die durch Paul Hausser, Otto Kumm oder Johann Böhm unternommenen Versuche, die Division von Schuld freizusprechen, noch die undifferenzierte Verdammung der „Prinz Eugen“, wie sie oft in der jugoslawischen und post-jugoslawischen Geschichtsschreibung und in Zeitungen dieser Länder anzutreffen ist, ${ }^{18}$ als Herangehensweise fruchtbar. Vielmehr gilt es, wie dies Paul Milata hinsichtlich der rumänischen Divisionsangehörigen tut, nach Motivationen, Intentionen und Zwängen innerhalb von Gruppen, aber auch

14 August Schmidhuber, Kriegsgefangenenbericht, Juni 1946 (genaues Datum nicht angegeben), VA HEM.OK.BOJCKA, 72/2-1/3.

15 Wittmann, Croat Volksdeutsche, S. 256.

16 Vgl. etwa Dieter Pohl, Die Herrschaft der Wehrmacht. Deutsche Militärbesatzung und einheimische Bevölkerung in der Sowjetunion 1941-1944, München: Oldenbourg $2009^{2}$ oder als Versuch einer Bilanz anhaltender Debatten: Christian Hartmann; Johannes Hürter; Ulrike Jureit, Verbrechen der Wehrmacht. Bilanz einer Debatte, München: C.H. Beck, 2005.

17 Im Bestand 110 des Arhiv Jugoslavije sind hierzu zahlreiche Ortsnamen zu finden, so etwa Rekrutierungen aus Vinkovci.

18 Vgl. Paul Hausser, Soldaten wie andere auch. Der Weg der Waffen-SS, Osnabrück: Munin 1966. Otto Kumm, Vorwärts Prinz Eugen! oder Johann Böhm, Die deutschen Volksgruppen im unabhängigen Staat Kroatien und im serbischen Banat: ihr Verhältnis zum Dritten Reich 1941-1944, Frankfurt a.M. u. a.: Lang 2012. Vgl. auch Frano Glavina, Stravican pokolj u cetinskoj krajini, https://kamenjar.com/stravican-pokolj-u-cetinskoj-krajini/ (Stand: 11.2.2019). 
bei Individuen $\mathrm{zu}$ fragen, die sich nach Ort und Zeitpunkt stark unterscheiden konnten. ${ }^{19}$

\subsection{Zwischen Neuanfang und Verfolgung: Die Situation der südosteuropäischen „Volksdeutschen“ nach dem Balkanfeldzug 1941}

Südosteuropäischen „Volksdeutschen“, die sich vielerorts vor dem Balkanfeldzug der Wehrmacht im April 1941 als Teil der Vielvölkergemeinschaft auf dem Balkan gesehen hatten, wurde nun eingeschärft, dass sie „als Bollwerk des Reiches den Raum an den schnittigen Brennpunkten halten müss[ten], um die nun einmal für das Reich lebensnotwendige Ader, die Donau, zu sichern und zu halten. ${ }^{20}$ Berger war sich sicher, dass diese nationalsozialistische Propaganda Wirkung gezeigt habe, denn „selbst bei den einfachsten Volksdeutschen ist diese politische und wirtschaftliche Notwendigkeit in Fleisch und Blut übergangen.“21 Für die bevorstehenden Rekrutierungen sollten sich diese „Volksdeutschen“ ihres „Deutschtums“ bewusst werden, um für ein neues Europa unter deutscher Vorherrschaft zu kämpfen und zu sterben. ${ }^{22}$

Viele der rund zwei Millionen „Volksdeutschen“ in Südosteuropa hatten aber kaum einen Bezug zu Deutschland. Sie lebten ein Leben weit weg vom „Reich“, hatten zwar viele deutsche Traditionen bewahrt, andere aber zugunsten der lokalen Kultur, teilweise auch auf Druck der jugoslawischen Regierung, aufgegeben. ${ }^{23}$ Allen „volksdeutschen“ Gemeinschaften war immanent, dass es sich um relativ geschlossene Gefüge handelte. Ihre Vorfahren waren schon vor Generationen aus deutschsprachigen Gebieten ausgewandert bzw. umgesiedelt worden. Die meisten deutschen Siedler waren im Laufe des 18. Jahrhunderts in drei größeren Wellen nach Südosteuropa gekommen. Die erste Einwanderungswelle erfolgte auf Vorschlag Prinz Eugens von Savoyen: Graf Claudius Florimund de Mercy erhielt den Auftrag, die kaiserliche Herrschaft im Banat aufzubauen und sich um die Errichtung der Kolonistensiedlungen zu kümmern. ${ }^{24}$ Zwei wei-

19 Vgl. beispielsweise Milata, Zwischen Hitler, Stalin und Antonescu, S. 4 oder Wittmann, Croat Volksdeutsche, S. 256.

20 Bericht Berger an Chef der Volksdeutschen Mittelstelle, SS-Obergruppenführer Werner Lorenz, betr. „Lage der Volksdeutschen in Kroatien“, 21.2.1942, BArchB, NS19/319, Bl. 76.

21 Ebd.

22 Vgl. Wegner, Soldaten, S. 310.

23 Vgl. Wittmann, Croat Volksdeutsche, S. 255.

24 Vgl. Casagrande, Volksdeutsche SS-Division, S. 89. 
tere Einwanderungswellen folgten unter Kaiserin Maria Theresia und Kaiser Joseph II. gegen Ende des 18. Jahrhunderts. Wie Casagrande betont, kann diese Ansiedlung als bevölkerungspolitische Maßnahme gewertet werden, hatte sie doch zum Ziel, die Südgrenze der Habsburger Monarchie gegen das Osmanische Reich abzusichern. Einerseits sollte damit eine militärische Grenze geschaffen, andererseits diese Randregion auf sozioökonomischer Ebene auch langfristig in das Habsburgerreich integriert werden. ${ }^{25}$ Die Art und Weise der Ansiedlung, die manchmal auch mit Zwangsumsiedlungen der bereits dort lebenden lokalen Bevölkerung einherging, sowie die ungleiche Behandlung und sehr unterschiedliche soziale Aufstiegschancen der lokalen und zugewanderten Bevölkerung schufen rasch ethnische Probleme, die seither die Region belasteten und letztlich auch die Rekrutierungsbereitschaft für die Waffen-SS erhöhten. ${ }^{26}$

Seit die Nationalsozialisten 1933 an die Macht kamen, insbesondere aber seit Kriegsbeginn verfolgten die „Volkdeutschen“ Südosteuropas das Näherrücken des Deutschen Reiches mit großer Aufmerksamkeit. Als Hitler im Frühjahr 1941 Jugoslawien angriff und zerschlug, versprachen sich viele von ihnen Vorteile aufgrund ihrer „rassischen“ Herkunft. Zahlreiche „Volksdeutsche“ traten daher schon während des Balkanfeldzugs auf Seiten der Deutschen in den Krieg ein und die jugoslawische Regierung warf ihnen vor, als „Fünfte Kolonne“ im Einsatz zu stehen. ${ }^{27}$ Casagrande betont, dass zwar die Teilnahme von „Volksdeutschen“ am Kampf in Serbien und Kroatien für den Ausgang der Kriegshandlungen nicht relevant gewesen sei, dass sie aber ein Ausdruck ideeller und organisatorischer Parteinahme für das „Dritte Reich“ war. ${ }^{28}$

Es lassen sich grob zwei Arten von „Volksdeutschen“ unterscheiden: zum einen solche, die sich bewusst als „Deutsche“ von der übrigen Bevölkerung abgrenzten oder sogar in Konflikt mit ihr standen. So rückte etwa die „Volkszugehörigkeit“ bei der „volksdeutschen“ „Erneuerungsbewegung“ im Jugoslawien

25 Vgl. ebd., S. $89 \mathrm{f}$.

26 Vgl. ebd., S. 92-98.

27 Vgl. ebd., S. $157 \mathrm{f}$.

28 Vgl. ebd., S. 158. Ähnlich war das Verhalten vieler „Volksdeutscher“ in Polen, die in Grenzgebieten zu Deutschland auch in der Zwischenkriegszeit in paramilitärischen Verbänden, als „Freikorps“, organisiert waren und kurz nach Kriegsbeginn von den Deutschen zum sogenannten „volksdeutschen Selbstschutz“ zusammengefasst wurden. Dieser „Selbstschutz“ aus polnischen „Volksdeutschen“ bestand zwar nur wenige Monate, war aber verantwortlich für die Ermordung von rund 10.000 Menschen. Vgl. Böhler, Civil War oder auch Jochen Böhler, Der Überfall. Deutschlands Krieg gegen Polen, Frankfurt a.M.: Eichborn 2009, S. 13-17, 137. Vgl. auch Arno Weckbecker; Christian Jansen, Der „Volksdeutsche Selbstschutz“, S. 8. 


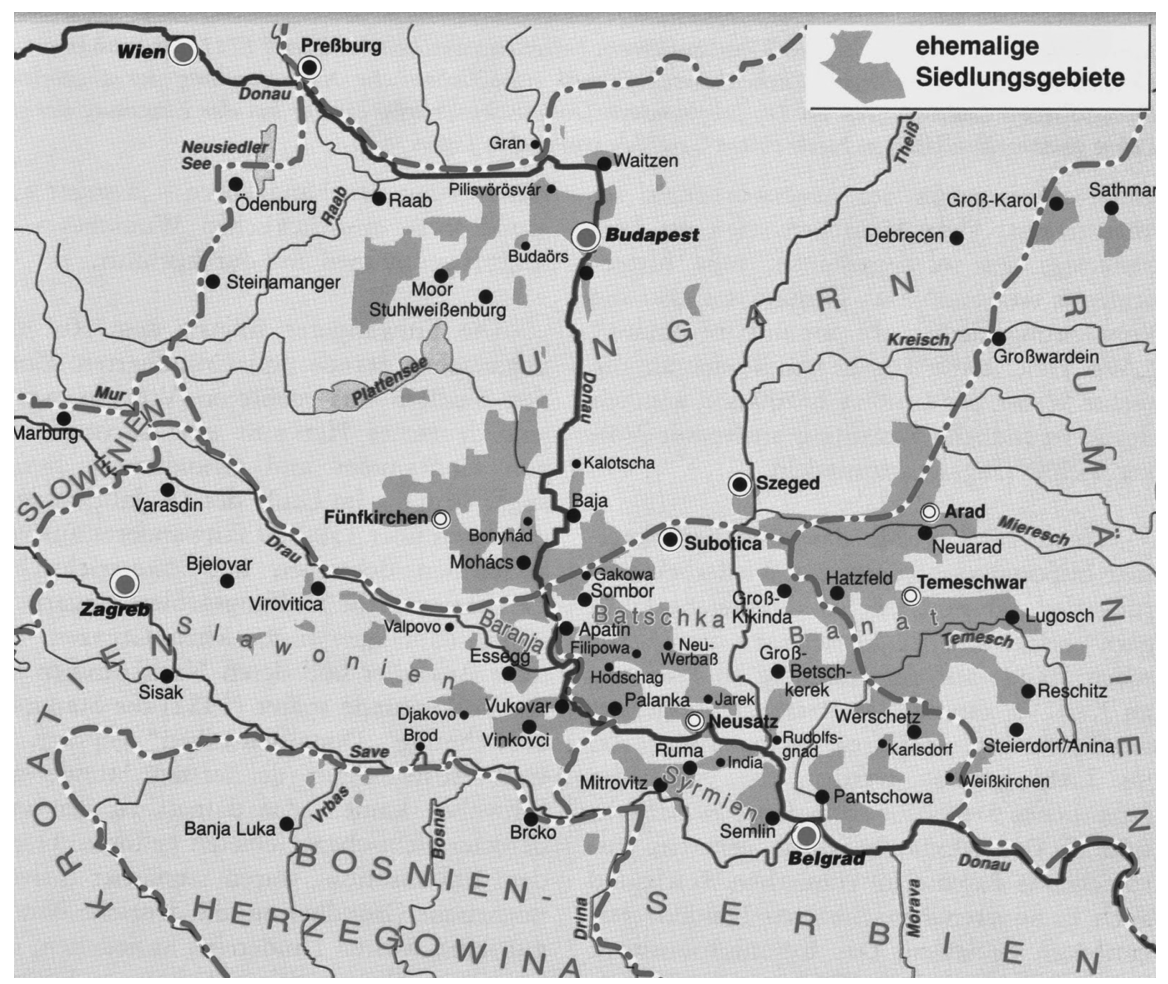

Abb. 4: Die Grafik zeigt die Verteilung der ehemaligen „volksdeutschen“ Siedlungsgebiete auf die verschiedenen südosteuropäischen Staaten. ${ }^{29}$

bereits in der Zwischenkriegszeit in den Vordergrund. ${ }^{30}$ Zum anderen lebten aber auch „Volksdeutsche“ in Südosteuropa, die sich über Jahrzehnte oder Jahrhunderte in ihre regionale Umgebung integriert hatten, die friedlich mit ihren orthodoxen, katholischen und muslimischen Nachbarn lebten, mit Angehörigen anderer Religionen verheiratet waren und teilweise die deutsche Sprache

29 Grafik ehemaliger deutscher Siedlungsgebiete in Südosteuropa: http://varietatendeutscher sprache.blogspot.ch/2014/06/donauschwaebisch.html (Stand: 1.12.2019).

30 Vgl. Casagrande, Volksdeutsche SS-Division, S. 156. Vgl. auch Janko, Weg und Ende der deutschen Volksgruppe, S. 30-34. 
nicht mehr beherrschten. ${ }^{31}$ Größer als ethnische Unterschiede scheint in dieser Zeit der Unterschied zwischen arm und reich gewesen zu sein. ${ }^{32}$

Teile der „volksdeutschen“ Minderheiten waren allerdings bereits im Ersten Jugoslawien unter Druck geraten: In einigen Gebieten wurde die deutsche Sprache verboten und deutsche Schulen wurden geschlossen. ${ }^{33}$ Wer seine Anstellung behalten wollte, musste die serbokroatische Sprache beherrschen. ${ }^{34}$ Gerade aufgrund ihrer besseren serbokratischen Sprachkenntnisse und die dadurch zumindest in Teilen erfolgreiche Integration, identifizierten sich die jüngeren Generationen "Volksdeutscher" in den Gebieten Kroatiens, Bosniens und Serbiens leichter mit dem jugoslawischen Staat. Andererseits traten bereits im Jugoslawischen Königreich Spannungen zwischen der slawischen und „volksdeutschen“ Bevölkerung auf, die auch eine parlamentarische Vertretung der "volksdeutschen" Bevölkerungsteile nicht zu beheben vermochte. ${ }^{35}$

Für diese "Volksdeutschen" im Ersten Jugoslawien brach mit dem Balkanfeldzug im April 1941 eine neue Zeit an. Im nun zum NDH gehörenden Teil entstand unter Volksgruppenführer Branimir Altgayer eine „Organisation und Einrichtungen nach reichsdeutschem Vorbild““. ${ }^{36}$ Auch der seit Juni 1939 eingesetzte Vorsteher der „Volksdeutschen“ im Banat und Serbien, Sepp Janko, berichtete von tiefgreifenden Veränderungen. ${ }^{37}$ Doch trotz der Stärkung ihrer Rechte mussten zahlreiche „Volksdeutsche“ auf dem Gebiet des ehemaligen Königreichs Jugoslawien teilweise ihre Heimat verlassen und wurden im Rahmen eines großangelegten nationalsozialistischen Umsiedlungsprogramms deportiert. Viele „Bosniendeutsche“ wurden beispielsweise nach Łódz/Litzmannstadt umgesiedelt. Solche Umsiedlungen riefen in der „volksdeutschen“ Bevölkerung oft Empörung hervor, da sie befürchtete, dass das Reich die „alte Grenze an der Save“ wie auch die Donau und somit

31 Bernwald etwa schreibt, dass sein Vater, um dem Zusammenleben verschiedener Kulturen auf dem Balkan Respekt zu zollen, für ihn und seine Brüder je den Namen eines russischen, eines kroatischen und eines österreichischen Herrschers gewählt habe. Vgl. Bernwald, Muslime in der Waffen-SS, S. 14. Zur Nicht-Beherrschung der deutschen Sprache vgl. beispielweise Alois Gasparitsch aus Slavonski Brod, welcher zwar dem Deutschen Kroatenbund (DKB) angehörte, jedoch der deutschen Sprache nicht mächtig war, Akte Alois Gasparitsch, AJ, 110/F702/Nr. 2114.

32 Vgl. Bernwald, Muslime in der Waffen-SS, S. 16-22.

33 Vgl. Casagrande, Schvarc, Spannenberger, Traşca, Volksdeutsche, S. 212.

34 Vgl. Janko, Weg und Ende der deutschen Volksgruppe, S. 52.

35 Vgl. ebd., S. 45, 52.

36 Vgl. Bericht Berger an Chef der Volksdeutschen Mittelstelle, SS-Obergruppenführer Werner Lorenz, betr. „Lage der Volksdeutschen in Kroatien“, 21.2.1942, BArchB, NS19/319, Bl. 67.

37 Vgl. Janko, Weg und Ende der deutschen Volksgruppe, S. 38. 
ihre Siedlungsgebiete aufgegeben würde. ${ }^{38}$ Letztlich waren insbesondere im Gebiet des NDH auch „Volksdeutsche“ von Übergriffen durch Banden bedroht, die beim Einmarsch 1941 nicht für die deutschen Besatzer Partei ergriffen hatten. ${ }^{39}$

Etwas anders gestaltete sich die Situation von „Rumäniendeutschen“, da sie nicht unter direkter nationalsozialistischer Herrschaft standen wie in Serbien, sondern, wie im NDH, Bürger eines verbündeten Staates unter Ion Victor Antonescu waren. Doch auch im Falle Rumäniens wurden die „Volksdeutschen“, insbesondere beim Militärdienst, als minderwertige Bürger behandelt. ${ }^{40} \mathrm{Im}$ Falle Ungarns hatten Teile der ungarischen Elite um Miklós Horthy nichts dagegen, den SS-Werbern den Zugriff auf die deutsche Volksgruppe zu gewähren, um sich ihrer zu entledigen, wie Ungváry schreibt. ${ }^{41}$

\subsection{Ausgangslage und Absichten auf deutscher Seite}

In diese Kapitel sollen Voraussetzungen und Vorgehensweisen auf deutscher Seite aufgezeigt werden, um zu verdeutlichen, auf welchen Motivationshintergründen oder Zwängen die Rekrutierungen basierten. Unterteilen lassen sie sich in zwei Gruppen, in positive Motivationsfaktoren bzw. Intentionen auf der einen und in Zwänge auf der anderen Seite, welche die SS-Spitze, aber auch NS-Vertreter vor Ort dazu veranlassten, die Rekrutierung einer „volksdeutschen“ Division zu fördern.

Einen wesentlichen Beitrag im Bereich der Rekrutierung „Volksdeutscher“ leistete die „Volksdeutsche Mittelstelle“ (VoMi), die von Werner Lorenz geleitet seit 1941 als SS-Hauptamt fungierte und Himmler direkt unterstellt war. Auf Seiten der VoMi stellten aber die verschiedenen, teilweise parallellaufenden Rekrutierungsvorhaben von „Volksdeutschen“ auf dem Balkan nur einen kleinen Teil eines viel mächtigeren Programms von Umsiedlungen und der Einbindung „Volkdeutscher“ in ein zukünftiges nationalsozialistisches Europa und den „Kampf gegen den Bolschewismus“ dar. ${ }^{42}$

38 Vgl. Bericht Berger an Chef der Volksdeutschen Mittelstelle, SS-Obergruppenführer Werner Lorenz, betr. „Lage der Volksdeutschen in Kroatien“, 21.2.1942, BArchB, NS19/319, Bl. 77.

39 Vgl. Casagrande, Volksdeutsche SS-Division, S. 156, 180.

40 Vgl. Casagrande, Schvarc, Spannenberger, Traşca, Volksdeutsche, S. 214.

41 Nach Ungvárys Angaben wurden schließlich 122.860 Ungarn mit deutschen Wurzeln rekrutiert, davon rund 80.000 unfreiwillig. Vgl. Ungváry, Kriegsschauplatz Ungarn S. 862f.

42 Vgl. Casagrande, Volksdeutsche SS-Division, S. $323 \mathrm{f}$. 


\subsubsection{Die involvierten deutschen Dienststellen}

Da sich die Rekrutierung von „Volksdeutschen“ über mehrere Staaten erstreckte, werden hier die einzelnen Dienststellen, ihre Absichten und Vorgehensweisen kurz vorgestellt. Grob kann man die deutschen Akteure in drei Gruppen einteilen: Erstens agierten sie, wie etwa das SS-Hauptamt, das Auswärtige Amt oder der Sonderbeauftragte Südost, auf supranationaler Ebene, zweitens auf nationaler Ebene, wie die übergeordneten Stellen des Auswärtigen Amtes, der VoMi, der Wehrmacht und der Waffen-SS vor Ort, und drittens auf lokaler Ebene, beispielsweise Rekrutierungsleiter oder Divisionskommandeure. Soweit ihre Intentionen und Vorgehensweisen in eine ähnliche Richtung tendierten, konnten die verschiedenen Akteure Synergien nutzen. Allerdings lassen sich im Alltag auch mannigfach Auseinandersetzungen sowie kleinere und größere Konkurrenzkämpfe feststellen. Selbst innerhalb der SS führte die Überlappung von Kompetenzen zu Spannungen zwischen den dafür zuständigen Dienststellen, da Himmler als „Reichskommissar für die Festigung des deutschen Volkstums“ sowie als Reichsführer SS über das SS-Hauptamt für die Rekrutierungen in die Waffen-SS zuständig war. ${ }^{43}$

Nicht nur unterschiedliche Zuständigkeiten von SS-Dienststellen bei den Rekrutierungen für die „Prinz Eugen“ führten zu Auseinandersetzungen, ${ }^{44}$ auch über die Frage, ob nun „Volksdeutsche“ nur für die Wehrmacht, nicht aber für die Waffen-SS geworben werden durften, entbrannte ein Streit. Sundhaussen sah darin „ein[en] langwierige[n] Kampf zwischen SSHA auf der einen, dem OKW und AA bzw. der Gesandtschaft in Zagreb auf der anderen Seite.“ Erst Anfang 1943 wurden diese Differenzen beigelegt, nachdem das OKW und der Reichsführer SS vereinbart hatten, „dass die ES [Einsatzstaffel der Deutschen Mannschaft] am 1. Mai d. J. der 7. SS-Freiwilligen-Gebirgs-Division ,Prinz Eugen“ unterstellt werden sollte“. 45

Doch nicht nur zwischen SS und Wehrmacht, auch - und vor allem - mit dem Vertreter des Auswärtigen Amtes, Siegfried Kasche, und der „Volksgruppenführung“ kam es zu ständigen Diskussionen: Als Himmler im Herbst 1941 die Absicht äußerte, die gesamten zehn Prozent wehrpflichtiger „Volksdeutscher“ im Bereich des NDH, die bereits für die deutsche Wehrmacht im Einsatz standen, für seine Waffen-SS-Formationen zu beanspruchen, führten Kasche und „Volksgruppenführer“ Branimir Altgayer an, dass der deutschen Volksgruppe in diesem

43 Vgl. Sundhaussen, Waffen-SS in Kroatien, S. 181.

44 Ebd., S. 177.

45 Vgl. ebd., S. 180. Die Einsatzstaffel der Deutschen Mannschaft war eine paramilitärische Miliz im NDH bestehend aus „Volksdeutschen“. 
schweren Moment des „Volkstumskampfes“ nicht „zu viel Blut entzogen“ werden dürfte. ${ }^{46}$ Diese Überlegung hatte durchaus ihre Berechtigung, denn je mehr wehrpflichtige Männer aus den „volksdeutschen“ Gebieten abgezogen wurden, desto ungeschützter blieb die lokale Bevölkerung zurück und war Übergriffen gegnerischer Gruppierungen, so etwa Četniks, Ustaše und kommunistischen Partisanen, wehrlos ausgesetzt. ${ }^{47}$

Berger wollte jedoch mehr „Volksdeutsche“ für die Division „Prinz Eugen“ rekrutieren als nur zehn Prozent: Seiner Ansicht nach sollten 20.000 „Volksdeutsche“ der im Banat aufgestellten Division zugeführt werden. Himmler schlug daher vor, großangelegte Umsiedlungen durchzuführen, um die kleineren „volkdeutschen“ Siedlungen möglichen Übergriffen durch andere Ethnien zu entziehen. Dieses Vorhaben lehnte aber die Regierung des NDH kategorisch ab. ${ }^{48}$ Berger beharrte schließlich für die geplante Aufstellung auf einem Kontingent von 6.000 Mann. ${ }^{49}$

Er und andere Vertreter des Dritten Reiches sahen das „Deutschtum“ nicht nur durch Angriffe auf die „volksdeutsche“ Bevölkerung gefährdet, sondern auch durch die Unfähigkeit der „Volksgruppenführung“ im NDH, namentlich Altgayer, die nicht in der Lage schien, „eine gesunde Volkstums-Politik“ zu betreiben. Daneben befand die SS-Spitze auch Kasche für unfähig, da Berger der Überzeugung war, dass Kasche „das deutsche Volkstum und seine politische Bedeutung in diesem Raum ebenfalls nicht erkannt hat, bzw. nicht erkennen will oder dazu nicht in der Lage ist““. ${ }^{50}$ Dieses Unvermögen war für Berger mit ein Grund, weshalb Kasche die Rekrutierungen nicht unterstützte. Zwischen dem Vertreter des Auswärtigen Amtes und der Spitze der Waffen-SS herrschte nicht nur in Bezug auf die „Volksdeutschen“, sondern bei den Werbungen für alle vier südosteuropäischen Divisionen ein angespanntes Verhältnis, wie noch zu zeigen sein wird. ${ }^{51}$ Letztlich traute die SS-Spitze auch SS-nahen Institutionen wie der VoMi nicht: Selbst sie, so schien es Himmler, würde sich gegen die Rekrutierungen von „Volksdeutschen“ wenden, indem sie „die obersten Reichsstellen über die tatsächlichen Zustände nicht objektiv und klar“" unterrichten würde. ${ }^{52}$

46 Vortragsnotiz Luther zur Vorlage beim RAM, 18. 10.1941, PAAA, Inl. IIg, Bd. 305, nach: Sundhaussen, Waffen-SS in Kroatien, S. 181.

47 Vgl. ebd.

48 Vgl. ebd., S. 182.

49 Vgl. ebd.

50 Bericht Berger an Chef der Volksdeutschen Mittelstelle, SS-Obergruppenführer Werner Lorenz, betr. „Lage der Volksdeutschen in Kroatien“, 21.2.1942, BArchB, NS19/319, Bl. 68.

51 Vgl. Zaugg, Albanische Muslime, S. 111, 184.

52 Vgl. Himmler, 1942, BArchB, NS19/319. 
Nicht nur echte und vermeintliche Gegner aus den eigenen Reihen, sondern auch die faschistische kroatische Regierung unter Ante Pavelić stand den Rekrutierungen kritisch gegenüber, was Berger zur Äußerung veranlasste, Pavelić und sein Gefolge würden einen ,ausgesprochen deutsch-feindlichen Kurs mit dem Ziele der Ausrottung der deutschen Volksgruppe“ an den Tag legen. ${ }^{53}$ Das Misstrauen der SS-Führung gegenüber Mussolini, der „im Rahmen der Basis Rom-Budapest-Vichy-Madrid“ versuchte, einen katholischen gegen den germanischen Block aufzubauen, war deshalb letztlich naheliegend: Insgeheim wurde vermutet, dass die Italiener den anti-deutschen Widerstand unterstützen würden, da es sich bei den bei Partisanen gefundenen Waffen um italienische Fabrikate handelte. ${ }^{54}$ Dass die Italiener tatsächlich anti-deutsche Gruppierungen, insbesondere Četnik-Verbände, unterstützten, lässt sich heute belegen. ${ }^{55}$ Dennoch zeichnete diese durch die SS verkündete Propaganda bewusst eine schwierigere Ausgangslage der rund 200.000 „Volksdeutschen“ im bosnisch-kroatischen Raum, die, bedroht, ,angefeindet und bekämpft mit dem Ziel der Vernichtung und Ausrottung“, auf die „Hilfe“ der Deutschen angewiesen wären. Diese Hilfe in Form einer „volksdeutschen“ Waffen-SS-Einheit nahm schon bald konkrete Formen an. ${ }^{56}$

Wie bereits im Einleitungsteil beschrieben war es auch im Falle der „Prinz Eugen“ der Gesandte Kasche, der sich schon 1942 in die Rekrutierungsbemühungen der Waffen-SS einmischte. Ihm schienen diese Rekrutierungen in einem ,souveränen" Staat wie dem NDH unangebracht, ${ }^{57}$ und er betonte immer wieder, dass SS-Obersturmführer Günther Herrmann in ganz Kroatien mit Rekrutierungen begonnen hätte, ohne vorher mit ihm Rücksprache genommen zu haben. In diese Querelen mischte sich schließlich auch Unterstaatssekretär Martin Luther ein, der sich wiederum bei SS-Obergruppenführer und General der Waffen-SS Karl Wolff und bei Berger beschwerte. ${ }^{58}$

Da ähnliche Auseinandersetzungen zwischen deutschen Dienststellen auch für die Division „Handschar“ und die Division „Skanderbeg“ nachgewiesen werden können, wie noch zu zeigen sein wird, kann vermutet werden, dass es sich nicht um Einzelfälle handelte, sondern um Fehler eines Systems, dessen alte und

53 Bericht Berger an Chef der Volksdeutschen Mittelstelle, SS-Obergruppenführer Werner Lorenz, betr. „Lage der Volksdeutschen in Kroatien“, 21.2.1942, BArchB, NS19/319, Bl. 78.

54 Ebd.

55 Vgl. bspw. Schmider, Jugoslawischer Kriegsschauplatz, S. 1017.

56 Bericht Berger an Chef der Volksdeutschen Mittelstelle, SS-Obergruppenführer Werner Lorenz, betr. „Lage der Volksdeutschen in Kroatien“, 21.2.1942, BArchB, NS19/319, Bl. 68 f., 78.

57 Vgl. Sundhaussen, Waffen-SS in Kroatien, S. 178.

58 Vgl. Kapitel „Rekrutierungen im NDH“. Bspw. Luther an SS-Obergruppenführer Wolff, 5.11.1944, BArchB, NS19/319, Bl. 61. 
neue Institutionen miteinander konkurrierten. Auch ein Jahr später, 1943, hörte Kasche nicht auf, sich in Angelegenheiten der Division „Prinz Eugen“ einzumischen. Diesmal versuchte er, ältere Jahrgänge, die entlassen und in sogenannte „Ortswehr und Dorfschutz-Einheiten“ eingegliedert werden sollten, dem kroatischen Landwehrministerium zuzuführen. Berger wehrte sich jedoch, da er der Meinung war, dass diese Männer unter allen Umständen nach Hause entlassen werden sollten, einerseits weil die „volksdeutschen“ Gemeinden sonst ohne Schutz wären, andererseits weil sie sonst bei der Frühjahressaat als Arbeitskräfte auf den Höfen fehlen würden. ${ }^{59}$

Konkurrenzsituationen traten aber nicht nur zwischen dem Auswärtigen Amt und der Waffen-SS, sondern aufgrund knapper Personalressourcen auch zwischen Wehrmacht und Waffen-SS bei der Rekrutierung von „Volksdeutschen“ und später von „Fremdvölkischen“ auf. ${ }^{60}$ Diesen Umstand hatte eine Besprechung zwischen Keitel und SS-Obergruppenführer Karl Wolff im August 1942 zum Gegenstand: „Nunmehr tritt die Aufstellung derartiger Formationen seitens der Wehrmacht dadurch, dass der Wehrmacht hierfür ganz erhebliche umfassende Mittel zur Verfügung stehen, in schärfste Konkurrenz zu den bereits bestehenden Bataillonen der SS und beeinträchtigt schwerstens die weiterhin geplante Neuaufstellung solcher Verbände durch die SS.“61

\subsubsection{Auf der Suche nach neuen Personalressourcen}

Seit Kriegsbeginn entwickelte sich für Himmler und Berger, deren Rekrutierungsmöglichkeiten sich vor allem außerhalb der Reichgrenzen auftaten, zuerst die einzigartige Gelegenheit, später eine zunehmende Notwendigkeit, die Waffen-SS auf „Volksdeutsche“ und schließlich „Fremdvölkische“ auszuweiten. ${ }^{62}$ Schon seit 1939 interessierten sie sich für die in anderen europäischen Staaten lebenden „Volksdeutschen“, vor allem für jene in Südosteuropa. Dieses Interesse hatte zwei Gründe: Einerseits gedachten sie mit der Öffnung der Waffen-SS für „Volksdeutsche“, „reichsdeutsche“ Ressourcen in anderen Gebieten einsetzen zu können. So

59 Vgl. Berger an Himmler, 9.3.1943, BArchB, NS19/3523, Bl. $35 \mathrm{f}$.

60 Vgl. Kroener, „Menschenbewirtschaftung“, Bevölkerungsverteilung und personelle Rüstung in der zweiten Kriegshälfte (1942-1944), in: Kroener, Umbreit, Kriegsverwaltung, S. $992 \mathrm{f}$.

61 Aktennotiz für SS-Obergruppenführer Wolff zu einer Besprechung mit Generalfeldmarschall Keitel, 2.8.1942, BArchB, NS 19/550, Bl. 1. Vgl. hierzu auch Rempel, Gottlob Berger and the Waffen-SS Recruitment, S. 113.

62 Vgl. Sørlie, Sonnenrad und Hakenkreuz, S. $47 \mathrm{f}$. Vgl. Casagrande, Volksdeutsche SS-Division, S. 325 . 
schreibt Schmidhuber in Kriegsgefangenschaft: „Ihr [Division „Prinz Eugen“] Auftrag war damals der Einsatz als Sicherungsdivision im serbischen Raum, um dadurch für den östlichen Kriegsschauplatz Truppen freizubekommen. “63 Andererseits würde ihnen die Zulassung „Volksdeutscher“ zur Waffen-SS Wege eröffnen, Soldaten zu rekrutieren, ohne mit dem OKW über Kontingente verhandeln zu müssen. ${ }^{64}$ Doch entgegen dieser Absicht, „volksdeutsche“ und, wenig später, „fremdvölkische“ Soldaten ohne langwierige Diskussionen für die Waffen-SS zu rekrutieren, sollten Berger und Himmler noch oft mit Vertretern der Wehrmacht und Diplomatie um Kontingente feilschen müssen. ${ }^{65}$

Ein Vorläufer der Rekrutierungen für die „Prinz Eugen“ und der Startpunkt der Massenrekrutierung von „Volksdeutschen“ in Südosteuropa markierte die „1.000-Mann-Aktion“ in Rumänien zwischen Oktober 1939 und Juni 1940. ${ }^{66}$ Eine vorangehende Aktion im Frühjahr 1939, die Berger mithilfe des Landesobmanns Fritz Fabritius ins Leben gerufen hatte, war an Protesten der rumänischen Regierung und des deutschen Gesandten in Bukarest, Wilhelm Fabricius, gescheitert. Dieser Vorfall offenbarte Himmler und Berger, dass eine massenhafte Rekrutierung von „Volksdeutschen“ in anderen Ländern unbedingt mit der jeweiligen Landesregierung abgesprochen werden musste, um eine zukünftige Zusammenarbeit in wirtschaftlicher, politischer und militärischer Hinsicht nicht zu gefährden. Andreas Schmidt, radikaler NSDAP-Anhänger aus Bukarest, erhielt den Auftrag, zwischen Oktober und Dezember 1939 1.000 Rumäniendeutsche für die SS zu gewinnen. Er überbot zwar die ihm vorgegebenen Rekrutierungskontingente und rekrutierte anstelle der 1.000 gleich 2.000 Rekruten, doch auf Protest der Regierung durften nur 1.000 Rumänen zur Ausbildung nach Deutschland ausreisen. Da Schmidts Engagement der NS-Führung nicht entgangen war, ernannten ihn Berger und Heydrich im Herbst 1939 zum „Stabsleiter in der Volksgruppe“ und im September 1940 wurde er durch die VoMi schließlich als „Volksgruppenführer“ der „deutschen Volksgruppe in Rumänien“ eingesetzt. ${ }^{67}$

63 August Schmidhuber, Kriegsgefangenenbericht, Juni 1946 (genaues Datum nicht angegeben), VA HEM.OK.BOJCKA, 72/2-1/2.

64 Vgl. Sundhaussen, Waffen-SS in Kroatien, S. 177. Nach Bergers Auffassung reichte der potentielle Rekrutierungsraum „,volksdeutscher“ Waffen-SS-Soldaten bis Nordamerika und Kanada. Dort waren in seinen Augen an die fünf Millionen „Volksdeutsche“ zu finden. Vgl. Casagrande, Südtiroler in der Waffen-SS, S. 21.

65 Vgl. beispielsweise Casagrande, Volksdeutsche SS-Division, S. 223, Zaugg, Albanische Muslime, S. 107-113 oder Rempel, Gottlob Berger and the Waffen-SS Recruitment, S. 107-109, 112, 115.

66 Vgl. Casagrande, Schvarc, Spannenberger, Traşca, Volksdeutsche, S. 214.

67 Vgl. Milata, Zwischen Hitler, Stalin und Antonescu, S. 49, 55. 
Neue Möglichkeiten der Rekrutierung eröffnete der Balkanfeldzug im Frühjahr 1941: Seit Mitte April 1941 hatten Berger und Himmler freien Zugriff auf alle „volksdeutschen“ Bewohner Serbiens. Sämtliche Männer zwischen 17 bis 50 Jahren sollten erfasst und bei Bedarf rekrutiert werden. ${ }^{68}$ Bereits im Dezember dieses Jahres forderte Himmler zur Verstärkung der Verbände der Waffen-SS die Rekrutierung weiterer 60.000 „Volksdeutscher“ aus Rumänien, Ungarn und der Slowakei. Kurze Zeit später gingen reichsdeutsche Stellen von weiteren 30.000 Rumäniendeutschen und deutschstämmigen Ungarn sowie zehn Prozent der „,volksdeutschen“ Wehrpflichtigen aus Kroatien aus. Doch Einwände des deutschen Gesandten in Bukarest, Manfred von Killinger, Ende Januar 1942 verhinderten vorerst weitere Rekrutierungen in Rumänien. ${ }^{69}$

Als im Frühjahr 1942 die „Volksgruppenführung“ im Banat und Serbien unter Sepp Janko gemeinsam mit Phleps die ersten großen Rekrutierungen für die „Prinz Eugen“ durchführten, wurde bald klar, dass die Banater Rekruten alleine noch keine Division stellen würden. Berger und Himmler sahen sich daher gezwungen, die Rekrutierungsanstrengungen auch auf Gebiete auszudehnen, die bisher aus außenpolitischen Gründen für größere Rekrutierungen gesperrt gewesen waren. ${ }^{70}$

Nun gerieten auch die von der VoMi auf 180.000 bis 200.000 geschätzte Zahl „Volksdeutscher“ innerhalb der Grenzen des NDH in den Fokus der SS-Werber. ${ }^{71}$ Doch Kasche, der stets die Interessen der Regierung Pavelić zu vertreten schien, äußerte sich bereits im Januar 1943 kritisch zu den laufenden Rekrutierungen von „Volksdeutschen“: „Es handelt sich nicht um eine ,Freiwilligen-Aktion in Kroatien“, sondern um eine vom RFSS befohlene, vom RAM [Reichsaußenminister] gebilligte und damit gegen die hier geltend gemachten Bedenken vorgeschriebene Maßnahme einer allgemeinen Rekrutierung der Wehrfähigen der Deutschen Volksgruppe in Kroatien." 72

Dennoch liefen die Rekrutierungsanstrengungen sowohl innerhalb des NDH als auch in umliegenden Ländern weiter: Im Frühjahr 1943 wies Himmler Berger

68 Vgl. Janko, Weg und Ende der deutschen Volksgruppe, S. 220.

69 Vgl. Milata, Zwischen Hitler, Stalin und Antonescu, S. 131. Siehe zur Heranziehung von „Volksdeutschen“ aus der Slowakei für die Waffen-SS auch: Martin Broszat, Heranziehung von slowakischen Staatsbürgern deutscher Volkszugehörigkeit für den Dienst in der Waffen-SS, in: Gutachten des Instituts für Zeitgeschichte 1 (1958), S. 412-417.

70 Vgl. Casagrande, Volksdeutsche SS-Division, S. 187.

71 Vgl. Sundhaussen, Waffen-SS in Kroatien, S. 181.

72 Kasche an AA, 25.1.1943, PAAA, Inland IIg, Bd. 307 nach Sundhaussen, Waffen-SS in Kroatien, S. 189. 
an, in Rumänien 20-30.000 „Volksdeutsche“ und 30-50.000 weitere in Ungarn zu rekrutieren. Letzterer organisierte schließlich im Laufe des Jahres 1943 die Rekrutierung von rund 50.000 Rumäniendeutschen. ${ }^{73}$ Am 30. April 1944 erreichte Deutschland mit einer zwischenstaatlichen Vereinbarung mit Ungarn sogar den Zugriff auf alle männlichen ungarischen Staatsbürger zwischen 17 und 55 Jahren, die sich als Deutsche bezeichneten oder durch ihre „Lebensweise und ihre Volkstums-Merkmale“ als solche eingestuft wurden. ${ }^{74}$

\subsubsection{Kontrolle über die Bevölkerung}

Ein weiterer wesentlicher Faktor, welcher den Aufbau der „Prinz Eugen“ begünstigte, war die angestrebte Kontrolle über Bevölkerungen und ihre Gebiete durch die „Volksgruppenführung“. Die so genannten „Volksgruppenführer“ der jeweiligen Länder bzw. Regionen wurden von Beginn an intensiv in der Werbung eingesetzt. Sie kannten die Situation und die Menschen vor Ort, womit sie als Kontrollinstanz fungierten, die in der Rekrutierung der „Volksdeutschen“ aufging. Um Zugriff auf die „volksdeutschen“ Siedlungsgebiete zu erhalten, kam auch für Südosteuropa das Argument des „Schutzes der deutschen Minderheiten“ zum Zuge, mit welchem unter anderem schon der Angriff auf Jugoslawien gerechtfertigt worden war. ${ }^{75}$

Wie bereits gezeigt war es vor allem die VoMi unter Werner Lorenz, welche auf übergeordneter Ebene Umsiedlungen dieser „Volksdeutschen“ koordinierte und somit auch Einblick in ihre Siedlungsgebiete hatte. Um diesen Rekrutierungen für die „Prinz Eugen“ den Schein „rassischer“ Reinheit zu geben, wurden die „Volksdeutschen“ Südosteuropas in drei Gruppen unterteilt:

A.) Hieß: Charakterlich, volkspolitisch einwandfrei, sozial sichergestellt. B.) Hieß: Charakterlich einwandfrei, volkspolitisch unzuverlässig. Da Mischehen eingegangen oder aus Mischehe stammend. Wobei keine Gewähr für die deutsche Erziehung der Kinder gegeben ist. Ebenso fielen in diese Gruppe jene, die rein deutscher Abstammung sind, aber schwer in eine sozial gehobene Stellung untergebracht werden können, bez. den Arbeitsplatz

73 Vgl. Milata, Zwischen Hitler, Stalin und Antonescu, S. 131f. Vgl. auch Milata, Rumäniendeutsche Freiwillige, S. 217.

74 Vgl. Krisztián Ungváry, Kriegsschauplatz Ungarn, in: Karl-Heinz Frieser u. a., Die Ostfront 1943/44 - Der Krieg im Osten und an den Nebenfronten, Reihe: Das Deutsche Reich und der Zweite Weltkrieg, Bd. 8, im Auftrag des MGFA hrsg. von Karl-Heinz Frieser, Deutsche VerlagsAnstalt, München 2007, S. 862. Vgl. Casagrande, Schvarc, Spannenberger, Traşca, Volksdeutsche, S. 216.

75 Vgl. Casagrande, Volksdeutsche SS-Division, S. 156. 
gerne wechseln. C.) Hieß: Zu viel serbisches [oder rumänisches, ungarisches, kroatisches, Anm. der Autorin] Blut, absolut unzuverlässig, asozial. C. wurde endgültig aus der Volksgruppe ausgeschlossen und ihr die Zugehörigkeit zum Deutschtum aberkannt. ${ }^{76}$

Doch bereits bei der Gruppe B, die im Banat 323 Familien bzw. insgesamt 1.765 Personen umfasste, war sich „Volksgruppenführer“ Janko sicher, dass sie nur „rassisch“ aufgewertet werden konnten, wenn sie ins Reich umgesiedelt würden, und auf diese Weise fern von ihrer „volksfremden“ Umgebung in Serbien „deutsche“ Erfahrungen sammeln könnten. Trotzdem konnte er sich nicht dazu durchringen, den Befehl zur Umsiedlung zu erteilen, da er aus dieser Gruppe B bereits zahlreiche Männer für den Dienst in der „Prinz Eugen“ verpflichtet hatte. ${ }^{77}$

Nicht nur die Kontrolle der „volksdeutschen“ Bevölkerung wurde angestrebt, über die „volksdeutschen“ Divisionsangehörigen sollte auch die Kontrolle der serbischen Bevölkerung erreicht werden:

Zur Erfüllung dieses Auftrags erschienen die Banater Volksdeutschen besonders geeignet, weil sie die serbische Sprache beherrschten $u[n d]$ die serbische Mentalität im allgemeinen kennen mussten. Man erwartete davon vor allem auch eine reibungslose $u[n d]$ verständige Zusammenarbeit mit der serb[ischen] Bevölkerung des Landes, das 1942 vorwiegend unter der Propaganda und der Organisationsarbeit des Draža Mihailović stand. ${ }^{78}$

\subsubsection{Orts- und sprachkundige Führer}

Orts- und sprachkundige Freiwillige waren sowohl für die Verbände der WaffenSS als auch der Wehrmacht während des Einmarschs und der darauffolgenden Befriedung der Gebiete unentbehrlich. ${ }^{79}$ Wie etwa das Beispiel von Zvonimir Bernwald, einem „Volksdeutschen“ aus Slavonski Brod zeigt, wurde gerne unter Abiturienten geworben, da sie als Mitglieder „volksdeutscher“ Gemeinden sowohl über gute Deutsch-, als auch über gute Serbokroatisch-Kenntnisse verfügten. ${ }^{80}$ Durch ihre Rekrutierung winkte diesen jungen „Volksdeutschen“ eine Ausbildung im Reich. Ihnen wurde dabei versprochen, nach einer Übersetzerausbildung als Dolmetscher eingesetzt zu werden, wobei sie gegen Ende des Krieges auch militä-

76 Janko, Einteilung der Volksdeutschen in Banat und Serbien, BArchB, NS19/2601, zitiert nach Casagrande, Volksdeutsche SS-Division, S. 181.

77 Vgl. ebd., S. 181.

78 August Schmidhuber, Kriegsgefangenenbericht, Juni 1946 (genaues Datum nicht angegeben), VA HEM.OK.BOJCKA, 72/2-1/24.

79 Casagrande, Unsere Gegner, S. 165.

80 Berger an Himmler, betr. „Kroatische Führer“, 31.1.1942, BArchB NS19/319, Bl. 11. 
rische Funktionen als Kommandeure kleinerer Einheiten, etwa Kompanien, übernahmen, wie das Beispiel Bernwalds zeigt. ${ }^{81}$

\subsection{Ausgangslage und Absichten auf „volksdeutscher“ Seite}

Die Ausgangslage auf ,volksdeutscher“ Seite gestaltete sich je nach Rekrutierungsraum sehr unterschiedlich. Da die Rekrutierungen in Serbien, im NDH, in Ungarn und Rumänien in unterschiedlichen politischen Kontexten stattfanden, waren sie divergierenden Gesetzmäßigkeiten unterworfen. So hatte Berger bereits seit Frühjahr 1941 über die VoMi im Banat freien Zugriff auf „volksdeutsche“ Rekruten, musste aber in Kroatien, Rumänien und Ungarn auf die Regierungen Pavelić, Antonescu und Horthy Rücksicht nehmen, da es sich bei diesen Ländern um verbündete Staaten handelte. ${ }^{82}$

Wie für diese Division zu zeigen sein wird, handelt es sich bei der Bezeichnung „Freiwilligen-Division“ eher um ein Label denn um reale Verhältnisse. Casagrande hält jedoch fest, dass sich die „Volksdeutschen“ aus ganz unterschiedlichsten Gründen - manche auch freiwillig - für den Dienst in der „Prinz Eugen“ meldeten. “83 Im Falle der Slowakei etwa soll es sich bei einer ersten Rekrutierungsphase, die bis 1942 andauerte, um Freiwillige gehandelt haben. ${ }^{84}$ Auch Paul Milata betont in seiner Einleitung zu Rumäniendeutschen in der Waffen-SS, dass ihm die Frage nach unterschiedlichen Motivationshintergründen zwischen Zwang und persönlichen Vorteilen für einen Beitritt in die Waffen-SS so zentral erschien, dass sie sich schließlich zu einem der wichtigsten Aspekte seiner Untersuchung entwickelte. ${ }^{85}$

Im Folgenden werden verschiedene Arten von „Freiwilligkeit“ und Zwang untersucht, deren Grenzen allerdings fließend sind. Milata schreibt in seiner Untersuchung, dass er es - anders als bisherige Studien - ablehne, „den Anteil unfreiwilliger Meldungen einzig von der Quantität und Qualität des eindeutig nachweisbaren Rekrutierungszwangs abhängig zu machen." ${ }^{86}$ Vielmehr, und das scheint auch für dieses Kapitel der richtige Ansatz zu sein, soll darauf ein-

81 Vgl. Bernwald, Muslime, S. 310.

82 Siehe hierzu bspw. Martin Broszat, Waffendienst der Volksdeutschen in Kroatien, in: Gutachten des Instituts für Zeitgeschichte 2 (1966), S. 225-231.

83 Casagrande, Volksdeutsche SS-Division, S. 188.

84 Vgl. Casagrande, Schvarc, Spannenberger, Traşca, Volksdeutsche, S. $219 \mathrm{f}$.

85 Vgl. Milata, Zwischen Hitler, Stalin und Antonescu, S. 2f. Siehe hierzu auch die Rezension zu Milata, Zwischen Hitler, Stalin und Antonescu, welche insbesondere die Differenzierung der Eintrittsmotivation hervorhebt: https://www.siebenbuerger.de/zeitung/artikel/kultur/ 6800-rumaeniendeutsche-in-der-waffen_ss.html (Stand: 5.7.2019).

86 Vgl. Milata, Zwischen Hitler, Stalin und Antonescu, S. 4. 
gegangen werden, dass der Beitritt als Schlusspunkt individueller Abwägungen zu sehen ist, denen sowohl Zwang als auch bestimmte Anreize zugrunde liegen konnten, und die nur vor dem Hintergrund konkreter und zusammenhängender Umstände von Zeit, Ort und dem jeweiligen Bildungsgrad und sozialen Status der Rekrutierungsanwärter verstanden werden können. ${ }^{87}$

Obwohl also dem Beitritt ein persönlicher Entscheid vorausgegangen sein konnte, verstieß die Waffen-SS bei der Rekrutierung „Volksdeutscher“ zum ersten Mal gegen die in ihren Grundlagen festgeschriebene Freiwilligkeit. ${ }^{88}$ Ließ sich ein „Volksdeutscher“ nicht freiwillig rekrutieren, so gab es eine ganze Auswahl von Drohungen, um ihn dennoch von einem Beitritt in die Waffen-SS zu „überzeugen“. Welchen Motivationen und/oder Zwängen „Volksdeutsche“ bei ihrer Entscheidung, in die Waffen-SS einzutreten, gehorchten, soll in den folgenden Unterkapiteln erörtert werden.

\subsubsection{Die zentrale Rolle der „Volksgruppenführung“}

Die so genannten „Volksgruppenführer“ der jeweiligen deutschen „Volksgruppen“ im NDH, im Banat oder in Siebenbürgen waren für die Rekrutierungen der Waffen-SS zentral. Ihr Aktionsradius hing einerseits von den herrschenden politischen Verhältnissen, aber auch von ihrem persönlichen Engagement ab. Um diese Unterschiede aufzuzeigen, werden in den folgenden Abschnitten alle drei „Volksgruppenführer“ der „deutschen Volksgruppen“ in Südosteuropa kurz vorgestellt: Josef „Sepp“ Janko für Banat/Serbien, Andreas Schmitt für Siebenbürgen/Rumänien und Branimir Altgayer für die „Volksdeutschen“ im NDH.

\subsubsection{Banat/Serbien: Josef „Sepp“ Janko}

Josef Janko, 1905 in Ernőháza/Ernsthausen in Ungarn geboren, besuchte von 1917 bis 1919 die Bürgerschule in Zrenjanin/Groß-Betschkerek und anschließenddie Realschule in Žomboli/Hatzfeld. Er studierte in Graz Rechtswissenschaften und gehörte der sogenannten „Erneuerungsbewegung“ an, die in Konflikt zum älteren „Kulturbund“ stand. Seit Anfang der 1930er Jahre hatte sich eine Gruppe um Sepp Janko, Adam Krämer und Josef Trischler gebildet, die in Opposition zur bisherigen traditionellen Kulturbundführung stand und die Nähe zum Nationalsozialismus suchte. ${ }^{89}$ Ihre Kritik erfolgte auf zwei Ebenen: Da die alteingesesse-

87 Vgl. ebd.

88 Vgl. Casagrande, Unsere Gegner, S. 163.

89 Vgl. Casagrande, Volksdeutsche SS-Division, S. 136. 
nen Führer sämtliche wichtige Positionen in „volksdeutschen“ Organisationen in Jugoslawien bekleideten, hatten junge Anwärter Mühe, sich innerhalb der donauschwäbischen Volksgruppe zu etablieren. Außerdem stand ihre Bewegung für eine am Nationalsozialismus orientierte Volksgruppenpolitik ein, da sich die „Erneuerer“ als Vorposten des Dritten Reiches in Südosteuropa sahen. ${ }^{90}$ Die Auseinandersetzungen zwischen den alten und den neuen Anführern der Donauschwaben verschärften sich und führten schließlich zum Verbot von Organisationen wie der „Erneuerungsbewegung“. Die „Erneuerer“ selbst wurden aus dem Kulturbund mit der Begründung des vereinsschädigenden Verhaltens ausgeschlossen. Darauf gründete eine Gruppe um Branimir Altgayer und Jakob Lichtenberger einen eigenen Verein, die „Kultur- und Wohlfahrtsvereinigung“ in Osijek/Essegs, in welcher nun all jene Aspekte von Volkstumspolitik betrieben wurden, die bisher verboten waren. Ein wichtiges Ziel, so meinte Sepp Janko persönlich, war die Aufhebung von allen den sozialen Status betreffenden Unterschieden zwischen armen und reichen „volksdeutschen“ Bauern. ${ }^{91}$

Bereits im Sommer 1939 ernannte die VoMi Janko zum Obmann des „Schwäbisch-Deutschen-Kulturbundes“ und 1940 zum „Volksgruppenführer“ der im Banat und Serbien lebenden deutschen Volksgruppe. ${ }^{92}$ Dass Janko, obwohl selbst Anhänger der „Erneuerungsbewegung“, mit den herkömmlichen Organen des „Deutschen Volksbundes“ kooperierte, bzw. Teil von ihnen wurde, stieß nicht bei allen Erneuerern auf Verständnis. Janko aber argumentierte: „Doch war jetzt der Augenblick gekommen zu beweisen, dass man imstande war, alle Volksgenossen für die Ziele des Kulturbundes zu begeistern, sie zu erfassen und zu Opferleistungen zu bewegen. “93 Janko sorgte auch dafür, dass andere Aktivisten der „,volkdeutschen Erneuerungsbewegung“, beispielsweise Jakob Lichtenberger, Michel Reiser oder Gustav Halwax, frühzeitig (1941) eine umfassende Ausbildung in der Waffen-SS erhielten. ${ }^{94}$ Schon im Winter 1940/41 soll er Anweisungen erhalten haben, dafür zu sorgen, dass bereits von der SS gemusterte „Volksdeutsche“ wie auch solche, die zum jugoslawischen Militärdienst einberufen worden waren, dem jugoslawischen Marschbefehl nicht Folge leisteten, sobald die Deutschen einmarschierten. ${ }^{95}$

90 Vgl. ebd.

91 Janko, Weg und Ende, S. 22, nach: Casagrande, Volksdeutsche SS-Division, S. 137.

92 Vgl. Casagrande, Unsere Gegner, S. 164. Vgl. Janko, Weg und Ende der deutschen Volksgruppe, S. 37.

93 Vgl. ebd., S. 40.

94 Vgl. Schreiben Janko betr. Abordnung von Lichtenberger und Reiser, September 1941, BArchB NS 19/2358. Nach: Vgl. Casagrande, Unsere Gegner, S. 164.

95 Vgl. Suppan, Hitler - Beneš - Tito, S. 1026. Vgl. Janko, Weg und Ende der deutschen Volksgruppe, S. 77. 
Janko war eine verbindende Persönlichkeit zwischen den verschiedenen deutschen Volksgruppen, weil er für die „Volksdeutschen“ der Regionen Syrmien, Batschka und Banat bereits im Ersten Jugoslawien einen Autonomiestatus anstrebte. ${ }^{96} \mathrm{Um}$ im Zentrum der Rekrutierungsanstrengungen zu sein, zog Janko 1941 nach Zrenjanin/Groß-Betschkerek um. ${ }^{97}$ Janko handelte auch in Eigeninitiative. 1941 bildete er in Zusammenarbeit mit dem Kommandeur eines in Zrenjanin/Groß-Betschkerek stationierten Truppenteils der Wehrmacht, Oberstleutnant Botho Wendt Graf zu Eulenburg, „Selbstschutz“-Einheiten aus den „Deutschen Mannschaften“. ${ }^{98}$ Im Winter 1941/42 war Janko einer der ersten, der mit den Vorbereitungen, beispielsweise der Suche nach geeigneten Unterbringungsmöglichkeiten für die geplante Division „Prinz Eugen“, beauftragt wurde. ${ }^{99}$

Dass Sepp Janko über die ethnischen Grenzen der deutschen Volksgruppe als politische Figur in Jugoslawien wichtig war, zeigt auch sein Engagement am Ende der deutschen Besatzung, als er bei Verhandlungen mit albanischen Partisanen die Leitung übernahm. Er verhandelte mit ihnen über die Freilassung von drei weiblichen deutschen Geiseln, welche vom 5. auf den 6. September 1944 bei einem Überfall auf einen Konvoi mit 40 deutschen Frauen, von denen 22 getötet wurden, im Kosovo in Gefangenschaft geraten waren. ${ }^{100}$

\subsubsection{Siebenbürgen/Rumänien: Andreas Schmidt}

Am deutlichsten zeigte sich die Nähe zum Dritten Reich am Beispiel Andreas Schmidts, dem „Volksgruppenführer“ in Rumänien. Geboren 1912 in Mănărade/ Donnersmarkt, Siebenbürgen, damals unter österreichisch-ungarischer Herrschaft, besuchte er von 1923 bis 1929 das Gymnasium in Mediaș/Mediasch und begann danach ein Jurastudium in Cluj-Napoca/Klausenburg. Bereits 1938 reiste er, offiziell um eine Landwirtschaftliche Hochschule zu besuchen und wohl mit Unterstützung der unter der Königsdiktatur verbotenen „Deutschen Volkspartei Rumäniens“, nach Deutschland, um dort Kontakte zu SS-Dienststellen aufzubauen. Schon nach kurzer Zeit wurde er zur Mitarbeit beim Rasse- und Siedlungshauptamt (RuSHA) und beim SD eingeladen. Ob er für seine Mitarbeit bei der SS entlohnt wurde oder wer sonst für seinen Aufenthalt aufkam, bleibt unklar. Offensichtlich ist aber, dass Schmidt

96 Vgl. Janko, Weg und Ende der deutschen Volksgruppe, S. 91.

97 Vgl. ebd., S. 95.

98 Vgl. ebd., S. 213.

99 Vgl. ebd., S. 216.

100 Vgl. Gesandtschaftsrat Karl Werkmeister (Botschaft Budapest): Mitteilung Schliep (in Kitzbühel) über AA an Neubacher vom 22.10.1944, Aufzeichnung vom 26.10.1944, PAAA, R27772, S. 3. Vgl. Zaugg, Albanische Muslime, S. 273. 
bereits zu jener Zeit begann, persönlich „Volksdeutsche“ für die Waffen-SS zu rekrutieren. $^{101}$

Sein Engagement sollte auch private Folgen haben. Während seines Aufenthalts lernte er Gottlob Berger kennen, der im Juli 1938 seine neue Stelle als Chef des SS-Ergänzungsamtes angetreten hatte. Nur knappe drei Jahre später, am 3. März 1941, heiratete Schmidt Bergers Tochter Krista. Auch nachdem diese nur eineinhalb Jahre am 11. November 1942 an Tuberkulose verstarb, arbeiteten Schwiegersohn und Schwiegervater weiterhin eng zusammen. ${ }^{102}$ Schmidt soll bereits im Frühjahr und Sommer 1939 heimlich Rekrutierungen in Rumänien vorgenommen und zu Kriegsbeginn Anfang September 1939150 „,volksdeutsche“ Rumänen geworben haben. Im Herbst 1939 ernannten ihn Berger und Heydrich zum „Stabsleiter in der Volksgruppe“. 103

Im Frühjahr 1940 soll Schmidt auf Weisung Bergers weitere illegale Grenzübergänge „volksdeutscher“ Freiwilliger geleitet haben. ${ }^{104}$ Er wurde schließlich mit der Durchführung der 1.000-Mann-Aktion betraut und nach ihrer geglückten Durchführung im September 1940 durch die VoMi zum „Volksgruppenführer“ der Rumäniendeutschen ernannt. Milata weist aber darauf hin, dass Schmidt diesen Posten nie als Endziel seiner Karriere, sondern vielmehr als Sprungbrett für seinen Aufstieg im Reich betrachtete. Als dieser immer unwahrscheinlicher wurde, strebte er spätestens seit 1943 die Führung aller „volksdeutschen“ Gruppierungen Südosteuropas an. Als auch dieser Schritt missglückte, ließ er noch im August 1944 über Berger abklären, ob für ihn nicht die Funktion eines HSSPF Siebenbürgen geschaffen werden könnte. ${ }^{105}$ Obwohl Schmidt über keinerlei Abschluss verfügte und nur seinen Führerschein als Qualifikation angeben konnte, ermöglichten ihm mehrere kleinere und größere Rekrutierungserfolge trotz seines jungen Alters von noch nicht einmal dreißig Jahren schließlich die Wahl zum „Volksgruppenführer“. 106

\subsubsection{NDH/Kroatien: Branimir Altgayer}

Branimir Altgayer gehörte zu den Anhängern der „Erneuerungsbewegung“ im Raum Zrenjanin/Groß-Betschkerek, wo seit Anfang der 1930er Jahre die Gruppe um Sepp Janko, Adam Krämer und Josef Trischler die bisherige Kulturbundführung scharf kritisierte. ${ }^{107}$ Er sollte als „Volksgruppenführer“ der „Volksdeut-

\footnotetext{
101 Vgl. Milata, Zwischen Hitler, Stalin und Antonescu, S. 53.

102 Vgl. ebd., S. 54.

103 Vgl. ebd., S. 55.

104 Vgl. Casagrande, Volksdeutsche SS-Division, S. 209.

105 Vgl. Milata, Zwischen Hitler, Stalin und Antonescu, S. 55.

106 Vgl. ebd., S. 55.

107 Vgl. Casagrande, Volksdeutsche SS-Division, S. 136.
} 
schen“ in Kroatien, bzw. den Gebieten des NDH, die auch Bosnien-Herzegowina, Syrmien und Slawonien einschlossen, ebenfalls für die Rekrutierung der „Volksdeutschen“ in die „Prinz Eugen“ eingesetzt werden. ${ }^{108}$ Am 11. April 1941 hatte Janko Altgayer zum Führer der deutschen Volksgruppe im kroatischen Teil „bis zur endgültigen Lösung der Volksgruppen- und Gebietszugehörigkeit“ ernannt. Sämtliche „volksdeutsche“ „Organistaionen, Einheiten, Gliederungen und Einrichtungen“ im NDH wurden ihm durch diese Ernennung unterstellt. ${ }^{109}$ Im Gegensatz zu Janko und Schmidt schien Berger jedoch weniger überzeugt von Altgayer, was die Werbung von Volksdeutschen für die geplante Division anging. ${ }^{110}$

\subsubsection{Gesellschaftlicher Druck, Drohungen und Desinformation durch deutsche Dienststellen und „Volksgruppenführer“}

Obwohl es bereits seit Januar 1939 - trotz der in der SS und Waffen-SS großgeschriebenen „Freiwilligkeit“ - auch zu Einberufungen kam, ${ }^{111}$ wurde das Prinzip „Freiwilligkeit“ vordergründig auch für die Rekrutierungen in Südosteuropa 1942 eingehalten. So sind in der „Prinz Eugen“ zahlreiche Freiwillige zu finden, etwa aus Südtirol, aus Serbien, Kroatien oder Rumänien. ${ }^{112}$ Doch wer nicht freiwillig unterschrieb, konnte auch zur „Freiwilligkeit“ gezwungen werden. Wie Sundhaussen bereits in den 1970er Jahren feststellte, handelte es sich also „nicht um eine tatsächliche Freiwilligen-Aktion“, vielmehr wurde potentiellen Rekruten der Beitritt zur Waffen-SS mit autoritären Mitteln wie „Erziehung, Einschüchterung und Androhung von Repressalien" nahegelegt. ${ }^{113}$

108 Vgl. Kumm, Vorwärts Prinz Eugen, S. 38. Kumm hatte Altgayers Namen wohl vor allem gehört und weniger gelesen. In seiner Divisionsgeschichte der „Prinz Eugen“ bezeichnet er ihn als „B. Allgaier“ (ebd.).

109 Vgl. Böhm, Die deutschen Volksgruppen, S. $96 \mathrm{f}$.

110 Bericht Berger an Chef der Volksdeutschen Mittelstelle, SS-Obergruppenführer Werner Lorenz, betr. „Lage der Volksdeutschen in Kroatien“, 21.2.1942, BArchB, NS19/319, Bl. 68.

111 Vgl. Wegner, Hitlers Politische Soldaten, S. 125. Vgl. im Gegensatz dazu etwa den freiwilligen Beitritt von Norwegern in die Waffen-SS um 1940, Sørlie, Sonnenrad und Hakenkreuz, S. $82-84,371$.

112 Allerdings konnten sich die Südtiroler durch ihre Einbürgerung zwischen dem Dienst in der Wehrmacht und der Waffen-SS entscheiden. Sie wurden nach der Option zumindest auf dem Papier nicht mehr als „Volksdeutsche“ sondern fortan als „Reichsdeutsche“ betrachtet. Vgl. Casagrande, Südtiroler in der Waffen-SS, S. 30 f., 36. Vgl. auch Milata, Zwischen Hitler, Stalin und Antonescu, S. 45.

113 Sundhaussen, Waffen-SS in Kroatien, S. $188 \mathrm{f}$. 
Selbst Vopersal schreibt in seiner Divisionsgeschichte, bereits im August 1942 habe das SS- und Polizeigericht in Belgrad festgestellt, dass die „,volksdeutsche“ Bevölkerung des Banats zu großen Teilen von der „Volksgruppenführung“ und später durch die SS-Ergänzungsstelle unter Strafandrohung zum Dienst in der „Prinz Eugen“ gezwungen worden sei. Auf welcher juristischen Basis diese Strafandrohung fußte, war selbst dem Obersten SS-Gericht unklar. ${ }^{114}$ SS-Unterscharführer Stefan Helleis ging nach dem Krieg davon aus, dass rund 90 Prozent nicht freiwillig in die Division eingetreten waren. ${ }^{115}$

Für die späten Rekrutierungen im Frühjahr 1943 in Rumänien weist Milata auf die sehr unterschiedlichen Aussagen hin. Rumänische Behörden behaupteten, die Gemeinschaft der „Deutschen Volksgruppe in Rumänien“ hätte bei den Rekrutierungen direkte Gewalt angewandt, wohingegen Zeitzeugen berichten, der einzige Zwang sei der Druck der Öffentlichkeit gewesen. Rückblickend und vor dem Hintergrund wiedererstarkender nationalistischer Strömungen gaben viele der Zeitzeugen sogar an, freiwillig beigetreten zu sein. ${ }^{116}$ Entschieden zum sozialen Druck beigetragen hatte vor allem die konforme politische Alltagskultur in den rumäniendeutschen Gemeinden, die kaum abweichendes Verhalten duldete. ${ }^{117}$

Der Druck der Öffentlichkeit, die „richtige“ Entscheidung zu treffen bzw. für die „Deutsche Volksgruppe“ einzustehen, und gleichzeitig angedrohte Konsequenzen, können als wichtigster Faktor für einen Beitritt in die Division „Prinz Eugen“ gewertet werden. Hans-Werner Schuster meinte hierzu rückblickend: „Die bisher angeführten Argumente für den Beitritt in die Waffen-SS mündeten in einem so ausgeprägten Druck auf die SS-Verweigerer, dass damals das Wort vom freiwilligen Zwang unter den Sachsen aufkam. “118 Im Banat und Serbien drohte Berger höchstpersönlich denjenigen, welche die Rekrutierung verweigerten, „die Häuser zusammen[zu]schlagen“. Volksgruppenführer Branimir Altgayer schüchterte „Volksdeutsche“ im Gebiet des NDH ein: Wenn sie der Rekrutierung nicht Folge leisten würden, hätten sie „schwerste Folgen zu gewärtigen“. In Städten, wie etwa in Ruma in der Region Syrmien, wurde gedroht: „Nichterscheinende werden zur Verantwortung gezogen“. ${ }^{119}$ Auch für die Rekrutierungen in Rumänien

114 Vgl. Vopersal, Unveröffentlichte Divisionsgeschichte, BArchF, N756/149b.

115 Vgl. Kumm, Vorwärts Prinz Eugen, S. 39.

116 Vgl. Milata, Zwischen Hitler, Stalin und Antonescu, S. 205.

117 Vgl. Milata, Motive rumäniendeutscher Freiwilliger zum Eintritt in die Waffen-SS, in: Schulte, Lieb, Wegner (Hgg.), Die Waffen-SS. Neue Forschungen S. 227.

118 Hans-Werner Schuster, Die Rumäniendeutschen in der Waffen-SS. Ein Literaturbericht, [unveröffentlichtes Manuskript, Magisterarbeit Ludwig-Maximilian-Universität], München 1986, S. $91 \mathrm{ff}$. Zitiert nach: Milata, Motive rumäniendeutscher Freiwilliger, S. 227.

119 Sundhaussen, Waffen-SS in Kroatien, S. 189. 
waren bei Ablehnung des Beitritts konkrete Zwangsmaßnahmen vorgesehen: Disziplinar- und Ausschlussverfahren sowie die Androhung von Gewalt gegenüber Verweigerern, für die Hermann Jekeli, Erich Müller und Willi Deppner verantwortlich zeichneten und für deren Umsetzung die Bereitstellung einer Polizeitruppe „mit besonderen Aufgaben“ durch Erich Müller vorgesehen war. ${ }^{120}$

Auch August Schmidhuber, Regimentskommandeur in der „Prinz Eugen“, der als stellvertretender Divisionskommandeur (Winter 1943/44) für von Oberkamp und schließlich von Januar bis Mai 1945 Divisionskommandeur der „Prinz Eugen“ genügend Rekrutierungserfahrung hatte sammeln können, gab in Gefangenschaft zu Protokoll, dass die Bezeichnung „Freiwilligen“-Division Uneingeweihten ein falsches Bild über die Rekrutierung für die „Prinz Eugen“ und ihr „inneres Wesen“ geben würde. ${ }^{121}$ Selbst Otto Kumm, der die „Prinz Eugen“ von Januar 1944 bis Januar 1945 kommandierte, schreibt in der Einleitung seines apologetischen Werks „Vorwärts Prinz Eugen!“, viele „Volksdeutsche“ hätten ihren Einsatz „unfreiwillig“ geleistet. ${ }^{122}$ Diese Aussagen von Kommandeuren der „Prinz Eugen“ decken sich mit historischen Quellen, wenn beispielsweise Krisztián Ungváry schreibt, dass die SS-Werbekommissionen eine Art Menschenraub in ungarischen Dörfern betrieben hätte. ${ }^{123}$ Allerdings darf die Betonung von „Unfreiwilligkeit“ in der apologetischen Nachkriegsliteratur nicht darüber hinwegtäuschen, dass die Autoren damit oft auch eine Zurückweisung von Verantwortung für begangene Kriegsverbrechen anstrebten.

Vor allem für die „Volksdeutschen“ aus dem Banat galt das Prinzip der Freiwilligkeit schon bald ganz offiziell nicht mehr: 1942 verhängte die „Volksgruppenführung“ unter Sepp Janko sogar eine Dienstpflicht für sämtliche Mitglieder der deutschen „Volksgruppe“. Sie wurden der Waffen-SS-Division „Prinz Eugen“, der Polizei oder den „Selbstschutzeinheiten“ je nach ihrer Eignung zugeteilt eine Einteilung, die von Alter und Tauglichkeit der Rekruten abhing. ${ }^{124}$

Eine ähnliche offizielle Einberufung erfolgte ein Jahr später in Rumänien. Die einzige Option, welche den Rekruten in diesem Gebiet offenstand, war die Wahl zwischen rumänischer Armee und deutscher Waffen-SS, ${ }^{125}$ was der „Führer der deutschen Arbeiterschaft in Rumänien“, Fritz Cloos, bestätigte. Milata weist aber darauf hin, dass Führungspersönlichkeiten wie Cloos den zu Rekrutierenden oft wichtige Informationen vorenthielten, nämlich, dass ein Beitritt

120 Vgl. Milata, Zwischen Hitler, Stalin und Antonescu, S. 142.

121 Schmidhuber, Kriegsgefangenenbericht II, 19.8.1945, VA HEM.OK.BOJCKA, 72/1/2/3.

122 Vgl. Kumm, Vorwärts Prinz Eugen, S. 9.

123 Vgl. Ungváry, Kriegsschauplatz Ungarn, S. 862.

124 Vgl. Casagrande, Südtiroler in der Waffen-SS, S. 35.

125 Vgl. Wittmann, Umbrich, Alptraum Balkan, S. 66, 82. 
zur Waffen-SS üblicherweise auf freiwilliger Basis erfolgte. ${ }^{126}$ Einer der Rekrutierten, Friedrich Umbrich, erinnerte sich später, dass ihnen zwar die Wahl zwischen rumänischem und deutschem Militär offengestanden habe, dass sie aber, wenn sie sich erst einmal für den Dienst in der deutschen Armee entschieden hätten, ungefragt der Waffen-SS zugeteilt worden seien. ${ }^{127}$

\subsubsection{Benachteiligung im Ersten Jugoslawien und Angst, selbst Opfer zu werden}

In den 1920er Jahren hatten die „volksdeutschen“ Bevölkerungsteile innerhalb des neu entstandenen jugoslawischen Staates eine Verschlechterung ihres bisherigen Status hinnehmen müssen. Die Benachteiligungen und Einschränkungen waren vielen auch nach dem Balkanfeldzug 1941 noch lebhaft in Erinnerung. ${ }^{128}$ Eine Arbeit sollte beispielsweise nur noch erhalten, wer genügend Serbokroatisch sprach. Viele empfanden es zudem als Unterdrückung der eigenen Identität und Herkunft, dass in Schulen nur noch in serbokroatischer Sprache und nicht mehr auf Deutsch unterrichtet werden durfte. ${ }^{129}$

Die einmarschierenden deutschen Truppen wurden daher von vielen als Erlöser vom jugoslawischen Joch empfunden und begeistert empfangen. ${ }^{130}$ Während des deutschen Einmarschs wurde die Zerrissenheit der Völker innerhalb des Königreichs Jugoslawien und somit der jugoslawischen Armee sehr bald sichtbar: Von allen in der Armee vertretenen Ethnien leisteten vor allem serbische Einheiten bis zuletzt Widerstand. Kroaten und „Volkdeutsche“ hingegen legten oft die Waffen in der Hoffnung nieder, die Zeit für einen eigenen Staat oder zumindest einen verbesserten sozialen und ökonomischen Status wäre gekommen. ${ }^{131}$

Als sogenannte „fünfte Kolonne“ wurden die deutschen Volksgruppen in Südosteuropa früh Zielscheiben von - zumindest vordergründig - ethnischen Übergriffen. $\mathrm{Zu}$ frühen Opfern bewaffneter Überfälle gehörten vor allem die „volksdeutschen“ Gemeinden im neu gegründeten NDH: Beispiele sind etwa Schutzberg (Glogovac) in Bosnien, Manićevo u. Drenj, Slatinik Orahovica, Veovo und Darkovac. Banden von 80-100 Personen, der Uniform nach als kommunistische Partisanen beschrieben, sollen Dörfer überfallen und „Volksdeutsche teil-

126 Vgl. Milata, Zwischen Hitler, Stalin und Antonescu, S. 177.

127 Vgl. Wittmann, Umbrich, Alptraum Balkan, S. 66.

128 Vgl. Casagrande, Unsere Gegner, S. 164.

129 Vgl. Casagrande, Schvarc, Spannenberger, Traşca, Volksdeutsche, S. 212.

$130 \mathrm{Vgl}$. Casagrande, Unsere Gegner, S. 164.

131 Vgl. ebd. 


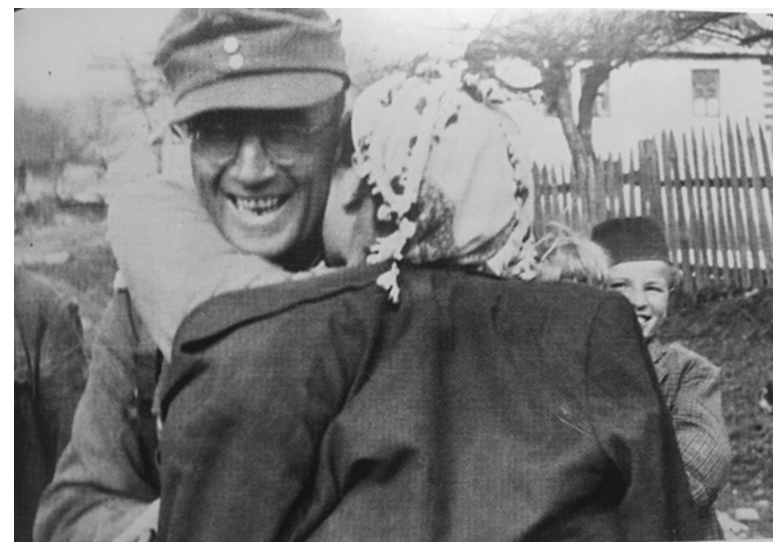

Abb. 5: Bildunterschrift: „Stabsführer Schmidhuber, Kommandeur Gebirgsjägerregiment 2, von der Bevölkerung herzlich begrüßt.“132

weise bestialisch hin[ge]mordet“ haben. ${ }^{133}$ Bei anderen Überfällen sollen das Vieh geraubt und die landwirtschaftlichen Erzeugnisse vernichtet worden sein, indem die Partisanen den Bauern verbaten, ihren Weizen zu ernten. ${ }^{134}$

In einem Bericht an Lorenz folgte Berger für die Rekrutierung „Volksdeutscher“ im Raum Kroatien einer auf solchen Vorfällen basierenden Argumentation, die er kurze Zeit später auch für die Rekrutierungen von Muslimen anwandte: Durch den bereits tobenden Bürgerkrieg, mitverursacht durch den Balkanfeldzug und den Aufbau des NDH, waren gewisse Bevölkerungsgruppen in eine prekäre Situation geraten, aus der die deutschen Besatzer sie durch die bevorstehenden Rekrutierungen zu befreien versprachen. Denn „die Lage in den meisten deutschen Gemeinden in Kroatien ist derart gefährdet, dass mit einer asymetrischen Ausrottung des Deutschtums durch die serbischen und kroatischen Aufständischen in absehbarer Zeit gerechnet werden muss“, wie Berger versicherte. ${ }^{135}$ Dass diese Einschätzung nicht nur aus der Luft gegriffen war, sondern durchaus realen Begebenheiten entsprach, bestätigt auch Casagrande: Während des Einmarschs deutscher

132 Vgl. Kumm, Vorwärts Prinz Eugen, ohne Seitenangabe.

133 Bericht Berger an Chef der Volksdeutschen Mittelstelle, SS-Obergruppenführer Werner Lorenz, betr. „Lage der Volksdeutschen in Kroatien“, 21.2.1942, BArchB, NS19/319, Bl. 70.

134 Vgl. ebd.

135 Ebd., Bl. 67. 
Truppen waren in zahlreichen Ortschaften „Volksdeutsche“ von anderen Ethnien als Geiseln genommen worden. ${ }^{136}$

Vor diesem Hintergrund war also einerseits die Angst, Opfer von Übergriffen zu werden, ein wichtiger Motivationsfaktor, um einer deutschen Einheit beizutreten. Um gefährdet zu sein, reichte bereits die Zugehörigkeit zur deutschen Volksgruppe. ${ }^{137}$ Sich für die Waffen-SS einzuschreiben hieß in dieser Logik auch, Bewaffnung, Ausrüstung und eine militärische Ausbildung zu erhalten, um zum Schutz der eigenen Familie und Gemeinde beitragen zu können. Andererseits fürchteten die „Volksdeutschen“ in Südosteuropa, wie bereits beschrieben, auch die Repressalien durch die eigene „Volksgruppenführung“ sowie durch Angehörige der Waffen-SS und Polizei, falls sie sich weigerten, einer deutschen Formation beizutreten. ${ }^{138}$

\subsubsection{Ethnische Aspekte und Dienst am „Vaterland“: Verteidigung, Erhalt und Erweiterung des eigenen Siedlungsgebiets}

Die Instrumentalisierung des Ethnischen war von Anfang bis Ende des Dritten Reiches ein grundsätzliches Merkmal nationalsozialistischer Innen- und Außenpolitik. Für die Rekrutierung der „Volksdeutschen“ im Banat und im NDH kann dessen Umsetzung als besonders erfolgreich eingestuft werden. ${ }^{139}$ Um die ethnische Konnotation hervorzuheben, wurde mit Artur Phleps sehr bewusst ein „Volksdeutscher“ aus Siebenbürgen an die Spitze der Division gestellt. ${ }^{140}$ Berger schrieb bereits am 10. April 1941, ein Jahr vor der Aufstellung der „Prinz Eugen“, dass Phleps von der SS-Führung zu fördern sei, weil man sich durch ihn eine größere Anziehung von „Volksdeutschen“ im Allgemeinen erhoffte. ${ }^{141}$

Ein wichtiger Motivationsfaktor unter den „Volksdeutschen“, insbesondere innerhalb der „Volksgruppenführung“ aller drei Regionen Siebenbürgen, Banat und Kroatien, war wie bereits erwähnt die Verteidigung des eigenen Siedlungsgebiets gegen benachbarte Bevölkerungsgruppen. In seinem Rekrutierungsaufruf versuchte Janko genau solche Ängste und Wünsche der „volksdeutschen“ Bevöl-

136 Vgl. Casagrande, Volksdeutsche SS-Division, S. 156.

137 Vgl. ebd., S. 180.

138 Vgl. Sundhaussen, Waffen-SS in Kroatien, S. 189.

139 Vgl. Casagrande, Volksdeutsche SS-Division, S. 188.

140 Vgl. ebd., S. $188 \mathrm{f}$.

141 Vgl. Berger an Himmler, 10.4.1941, BArchB, NS19/ 2724 nach: Casagrande, Volksdeutsche SS-Division, S. $188 \mathrm{f}$. 
kerung zu instrumentalisieren: Er rief alle Männer zwischen 17 und 50 Jahren auf, in Tradition ihrer Väter „den Schutz von Haus und Hof selbst zu übernehmen“, indem sie sich zur Waffen-SS meldeten. ${ }^{142}$ Damit spielte er auf die so genannten „Grenzer-Regimenter“ der Habsburgermonarchie an. ${ }^{143}$

Der Selbstverteidigungsgedanke war eng verbunden mit dem gleichzeitigen Streben nach einer zukünftigen Dominanz in den jeweiligen Regionen nach dem erhofften Sieg der Nationalsozialisten in Europa. Diesbezüglich deckten sich die Absichten der deutschen Besatzungsmacht zu großen Teilen mit derjenigen der „volkdeutschen“ Siedler in Südosteuropa. ${ }^{144}$ Diese Absicht äußerte sich schon in den ersten Tagen des Balkanfeldzugs im April 1941, als zahlreiche „Volksdeutsche“ aus der jugolsawischen Armee desertierten und spontan die deutsche Wehrmacht unterstützten. Bereits Ende März hatte Hitler über die VoMi dazu aufgerufen, sich zukünftigen Kampfhandlungen durch Desertion zu entziehen. ${ }^{145}$

Ähnliches gilt auch für Teile der „Volksdeutschen“, beispielsweise in der Bačka, die im Frühjahr 1941 den Einmarsch deutscher Truppen regelrecht erwartet hatten. Ein Hauptmann der ungarischen Wehrmacht, Dr. Novak, berichtete nach einer Rundreise durch die Region, dass die „Volksdeutschen“ enttäuscht wären, weil Teile ihres Siedlunsggebiets nach dem Balkanfeldzug nicht unter deutsche Herrschaft kamen, sondern an Ungarn gingen. ${ }^{146}$

Unter den ersten Freiwilligen für die „Prinz Eugen“ waren auch sogenannte „Optanten“ zu finden. Dabei handelte es sich um Südtiroler, die italienische Staatsbürger waren. Indem sie zwischen 1939 und 1943 für das Deutsche Reich optierten, hatten sie die Möglichkeit, die deutsche Staatsbürgerschaft zu erhalten. In einer ersten Rekrutierungswelle zwischen 1939 und 1941 meldeten sich viele freiwillig zur Waffen-SS, obwohl ihnen, da sie auf dem Papier nun nicht mehr nur als „Volks-“, sondern als „Reichsdeutsche“ galten, auch der Dienst in der Wehrmacht offen gestanden hätte. ${ }^{147}$ Bei diesen „Freiwilligen“ lässt sich

142 Vgl. Janko, Weg und Ende der deutschen Volksgruppe, S. 220.

143 Vgl. ebd. sowie Kumm, Vorwärts Prinz Eugen, S. 40.

144 Vgl. Casagrande, Unsere Gegner, S. 163f. Das Streben nach einem „Platz an der Sonne“ zählte auch in anderen Ländern zu den Hauptmotiven. Vgl. Sørlie, Sonnenrad und Hakenkreuz, S. 98.

145 Vgl. Casagrande, Volksdeutsche SS-Division, S. $155 \mathrm{f}$.

146 Vgl. ebd., S. 160.

147 Vgl. Casagrande, Südtiroler in der Waffen-SS, S. 22, 30-33. Casagrande gibt zwar an, dass keine vollständigen Listen der in der Waffen-SS dienenden Südtiroler existieren würden, er versucht aber, über die militärischen Suchkarten und weitere Quellen ein möglichst genaues Bild zu zeichnen. Die Gesamtzahl der Südtiroler in der Waffen-SS lag demnach zwischen 3.500 und 5.000 Mann. Vgl. Casagrande, Südtiroler in der Waffen-SS, S. 13f. Zum Schicksal der Optanten nach Kriegsende siehe auch: Stefan Lechner, Zwischen den Landesteilen: Südtirols Op- 
auch feststellen, dass sie in Bezug auf die Waffen-SS über genügend Informationen verfügten, um sich über die Organisation ein Bild zu machen. Teil eines deutschen „Elite-Verbandes“ zu sein und an der Schaffung eines europäischen Großreichs unter deutscher Vorherrschaft mitzuwirken, war für diese Gruppe ein wesentlicher Grund, der Waffen-SS beizutreten. Nicht zuletzt konnten sie so auch dem italienischen Wehrdienst entgehen. ${ }^{148}$

Die Instrumentalisierung des Ethnischen zeigte insbesondere unter den Jugendlichen Erfolg: Umbrich betont in seinen Memoiren, dass junge „Volksdeutsche“ bereits seit einigen Jahren in der „Deutschen Jugend“ einer „Gehirnwäsche“ unterzogen worden seien, indem ihnen beigebracht wurde, dass Deutschland „das Mekka aller germanischen Völker“ sei, und die „volksdeutschen“ Jugendlichen es daher als Ehre empfanden, gemeinsam mit Deutschland gegen den Kommunismus zu kämpfen ${ }^{149}$ : „Ich war fest entschlossen, in den Krieg zu gehen! Wäre ich bei der Untersuchung in Rumänien für untauglich erklärt worden, so hätte ich einen anderen Weg gefunden. Ich wäre nach Deutschland gefahren, wo die Wehrmacht mich als Freiwilligen nehmen musste, wie ich meinte. “150 Rückblickend umschreibt Umbrich jenes Verhalten mit folgenden Worten: „Wir Sachsen gingen, um den Deutschen zu helfen, den Krieg zu gewinnen, um für ein Vaterland zu kämpfen, das die meisten von uns noch nie gesehen hatten. “151

\subsubsection{Entlassung aus der Kriegsgefangenschaft}

Ein wesentlicher Motivationsgrund, auf Seiten der Deutschen an Kampfhandlungen teilzunehmen, war die versprochene Entlassung aus deutscher Kriegsgefangenschaft. Denn obwohl einige „Volksdeutsche“ bereits vor oder während des Balkanfeldzugs 1941 aus der jugolsawischen Armee desertierten und darum baten, in die Wehrmacht aufgenommen zu werden, gab es doch zahlreiche, die diesen Schritt nicht wagten oder nicht unternehmen wollten und in der Folge in deutsche Kriegsgefangenschaft geraten waren. Das Versprechen, aus der Gefangenschaft freizukommen, war somit ein wesentlicher Anreiz, sich zum Dienst in

tanten 1945-1948, in: Hans Heiss, Gustav Pfeifer (Hgg.), Südtirol - Stunde Null? Kriegsende 1945-1946, Innsbruck etc.: Studienverlag 2000, S. 281-295.

148 Vgl. Casagrande, Südtiroler in der Waffen-SS, S. 36.

149 Vgl. Wittmann, Umbrich, Alptraum Balkan, S. 74. Ähnliches schreibt Sørlie zu den Beweggründen von Jugendlichen in Norwegen. Vgl. Sørlie, Sonnenrad und Hakenkreuz, S. S. 95-100.

150 Wittmann, Umbrich, Alptraum Balkan, S. 73.

151 Ebd., S. 72. 
der Waffen-SS zu verpflichten. ${ }^{152}$ Noch während laufender Kampfhandlungen ordnete Reichsaußenminister von Ribbentrop am 15. April 1941 auf Drängen von Lorenz an, die „Volksdeutschen“ freizulassen. ${ }^{153}$ Dass ein solches Vorgehen auch bei „germanischen“ und „fremdvölkischen“ Formationen üblich war, bestätigen etwa Sigurd Sørlie für norwegische Einheiten der Waffen-SS oder die Verfasserin für die Rekrutierung von Albanern in die Division „Skanderbeg“. ${ }^{154}$

\subsubsection{Militärische Anreize}

Die drei Punkte - Bewaffnung, Ausrüstung und militärische Ausbildung - gehören für alle hier untersuchten Divisionen zu den wichtigsten Motivationsfaktoren. Militärische Anreize bildeten unter jenen „Volksdeutschen“, die keine Sympathien für die nationalsozialistische Ideologie hegten, ${ }^{155}$ einen wichtigen Beitrittsgrund. Denn selbst „Volksdeutsche“, die sich in den vergangenen beiden Jahrzenten in die jugoslawische Gesellschaft integriert hatten, waren in Serbien und den Gebieten des NDH durch den Einmarsch der Wehrmacht unter Druck geraten und wiederkehrender Gewalt durch marodierende Ustaša- und Četnik-Banden ausgesetzt. ${ }^{156}$

$\mathrm{Zu}$ dieser prekären Ausgangslage gesellten sich die oft positiven Erinnerungen an den Dienst in der österreichisch-ungarischen Armee, welche die Entscheidung, in die Waffen-SS einzutreten, erleichterten. Der Dienst in der Waffen-SS ermöglichte außerdem eine aktive Teilnahme am Kampf um die deutsche Vorherrschaft in Europa. So berichtete „Volksgruppenführer“ Janko am Beispiel des Banats, dass dort die Wünsche der deutschen Volksgruppe durch den deutschen Einmarsch und die darauffolgende Militärherrschaft in Serbien nach 1941 in Erfüllung gegangen wären. Somit galt es, diesen neuen Status auch mit der Waffe in der Hand zu verteidigen. ${ }^{157}$

Nebst dem Anreiz, eine Militärausbildung in einer „hochmodernen, mit neuester Technik ausgestatteten Truppe““158 zu erhalten, basierte die Entscheidung oft auf pragmatischeren Wehrpflichts-Überlegungen: Gerade für die Rumäniendeutschen stellte sich nämlich nicht die Frage, ob sie Wehrdienst leisten sollten

152 Vgl. Casagrande, Unsere Gegner, S. 165.

153 Vgl. Casagrande, Volksdeutsche SS-Division, S. 167.

154 Vgl. Sørlie, Sonnenrad und Hakenkreuz, S. 108. Zaugg, Albanische Muslime, S. 220-222.

155 Vgl. Bernwald, Muslime in der Waffen-SS, S. 14.

$156 \mathrm{Vgl}$. Sundhaussen, Waffen-SS in Kroatien, S. 181.

157 Vgl. Casagrande, Volksdeutsche SS-Division, S. 180.

158 Sørlie, Sonnenrad und Hakenkreuz, S. 111. 
oder nicht, sondern nur, in welcher Armee. Diese Umstände ließen die deutsche Wehrmacht und Waffen-SS in einem strahlenden Licht erscheinen, hatte doch die rumänische Armee seit Jahrzehnten den Ruf brutaler Ausbildungsmethoden und miserabler Ausrüstung. ${ }^{159}$ Bereits im Sommer 1942 führten Vertreter der Waffen-SS beim Auswärtigen Amt an, dass in der rumänischen Armee 40.000 „Volksdeutsche“ dienen würden, die aufgrund der schlechten Behandlung lieber in deutschen Einheiten dienen wollten. ${ }^{160}$

Obwohl auch die rumänische Armee bei Stalingrad enorme Verluste zu beklagen hatte (18 von 26 Divisionen wurden dabei vernichtet und die verbliebenen acht rumänischen Divisionen gingen auf der Krim und beim Kampf um den Kuban-Brückenkopf unter), sah Antonescu darin keinen Grund abzurüsten. Im Gegenteil, im April 1943 sollte eine Generalmobilmachung lanciert werden, mit dem Ziel, bis Herbst 194322 neue Reservedivisionen aufzubauen. Dass dieser Aufruf zum Wehrdienst in der rumänischen Armee just zu dem Zeitpunkt kam, als auch die Deutschen in Rumänien eine Massenrekrutierung planten, spielte schließlich letzteren in die Hände. Vor die Wahl gestellt, entschieden sich noch 194350.000 Rumäniendeutsche zum Dienst in der Waffen-SS. ${ }^{161}$ Es schien, dass viele von ihnen der Gewalt im rumänischen Militär, wo sie laut Aussagen von Betroffenen fast täglich mit der Peitsche geschlagen wurden, durch einen Beitritt zur Waffen-SS zu entrinnen suchten. Hinzu kam, dass sich viele der zahlreichen versprengten Rumäniendeutschen, die vorher an der Ostfront gedient hatten, ohnehin bereits deutschen Verbänden angeschlossen hatten. ${ }^{162}$

Gegenteilige Umstände herrschten etwa in Ungarn, wo sich kurz vor der Rekrutierung für die Waffen-SS die Neuigkeit verbreitete, dass eine Abrüstung der ungarischen Armee bevorstehe. Dieses Gerücht trug dazu bei, dass sich nur 20.000 Ungarndeutsche rekrutieren ließen. ${ }^{163}$

\subsubsection{Finanzielle und materielle Anreize}

Blättert man durch die Unterlagen im Arhiv Jugoslavije in Belgrad, so fallen vor allem die vielen Anträge auf Familienzulagen auf. ${ }^{164}$ Solche wurden beispiel-

159 Vgl. Milata, Zwischen Hitler, Stalin und Antonescu, S. 131, 175.

160 Vgl. ebd., S. 131.

161 Vgl. ebd., S. 176.

162 Vgl. ebd., S. $132 \mathrm{f}$.

163 Vgl. ebd., S. 176.

164 Vgl. bspw. Antrag auf Familienunterhalt von Buch, Josef, Belgrad, 24.4.1942, 2500,- Din (250,- Din =1 RM), AJ 110/698, Bl. 4f. Bayer, Josef, geb. Vinkovci, 10.7.1942, 2225,- Din, AJ 110/ 
weise vom rumänischen Militär nicht bezahlt. ${ }^{165}$ Sepp Janko erwähnt die vorgesehenen Familienzulagen bereits bei der Aufstellung der „Prinz Eugen“ und betont, dass auf individuelle Fälle besondere Rücksicht genommen würde. ${ }^{166}$ Tatsächlich sind in den Personalunterlagen im Arhiv Jugoslavije zahlreiche persönliche Anhaltspunkte zu Rekruten aus Serbien und dem NDH zu finden, die darauf hinweisen, dass individuelle Anliegen von lokalen SS-Behörden ernstgenommen und nach Zrenjanin/Groß-Betschkerek oder Belgrad weitergeleitet wurden. ${ }^{167}$ Selbst ältere Männer sollten, sofern sie zum Einsatz in einer „Selbstschutz“-Einheit verpflichtet wurden, den im Reich geltenden Fürsorgebestimmungen bei Unfall bzw. Todesfall unterliegen. ${ }^{168}$ Neben dem eigentlichen Sold gab es weitere materielle Anreize, wie etwa die Inbesitznahme arisierter Güter oder des Eigentums geflohener serbischer Bauern. NS-treue „Volksdeutsche“ durften diese übernehmen und selbst bewirtschaften. ${ }^{169}$ Allerdings konnte das Anrecht auf Angehörigenunterstützung auch erlöschen, wenn in Erfahrung gebracht werden konnte, dass die Ehefrauen aus jüdischen oder Roma-Familien stammten. ${ }^{170}$

Finanzielle Anreize stellten auch für Rumäniendeutsche einen wesentlichen Beitrittsgrund dar: Ein in Rumänien stationierter Soldat erhielt 2 Lei, ein in besetzten Sowjetgebieten stationierter rumänischer Soldat sogar nur 1,2 Lei pro Tag, während ein Soldat in deutschen Diensten umgerechnet ungefähr 100 Lei am Tag erhielt. Da der Regierung in Bukarest der finanzielle Anreiz, den die Waffen-SS bot, nicht entgangen war, forderte sie, dass die SS ihre Angehörigenunterstützung für Rumäniendeutsche von 130 RM auf 35 RM reduzieren sollte. ${ }^{171}$

695, Bl. 927 f. Abrecht, Fritz, Belgrad, 16.4.1942, 4450,-Din, AJ 110/694, Bl 242f., Gössl, Georg, 23.4.1942, 6200,- Din, AJ 110/703, Bl. $53 \mathrm{f}$.

165 Vgl. Milata, Zwischen Hitler, Stalin und Antonescu, S. 178.

166 Vgl. Janko, Weg und Ende der deutschen Volksgruppe, S. 219.

167 Im Fall Josef Bayer etwa wurde am 10.2.1944 nach Zrenjanin/Betschkerek gemeldet, dieser müsse einen im Jahr 1942 gewährten Vorschuss von 1000,- noch nicht zurückzahlen, da dies eine „untragbare Härte“ darstelle. Fürsorgeoffizier der Waffen-SS Serbien, gez. SS-Ustuf. Hartung, 10.2.1944, Bayer, Josef, AJ 110/695, Bl. 95.

168 Berger an SS-Obersturmbannführer Nageler, 26.8.1942, BArchB, NS19/319, Bl. 46.

169 Vgl. Casagrande, Unsere Gegner, S. 165.

170 Fall Sattler, Karl, AJ 110, F 723.

171 Vgl. Milata, Zwischen Hitler, Stalin und Antonescu, S. 178. Die Familienunterstützung von 130 RM scheint allerdings verglichen mit serbischen Beispielen aus dem Arhiv Jugoslavjie etwas hoch gegriffen. Vgl. Buch, Josef, Belgrad, 24.4.1942, 2500,- Din (250,- Din=1 RM), AJ 110/698, Bl. 4 f. Bayer, Josef, geb. Vinkovci, 10.7.1942, 2225,- Din, AJ 110/695, Bl. 927 f. Abrecht, Fritz, Belgrad, 16.4.1942, 4450,-Din, AJ 110/694, Bl. 242f., Gössl, Georg, 23.4.1942, 6200,- Din, AJ 110/703, Bl. 53 f. 


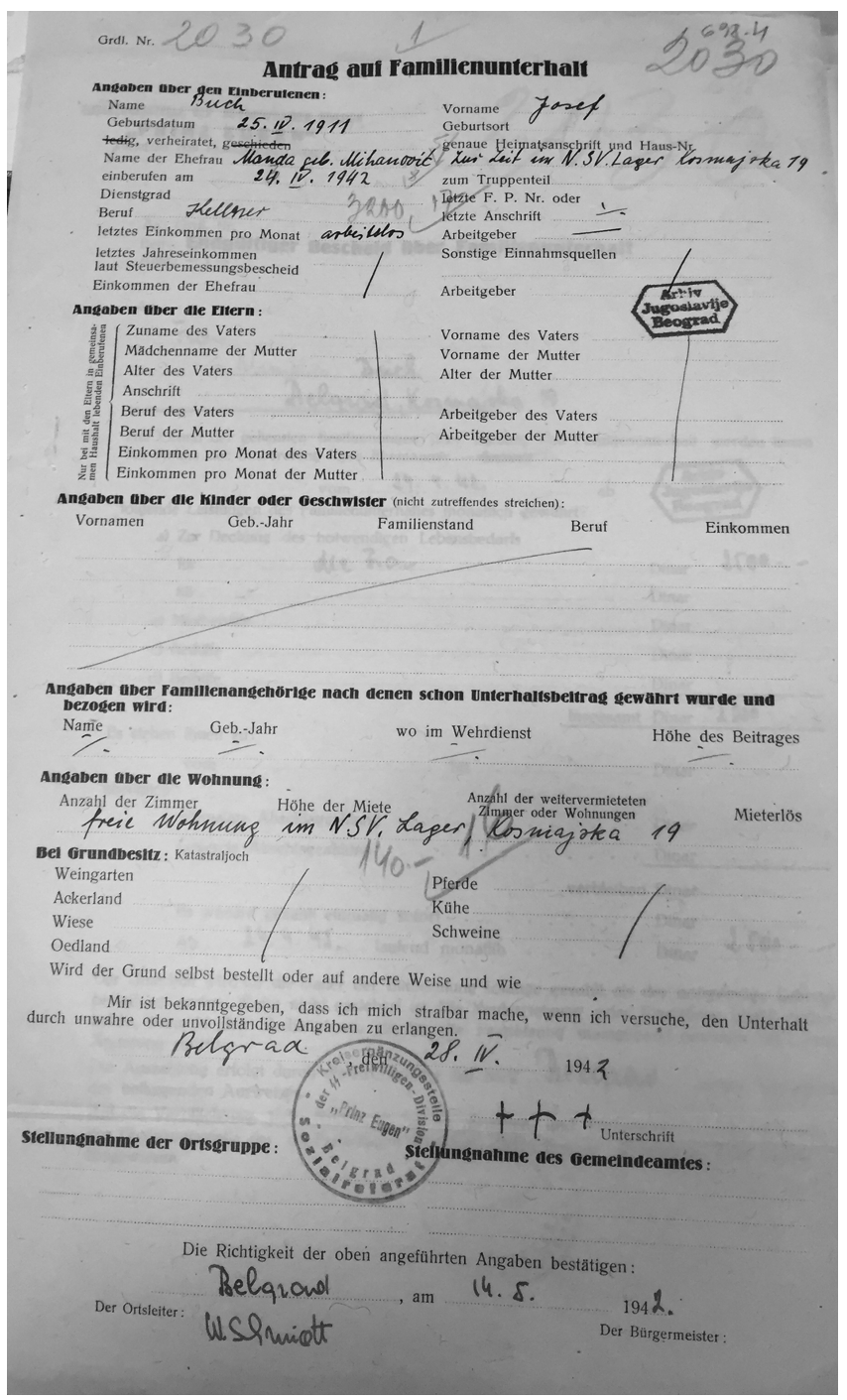

Abb. 6: Josef Buch war des Schreibens nicht kundig. Bei inm scheinen vor allem finanzielle Gründe für den Beitritt zur Waffen-SS ausschlaggebend gewesen zu sein. Er ist als arbeitsloser Kellner verzeichnet ist. ${ }^{172}$

172 Buch, Josef, Belgrad, 24.4.1942, AJ 110/698, Bl. 4. 


\subsubsection{Der Krieg gegen den „Bolschewismus“}

Neben den oben genannten Gründen war der Antibolschewismus ein wichtiger Grund, um der Waffen-SS beizutreten - nicht nur bei den „Volksdeutschen“ bzw. bei Südosteuropäern stellte er eine wesentliche Motivation dar. ${ }^{173}$ Wer sich in Südosteuropa nicht den Četniks, der Ustaša oder anderen nationalen Organisationen anschließen wollte bzw. aufgrund seiner Abstammung nicht konnte, dem bot die Waffen-SS die vermeintliche Gelegenheit, in ihren Reihen kämpfend das eigene Land gegen den Kommunismus zu verteidigen und seinem Land oder seiner Volksgruppe einen Platz in der Neuordnung Europas zu sichern. ${ }^{174}$ Insbesondere nach der Niederlage in Stalingrad 1943 diente die Angst vor dem „Bolschewismus“ als Rekrutierungsmotor. ${ }^{175}$

So sahen viele Rumänen ihre Kriegsteilnahme auf Seiten der Deutschen nicht etwa als Kriegserklärung gegen Großbritannien oder die USA, sondern es schien ihnen vielmehr, dass in erster Linie der Krieg gegen die Sowjetunion gewonnen werden müsse, um die an Stalins Staat verlorenen Gebiete Bessarabiens und der Bukowina wiederzugewinnen. ${ }^{176}$ Die UdSSR hatte in der Zwischenkriegszeit in einer systematischen und aggressiven Weise kleine Nachbarstaaten besetzt, anerkannte die rumänische Ostgrenze nicht und forderte schließlich im Juni 1940 die genannten Gebiete Bessarabiens und die nördliche Bukowina. Die dadurch geschürten Ängste der „Volksdeutschen“ ließen sie die Nähe des Deutschen Reiches suchen. ${ }^{177}$

Hier ging es also um konkrete durch die Sowjetunion verursachte Gebietsverluste und die Angst, dass es zu weiteren kommen würde. Umbrich erinnert sich indes, dass er und seine Kameraden sich zwar geehrt gefühlt hätten, Deutschland im Kampf gegen den Kommunismus zu unterstützen, doch was Kommunismus genau bedeutete, hätten sie nicht gewusst: „Es war nur ein Begriff, der ein unbekanntes Übel heraufbeschwor!“"178 Dennoch ist Miliata der Meinung, dass die „sowjetische Bedrohung in unmittelbarer Nähe“ eine entscheidende Rolle für den Beitritt zu den Verbänden der Waffen-SS gespielt habe. ${ }^{179}$

173 Dies war auch ein wesentlicher Beitrittsgrund unter „germanischen“ wie auch „fremdvölkischen“ Rekruten. Vgl. etwa Sørlie, Sonnenrad und Hakenkreuz, S. 95-97. Zaugg, Albanische Muslime, S. 140, 145, 205.

174 Vgl. hierzu auch Sørlie, Sonnenrad und Hakenkreuz, S. 91.

175 Vgl. Milata, Zwischen Hitler, Stalin und Antonescu, S. 175.

176 Vgl. ebd., S. 180.

177 Vgl. Milata, Motive rumäniendeutscher Freiwilliger, S. 225 f.

178 Wittmann, Umbrich, Alptraum Balkan, S. 74.

179 Milata, Motive rumäniendeutscher Freiwilliger, S. 225. 


\subsubsection{Der Kampf ums Überleben}

Nachdem bei Stalingrad ein Großteil der rumänischen Divisionen vernichtet worden war, schienen den ,volksdeutschen“ Soldaten die Überlebenschancen in deutschen Verbänden höher. ${ }^{180}$ Etliche „Volksdeutsche“, die teilweise schon seit Mitte 1941 als rumänische Soldaten an der Ostfront im Einsatz gestanden hatten, traten deshalb in die Waffen-SS ein. Sie betrachteten das Überlaufen von der rumänischen Armee zu Verbänden der Wehrmacht und Waffen-SS als Möglichkeit, ihre Überlebenschancen zu erhöhen. Trotz des Abkommens, welches am 12. Mai 1943 zwischen Deutschland und Rumänien bezüglich der Rekrutierung von „Volksdeutschen“ abgeschlossen wurde, durften „volksdeutsche“ Soldaten, die bereits auf der Krim und ostwärts des Dons im Einsatz standen, nicht zu den deutschen Truppen wechseln. Dennoch setzten sich die Desertionen aus der rumänischen Armee fort - unterstützt durch die Waffen-SS. ${ }^{181}$

\subsection{Werbung und Aufstellung}

\subsubsection{Vorgängereinheiten und verwandte Verbände}

Wie bereits erwähnt waren schon ein bis zwei Jahre vor der Aufstellung der Division „Prinz Eugen“ in Südosteuropa „Volksdeutsche“ für verschiedene Verbände der Waffen-SS geworben worden, wenngleich in geringerem Umfang, so etwa kroatische und rumänische Staatsangehörige für die SS-Division „Wiking“. Unter diesen frühen Rekruten befand sich auch der spätere Divisionskommandeur Artur Phleps. ${ }^{182}$ Selbst als die Aufstellung der „Prinz Eugen“ längst begonnen hatte, wurden „Volksdeutsche“ auch für andere Verbände der Waffen-SS geworben, so für die Division „Nordland“, beispielsweise im Regiment „Norge“. ${ }^{183}$

Obwohl Berger damit prahlte, bereits 1938 eine größere Werbeaktion in Siebenbürgen durchgeführt zu haben, stellt Milata klar, dass es keine solche gegeben habe und Berger wohl zu propagandistischen Zwecken die erste größere Rekrutierung von „Volksdeutschen“, die erst im Herbst 1939 durchgeführt wurde, nachträglich vordatiert haben muss. Milata räumt aber ein, dass Berger zumindest gegen Anfang 1939 erfolglos ein ähnliches Rekrutierungsprojekt angestrebt

180 Vgl. Milata, Zwischen Hitler, Stalin und Antonescu, S. 175.

181 Vgl. Casagrande, Volksdeutsche SS-Division, S. 210.

182 Vgl. ebd., S. 189.

183 Vgl. Sørlie, Sonnenrad und Hakenkreuz, S. 351. 
habe. ${ }^{184}$ Die sogenannte „1.000-Mann-Aktion“, die zwischen Oktober 1939 und Juni 1940 in Rumänien stattfand, stellte den ersten Versuch dar, „volksdeutsche“ Südosteuropäer in einem größeren Maß für die Waffen-SS zu gewinnen. ${ }^{185}$ Diese verteilten sich auf unterschiedliche Divisionen, waren also nicht als „Volksgruppe“ in einer Division vereint. ${ }^{186}$

Die von Ribbentrop auf Anregung Lorenz’ am 15. April 1941 angeordnete Freilassung sämtlicher „volksdeutscher“ Kriegsgefangenen zwecks Rekrutierung in die Waffen-SS weckte in Berger die Hoffnung, aus diesem Kontingent mindestens tausend Mann für die geplanten Waffen-SS-Verbände rekrutieren zu können. In Anbetracht der Tatsache, dass zu diesem Zeitpunkt von den für den Balkanfeldzug in Südosteuropa konzentrierten 23 deutschen Divisionen 16 bereits abgezogen worden waren und sich teilweise schon auf dem Weg Richtung Osten befanden, musste das neu eroberte Gebiet zuerst mit sieben und schon bald mit drei zweitrangigen, noch in Ausbildung stehenden Wehrmachtsdivisionen (704., 714. und die 717. Infanterie-Division) gesichert werden. ${ }^{187}$ Dieser offensichtliche Personalengpass auf militärischer Ebene zwang nicht nur die Wehrmacht, sondern auch die Waffen-SS dazu, Rekrutierungspotenziale vor Ort abzuklären und auszunutzen. ${ }^{188}$

Bereits am 18. April 1941, nur einen Tag nach der Kapitulation Jugoslawiens, traf eine Werbekommission der Waffen-SS unter SS-Sturmbannführer Hans Hauser in Kroatien ein. Diese nahm mit Einwilligung des neu eingesetzten kroatischen Kriegsministers Slavko Kvaternik unverzüglich ihre Arbeit auf. ${ }^{189}$ Obwohl viele „Volksdeutsche“ auch in Kroatien den Einmarsch deutscher Truppen begrüßt hatten, war die Bereitschaft der „Volksdeutschen“, sich freiwillig für die Waffen-SS zu melden, vorerst gering. ${ }^{190}$ Unter SS-Untersturmführer Gustav Halwax, der sich bereits seit den 1930er Jahren als begeisterter Nationalsozialist hervorgetan hatte, sollten auch im serbischen Banat vier Annahmekommissionen aufgestellt werden und planmäßig in deutschen Gemeinden Musterungen durchführen. ${ }^{191}$

Neben dem erwähnten Personalengpass führten erste Partisanenüberfälle von Četniks und Kommunisten auf deutscher Seite zur Überzeugung, dass mög-

184 Vgl. Milata, Zwischen Hitler, Stalin und Antonescu, S. 49.

185 Vgl. ebd., S. 49-55.

186 Vgl. beispielsweise Casagrande, Schvarc, Spannenberger, Traşca, Volksdeutsche, S. 224, 231, 242-243, Casagrande, Südtiroler in der Waffen-SS, S. 32.

187 Vgl. Schmider, Der jugoslawische Kriegsschauplatz, S. 1013.

188 Vgl. Casagrande, Volksdeutsche SS-Division, S. 167.

189 Vgl. Sundhaussen, Waffen-SS in Kroatien, S. 178.

190 Vgl. ebd.

191 Vgl. Casagrande, Volksdeutsche SS-Division, S. 136, 167. 
lichst rasch mit der Werbung von „Volksdeutschen“ begonnen werden müsse; auf serbischem Gebiet allerdings vorerst nur im Banat und ohne genaue Angabe der späteren Verwendung der betreffenden Truppen. Auch diese früh Rekrutierten wurden auf die verschiedenen, bereits aufgestellten SS-Divisionen verteilt. ${ }^{192} \mathrm{Au}$ ßerdem waren deutsche Militärbehörden über den Gesandten Benzler an Janko herangetreten, um die Bildung eines „Volksdeutschen Freikorps“ anzuregen. Dieses Freikorps sollte rund 1.200 Mann umfassen und die schwachen deutschen Truppen im Partisanenkrieg unterstützen. ${ }^{193}$ Im Herbst 1941 existierten schließlich zum Schutz der Bevölkerung im Banat offiziell bereits verschiedene Formationen: die „Deutsche Mannschaft“ mit ihrer „Einsatzstaffel“, die „Banater Staatswache“ sowie die „Hilfspolizei“ (HiPo). ${ }^{194}$

Bis Winter 1941/42 wurden die „Volksdeutschen“ unter rein quantitativen Aspekten geworben, in erster Linie also, um bereits bestehende Waffen-SS-Divisionen zu verstärken. Die Anfang 1942 einsetzende Orientierung weg vom bisher angewandten Prinzip der Verteilung von „Volksdeutschen“ auf bereits bestehende Divisionen hin zu einer rein ,volksdeutschen“ Division, hing eng mit der äußerst komplizierten Lage in Jugoslawien Ende 1941 und der beabsichtigten Instrumentalisierung „ethnischer“ Aspekte im Partisanenkampf zusammen. ${ }^{195}$ Hinter den Kulissen hatte man bereits im Januar 1942 für die geplante „volksdeutsche“ Division hunderte von geflohenen Rumäniendeutschen in die Reihen der WaffenSS aufgenommen. ${ }^{196}$

\subsubsection{Die Einsatzstaffel der Deutschen Mannschaft}

Bereits im Juli 1941 rekrutierten SS-Werber eine erste Einheit nach Vorbild der deutschen SS-Divisionen. In ihrem Aufbau entsprach die so genannte „Einsatzstaffel“ der als „Deutsche Mannschaft“197 bezeichneten Formation im NDH einer Einheit der Waffen-SS. Auch das Auswahlverfahren basierte auf ähnlichen Vorgaben wie bei der Waffen-SS: Die Bewerber sollten zwischen 17 und 20 Jahre alt sein und

192 Vgl. ebd., S. 183.

193 Vgl. ebd., S. 168.

194 Vgl. Michael Portmann, Arnold Suppan, Serbien und Montenegro im Zweiten Weltkrieg, in: Walter Lukan, Valeria Heuberger (Hg.): Serbien und Montenegro. Raum und Bevölkerung, Geschichte, Sprache und Literatur, Kultur, Politik, Gesellschaft, Wirtschaft, Recht, Wien/Münster: LIT 2006, S. 276.

195 Vgl. Casagrande, Volksdeutsche SS-Division, S. 183.

196 Vgl. Milata, Zwischen Hitler, Stalin und Antonescu, S. 131.

197 Vgl. zur „Einsatzstaffel“ der „Deutschen Mannschaft“ im NDH und der „Deutschen Mannschaft“ im Banat und in Serbien ausführlich Böhm, Die deutschen Volksgruppen, S. 142-154, 260-270. 
eine Mindestgröße von 1,70 m aufweisen. Selbst die „rassische Eignung“ sowie „moralische und politische Zuverlässigkeit“ unterlagen denselben Aufnahmekriterien. ${ }^{198}$ Formal wurde die „Einsatzstaffel“ der „Deutschen Mannschaft“ in die Ustaša eingegliedert und im Partisanenkampf eingesetzt. Sundhaussen geht von einer Stärke von durchschnittlich 2.500 Mann aus, Böhm dagegen von nahezu 5.000 Mann auf dem Gebiet des NDH. ${ }^{199}$ Als Vorbild dienten auch die in der Slowakei aufgestellten „Einsatztruppe-Sturmbanne“, kurz „E.T.-Sturmbanne“. Berger sprach daher auch in Hinblick auf die „Einsatzstaffel“ oft von „E.T.-Sturmbannen“, die er als Einrichtungen der Allgemeinen SS präsentierte. ${ }^{200}$

Auf dem Papier zeichnete zwar Altgayer für die „Einsatzstaffel“ verantwortlich, de facto hatte aber der „Volksdeutsche“ Jakob Lichtenberger das Kommando dieses Verbands inne. Mit der Aufstellung betreute Altgayer einen ehemaligen Hauptmann des jugoslawischen Heers, Willibald Keller. ${ }^{201}$ Schließlich gab Kasche im Januar 1942 grünes Licht für die Unterstellung der „Einsatzstaffel“ sowie eines „volksdeutschen“ Bataillons der kroatischen Armee unter eine deutsche Wehrmachtsdivision in Bosnien. Dies war das Startzeichen für Berger, die Rekrutierungen für die eigenen Reihen zu intensivieren, was schließlich zu weiteren Auseinandersetzungen zwischen den in Kroatien aktiven deutschen Dienststellen führte. ${ }^{202}$

Auch in den Gebieten Banat und Serbien bestand eine „Deutsche Mannschaft“, die nach dem Einmarsch der Deutschen den Sicherheitsdienst übernahm und in der Partisanenbekämpfung sowie im Polizei- und Flurdienst eingesetzt wurde. $^{203}$ Die „Deutsche Mannschaft“ bestand nach der einsetzenden Werbung für die „Prinz Eugen“ fort. Bereits im September 1942 wurde die allgemeine Werbung von „Volksdeutschen“ auf ältere Jahrgänge ausgedehnt, wobei sich alle 17bis 60-Jährigen melden sollten. Solche, die aus körperlichen Gründen nicht in der „Prinz Eugen“ Dienst leisten konnten, wurden in die „Deutsche Mannschaft“ eingegliedert. ${ }^{204}$ Ihre Aufgabe bestand vor allem darin, zusammen mit der lokalen Po-

198 Vgl. Sundhaussen, Waffen-SS in Kroatien, S. 179. Vgl. Casagrande, Unsere Gegner, S. 165. 199 Vgl. Sundhaussen, Waffen-SS in Kroatien, S. 179. Vgl. Böhm, Die deutschen Volksgruppen, S. 145.

$200 \mathrm{Vgl}$. Sundhaussen, Waffen-SS in Kroatien, S. 179.

201 Vgl. Böhm, Die deutschen Volksgruppen, S. 144.

202 Vgl. Sundhaussen, Waffen-SS in Kroatien, S. 180.

$203 \mathrm{Vgl}$. Böhm, Die deutschen Volksgruppen, S. 260.

204 Vgl. Casagrande, Volksdeutsche SS-Division, S. 196. Böhm schreibt von 18-45-jährigen Männern für den NDH und bestätigt die Einberufung aller 17-60-Jährigen für die Gebiete Banat und Serbien, vgl. Böhm, Die deutschen Volksgruppen, S. 144, 264. 
lizei die deutschen Siedlungen der Region vor Partisanenüberfällen zu schützen, da alle wehrfähigen Männer eingezogen worden waren. ${ }^{205}$

\subsubsection{Der „volksdeutsche Selbstschutz“ und Einheiten der Hilfspolizei}

Bereits seit den 1930er Jahren bestand ein so genannter „Selbstschutz“ in den von „Volksdeutschen“ bewohnten Gebieten des Banats. Dieser beteiligte sich im April 1941 aktiv auf Seiten der Deutschen an den Kämpfen. Darüber hinaus besetzten die Angehörigen des „Selbstschutzes“ Ortschaften und entwaffneten serbische Einheiten. ${ }^{206}$ Ende August 1941 trat die VoMi mit dem Vorschlag an Reichsaußenminister Ribbentrop heran, das bereits aufgestellte Banater Wachregiment in „Selbstschutz“ umzubenennen. Diese ungefähr 1.000 Mann starke Formation wurde im Rahmen der Hilfspolizei aufgestellt. Hinzu kamen fünfzehn Polizeioffiziere und fünfzig Wachtmeister, die aus dem Reich für sechs Wochen zur Ausbildung des „Selbstschutzes“ nach Südosteuropa versetzt wurden. ${ }^{207}$ Janko hingegen schreibt in seinen Memoiren, er habe 1941 „Selbstschutz“-Einheiten, fünf Kompanien zu je 300 Mann, aus den bereits bestehenden Einheiten der „Deutschen Mannschaft“ zusammengestellt. Dies tat er in Zusammenarbeit mit dem bereits erwähnten Oberstleutnant Eulenburg. Als die Einheit schließlich versetzt werden sollte, wollte letzterer die frisch rekrutierten jungen Männer für sein eigenes Regiment gewinnen. Janko selbst zeigte kein Interesse an einer solchen Versetzung „Volksdeutscher“ in andere Gebiete. Rund hundert Mann hätten sich aber dem Regiment Eulenburg angeschlossen. ${ }^{208}$

\subsubsection{3 „Sonderkommando Künsberg“}

In alle hier vorgestellten Divisionen wurden auch Männer aus dem „Sonderkommando Künsberg“ übernommen. Dieses war bereits für den Polenfeldzug 1939 aufgestellt worden, mit dem Auftrag, Botschaften feindlicher Staaten zu sichern und relevantes, diplomatisches Material in deutschen Besitz zu bringen. Während dem Balkanfeldzug stellten Künsberg und sein Sonderkommando umfangreiches Kartenmaterial sicher, das für das weitere Vorgehen in Serbien, Bosnien und Kroatien wesentlich sein würde. Noch im selben Jahr gelang es Künsberg, den griechischen Staatsschatz auf Kreta zu orten und ihn nach Deutschland zu

205 Vgl. Casagrande, Volksdeutsche SS-Division, S. 196.

206 Vgl. Casagrande, Unsere Gegner, S. 165.

207 Vgl. Casagrande, Volksdeutsche SS-Division, S. 169.

208 Vgl. Janko, Weg und Ende der deutschen Volksgruppe, S. 213. 
bringen. In diesem Sonderkommando finden sich zahlreiche Namen, die später in der „Prinz Eugen“, aber auch in den anderen Balkan-Divisionen auftauchen. ${ }^{209}$

\subsubsection{Weitere Rekrutierungen von südosteuropäischen „Volksdeutschen“: Das Beispiel Division „Nordland“}

Ein Jahr nach Aufstellung der „Prinz Eugen“ im Juli 1943 wurde die 11. SS-Freiwilligen-Panzergrenadier-Division „Nordland“ aufgestellt. Ziel war es, diejenigen skandinavischen Soldaten, die bislang in der 5. SS-Panzer-Division „Wiking“ oder in landeseigenen SS-Legionen kämpften, in dieser neuen Formation zusammenzufassen. Auch „volksdeutsche“ Bevölkerungsteile in Rumänien sollten bei der Aufstellung berücksichtigt werden. Seit Sommer 1943 war die Division im Gebiet des NDH stationiert, dem III. SS-Panzerkorps unterstellt und in der Partisanenbekämpfung eingesetzt. Die Division wurde zuerst in die Gegend von Sisak, in der Nähe von Zagreb verlegt. Bei Sambor und Karlovać wurde die Division ab September 1943 zur Entwaffnung italienischer Soldaten eingesetzt. ${ }^{210}$ Während ihres Einsatzes in Südosteuropa waren Einheiten der „Nordland“ an zahlreichen Kriegsverbrechen gegen die lokale Zivilbevölkerung beteiligt. ${ }^{211}$ Danach kam die Division nach Russland, wo sie der 18. Armee unterstellt und im Raum Kirowa am Oranienbaumer Kessel eingesetzt war. ${ }^{212}$ Auch innerhalb der 6. SS-Gebirgs-Division „Nord“, der 8. SS-Kavallerie-Division „Florian Geyer“, der 9. SS-Panzer-Division „Hohenstaufen“, der 10. SS-Panzer-Division „Frundsberg“ und der 22. SS-Kavallerie-Division „Maria Theresia“ waren südosteuropäische „Volksdeutsche“ zu finden. Vereinzelt dienten sie zudem in zahlreichen weiteren Verbänden der Waffen-SS und Wehrmacht. ${ }^{213}$

\subsubsection{Werbung}

Wie bereits erläutert erstreckten sich die Rekrutierungsanstrengungen zuerst auf das Banat, danach auf die zum NDH gehörenden Gebiete und schließlich auf Rumänien und Ungarn. Sie können somit in verschiedene Phasen unterteilt werden, wobei stets mitgedacht werden muss, dass in den einzelnen Ländern

209 Das „Sonderkommando Künsberg“ bestand Anfang 1942 aus 7 Führern, 297 Unterführern und Mannschaften, 3 Pkw, 1 Tankwagen und 5 Lkw. Vgl. Krüger, 12.2.1942, BArchB, NS19/1618. 210 Vgl. Klietmann, Waffen-SS: eine Dokumentation, S. $175 \mathrm{f}$.

211 Vgl. Müller, An der Seite der Wehrmacht, S. 147.

212 Vgl. Sørlie, Sonnenrad und Hakenkreuz, S. 355.

213 Vgl. Kaltenegger, Totenkopf und Edelweiss, S. 116. Vgl. David Stahel, Joining Hitler's Crusade. European Nations and the Invasion of the Soviet Union 1941, Cambridge: Cambridge University Press 2017, S. 6 f. 
parallel weitere Rekrutierungen stattfanden. Offiziell wurden aber die Rekrutierungen 1942 aus außenpolitischen Gründen noch auf die Region Banat und allgemein Serbien beschränkt und die Werbung in anderen Staaten abgelehnt. ${ }^{214}$ In der zweiten Februarhälfte 1942 machte sich daher der zukünftige Divisionskommandeur Artur Phleps auf, im Banat nach geeigneten Rekrutierungsorten und Unterkünften für die aufzustellende Division zu suchen. Von Beginn an koordinierte er die bevorstehenden Rekrutierungen mit dem „Volksgruppenführer“ der deutschen Volksgruppe im Banat und Serbien, Sepp Janko. ${ }^{215}$ Kumm berichtet in seiner Divisiongeschichte, Phleps habe danach mit ,seiner zupackenden und mitreissenden Art“ begonnen, die geplante „volksdeutsche“ Division aufzubauen. ${ }^{216}$ Mit seiner Wahl zum Divisionskommandeur hoffte Berger die Anziehungskraft, welche die „Prinz Eugen“ auf die „Volksdeutschen“ haben sollte, zu steigern. ${ }^{217}$ Doch dass Phleps nicht nur auf diese Art, sondern noch in anderer Hinsicht „zupackend“ und „mitreissend“ agierte, zeigen andere Quellen, die belegen, dass er nicht nur auf freiwilliger Basis rekrutierte. Janko und er bauten sehr bald Druck auf, um auch zögernde junge „Volksdeutsche“ in die Division zu pressen. ${ }^{218}$

Dies wird deutlich, wenn man den Rekrutierungsaufruf von Janko von Anfang 1942 liest:

Die deutsche Wehrmacht hat im Frühjahr des vergangenen Jahres unsere Dörfer und Wohnstätten unter ihren Schutz genommen. Deutschland kämpft mit seinen Soldaten einen schweren Kampf, um ganz Europa vor dem Bolschewismus zu bewahren. Auch in unserem Lande versuchte der bolschewistische Gegner in den vergangenen Monaten und Wochen sein Haupt zu erheben, die Straßen unsicher zu machen und unsere Dörfer anzuzünden. Deutsche Truppen haben wiederum im Verein mit uns und allen ordnungsliebenden Elementen des Landes diese Gefahr gebannt. Für uns aber ist es nunmehr Ehrensache, dass wir, den Traditionen unserer Väter folgend, den Schutz von Haus und Hof selbst übernehmen. Ich rufe euch daher auf, dass alle Männer vom 17. bis zum 50. Lebensjahr, sobald der betreffende Jahrgang aufgerufen ist, sich bei ihrem Bürgermeister und in Belgrad bei der Kreisleitung der Volksgruppe zum Dienst mit der Waffe zum Schutze unserer Wohnstätten zu melden. Von diesem Dienst kann sich keiner, der gesund ist, ausschließen. Deutsche Volksgenossen, zeigt Euch Eurer Väter würdig durch mannhaften Einsatz und durch die Tat! Dr. Sepp Janko 219

214 Vgl. Casagrande, Volksdeutsche SS-Division, S. 187.

215 Vgl. Kumm, Vorwärts Prinz Eugen, S. 38.

216 Vgl. ebd., S. $38 \mathrm{f}$.

217 Vgl. Casagrande, Volksdeutsche SS-Division, S. 188.

218 Vgl. Kumm, Vorwärts Prinz Eugen, S. 38f.

219 Vgl. Janko, Weg und Ende der deutschen Volksgruppe, S. 220. 
Als Name für die Division schlug Phleps zuerst „Gebirgsdivision Südost“ vor. Diese sollte aus zwei Brigaden zu je sechs Bataillonen bestehen. Hinzu kamen schwere Waffen. Dieser Entwurf zur Gliederung stand bereits am 10. Februar 1942; am 15. Februar begann seine Erkundungstour durch das Banat. ${ }^{220}$ Bereits zu diesem Zeitpunkt diskutierten die Vertreter der beteiligten Stellen, dass der Anteil „Banater Schwaben“ nicht reichen würde, um eine Divison aufzustellen, für welche die ungewöhnlich große personelle Stärke von 24-25.000 Mann vorgesehen war. ${ }^{221}$ Dennoch war Phleps selbst nach einem Treffen mit Altgayer, Lorenz und Meyszner vom 13. Februar 1942 der Meinung, dass sogar eine zweite „volksdeutsche“ Division in Kroatien nach dem Vorbild der zukünftigen Banater Divsion aufgestellt werden könnte. ${ }^{222}$ Als sich herausstellte, dass mit „Volksdeutschen“ aus dem Banat allein die Divisionsstärke nicht zu erreichen war, wurde die Werbung für die „Prinz Eugen“ zuerst auf die Gebiete des NDH und 1943 auch auf Rumänien ausgedehnt. ${ }^{223}$ Bereits ein halbes Jahr nach Bekanntgabe der Aufstellung schrieb Lorenz an Himmler, dass in Zusammenarbeit mit der jeweiligen Volksgruppenführung auch Aushebungen in Ungarn und der Slowakei geplant wären. ${ }^{224}$

Von der anfänglichen Mindestgröße für den Dienst in der Waffen-SS von 1.70 bzw. $1.74 \mathrm{~m}^{225}$ rückte Berger im August $1942 \mathrm{ab}$ und meldete SS-Obersturmbannführer Nageler, dass auch Rekruten mit Untergröße bis $1.63 \mathrm{~m}$ in die „Prinz Eugen“ aufgenommen werden sollten. ${ }^{226}$ Casagrande schreibt, dass die Tauglichkeitsvoraussetzungen schließlich sogar bis $\mathrm{zu}$ einer Körpergröße von $1.60 \mathrm{~m}$ angepasst wurden. ${ }^{227}$ Die ärztliche Untersuchung bei den Aushebungen verlief oberflächlich, wie der ehemalige Waffen-SS-Angehörige Umbrich sich erinnert. Als er die von ihm mit 1,65 m angegebene Mindestgröße bei der Aushebung nicht erreichte, wies ihn der Arzt an, auf den Zehenspitzen zu stehen. ${ }^{228}$ Phleps selbst meldete am 26. April den Zugang von rund 5.000 Rekruten aus Siebenbürgen mit einer Körpergröße von unter $1,65 \mathrm{~m} .^{229}$

220 Vgl. Kumm, Vorwärts Prinz Eugen, S. $38 \mathrm{f}$.

221 Vgl. Casagrande, Volksdeutsche SS-Division, S. 189.

222 Vgl. Phleps an Altgayer, PAAA Inl. IIg 305/2563, Dok. J19-20, nach: Casagrande, Volksdeutsche SS-Division, S. 190.

223 Vgl. Casagrande, Volksdeutsche SS-Division, S. 187.

224 Berger an SS-Obersturmbannführer Nageler, 26.8.1942, BArchB, NS19/319, Bl. 46.

225 Vgl. Wegner, Soldaten, S. 135.

226 Vgl. Berger an SS-Obersturmbannführer Nageler, 26.8.1942, BArchB, NS19/319, Bl. 46.

227 Vgl. Casagrande, Unsere Gegner, S. 167. Vgl. auch Leleu, La Waffen-SS, S. 1130.

228 Vgl. Wittmann, Umbrich, Alptraum Balkan, S. 73.

229 Vgl. Kumm, Vorwärts Prinz Eugen, S. 70. 
Berger betonte außerdem, dass alle wehrfähigen Männer zwischen 17 bis 50 Jahren aufgenommen werden sollten. ${ }^{230}$ Im Gegenzug versprach Phleps, Männer innerhalb der „Prinz Eugen“, die als „garnisonverwendungsfähig [in der] Heimat“ (g.v. H.) oder „garnisonverwendungsfähig [im] Feld“ (g.v.Feld) eingestuft wurden, zum Arbeitseinsatz freizugeben. ${ }^{231}$ Dass solche Freigaben aber kaum vorkamen, zeigen folgende Aussagen Umbrichs: Von den Rekruten, die mit ihm zur Aushebung angetreten waren, wurde niemand zurückgewiesen, selbst sein Freund Christian Schuster nicht, der unter einer vergrößerten Schilddrüse litt und daher sehr rasch müde wurde. ${ }^{232}$ Aus den eingesehenen Personalunterlagen wird deutlich, dass teilweise ganze Familien bzw. alle männlichen Familienmitglieder ausgehoben wurden. So etwa bei diesem Beispiel aus dem heute an der bosnisch-kroatischen Grenze liegenden Slavonski Brod, wo fast gleichzeitig verschiedene Familienmitglieder, Vladimir, Vjekoslav, Josef und Alois Gasparitsch, rekrutiert wurden. ${ }^{233}$ Auffallend ist, dass die Waffen-SS in Propagandaschriften, welche der Werbung in „volksdeutschen“ Gebieten dienten, nicht namentlich erwähnt wurde. ${ }^{234}$

\subsubsection{Rekrutierungen im Banat}

Im Frühjahr 1942 setzten die Rekrutierungen im Banat ein. Mit Wirkung vom 1. März 1942 wurde folgende Aufstellungsverfügung erlassen: „Führerstellenbesetzung erfolgt durch das Divisionskommando, das auf das Personal des serbischen Raumes und gewesene aktive deutschvölkische Offiziere Nordsiebenbürgens zurückgreift.“235 Als Aufstellungsort für die Division wurde das Banat gewählt, da in diesem Dreieck zwischen Rumänien, Ungarn und Serbien zahlreiche „Volksdeutsche“ siedelten. ${ }^{236}$ Die Werbung sollte aus außenpolitischen Gründen vorerst auf diesen Raum beschränkt bleiben. ${ }^{237}$ In der ersten Phase der Aufstellung, im Frühjahr 1942, bildete somit die Vojvodina das Zentrum der Division; der Divisionsstab befand sich in Pančevo. Das erste Regiment war in Bela Crkva/Weißkirchen, weitere Truppenteile in Vršac/Werschetz und Kikinda an der Grenze zu Rumänien stationiert. ${ }^{238}$

230 Vgl. Janko, Weg und Ende der deutschen Volksgruppe, S. 220.

231 Berger an SS-Obersturmbannführer Nageler, 26.8.1942, BArchB, NS19/319, Bl. 46.

232 Vgl. Wittmann, Umbrich, Alptraum Balkan, S. 73.

233 Vgl. Fälle Vladimir, Vjekoslav, Josef und Alois Gasparitsch, AJ 110-702-263 bis AJ 110-702306.

234 Vgl. Janko, Weg und Ende der deutschen Volksgruppe, S. 220.

235 Klietmann, Waffen-SS: eine Dokumentation, S. 151.

$236 \mathrm{Vgl}$. Sundhaussen, Waffen-SS in Kroatien, S. 182.

237 Vgl. Casagrande, Volksdeutsche SS-Division, S. 187.

238 Vgl. Klietmann, Waffen-SS: eine Dokumentation, S. 152. Unveröffentlichte Divisionsgeschichte Vopersal, BArchF, N756/149b. 
Zuständig für diese frühen Rekrutierungen waren neben Phleps SS-Obersturmführer Günther Herrmann, SS-Obergruppenführer Lorenz sowie SS-Brigadeführer Behrends, der später auch für Rekrutierungen kroatischer und bosnischer Muslime, sowie Aushebungen von albanischen Muslimen im Raum Sandžak verantwortlich zeichnete. Im November 1942 lag aber alles in den Händen Herrmanns, der jedoch gegenüber dem deutschen Gesandten Kasche nicht den nötigen Respekt zeigte, wie sich letzterer beschwerte. Behrends selbst war in dieser Phase längere Zeit krankgeschrieben. ${ }^{239}$

Luther schätzte, dass sich bis April 1942 bereits zwischen 10.000 und 15.000 Mann für die „Prinz Eugen“ gemeldet hätten. ${ }^{240}$ Dies enstpricht auch den von Tessin gemachten Angaben für diese erste Phase des Bestehens der Division. ${ }^{241}$ De facto, so Casagrande, wurden im Laufe des Jahres 1942 alle wehrfähigen Männer der deutschen Volksgruppen im Banat zum Dienst in die Waffen-SS-Division eingezogen. ${ }^{242}$ Dadurch, dass die personellen Ressourcen im Banat quasi bis auf den letzten Mann aufgebraucht wurden, fehlten in zahlreichen Familien nun Väter, Söhne und Brüder, um die anfallenden Arbeiten auf den Höfen und Feldern zu erledigen. ${ }^{243}$ Ende 1943 dienten ungefähr 21.500 „Volksdeutsche“ aus dem Banat und Serbien in den Rängen der Waffen-SS sowie der SS angegliederten Hilfs- bzw. Banater Polizei. Davon taten rund 12.000 Dienst in der „Prinz Eugen““ ${ }^{244}$ Dass diese den größten Anteil der Division ausmachten, blieb auch im Sommer 1944 so. Ihren Einsatz leisteten sie oft in ihren Heimat- bzw. in umliegenden Gebieten. ${ }^{245}$

\subsubsection{Rekrutierungen im NDH}

Innerhalb der Grenzen des NDH wurde Ende März 1942 eine Erhebung durchgeführt, um alle „Volksdeutschen“ zu erfassen. Der männliche Anteil sollte der „Prinz Eugen“ bzw., falls zu alt oder untauglich, der „Deutschen Mannschaft“, wie auch später, etwa für Leitungsaufgaben und für spezielle Funktionen wie Übersetzer, der „Handschar“ zugeführt werden. So wurden beispielsweise bereits Ende Januar 1942 in Zagreb zwanzig „volksdeutsche“ Abiturienten ausgehoben, die unverzüglich zur weiteren Ausbildung nach Stralsund geschickt werden soll-

239 Vgl. Luther an Berger, 14.11.1942, BArchB, NS19/319, Bl. 85. Vgl. Kasche an AA, 12.11.1942, BArchB, NS19/319, Bl. $87 \mathrm{f}$.

240 Vgl. Casagrande, Volksdeutsche SS-Division, S. 196.

241 Vgl. Tessin, Verbände, Bd. 3, S. 83.

242 Vgl. Casagrande, Volksdeutsche SS-Division, S. 196.

243 Vgl. ebd., S. $196 \mathrm{f}$.

244 Vgl. ebd., S. 211.

245 Vgl. ebd., S. $211 \mathrm{f}$. 
ten. Weitere 140 Mann, deren Deutschkenntnisse allerdings zu wünschen übrigließen, wurden für die Stabswache ausgehoben. ${ }^{246}$

Nach einer neuen Erhebung von 1941 kam Lorenz zu dem Schluss, dass in der neuen Bestandsaufnahme 27 zusätzliche Ortschaften verzeichnet seien, die in der Erhebung von 1931 noch keine deutschen Bewohner gezählt hatten. Zudem fiel auf, dass Dörfer mit bereits deutscher Mehrheit eine starke Zunahme deutschstämmiger Einwohner aufwiesen, während die Zahl der „Volkdeutschen“ in kroatischen Städten abnahm. Agram beispielsweise verzeichnete einen Rückgang von 1.849 Bewohnern auf 4.438 oder India um 539 auf 5.357. Osijek/Essegg, wo auch die „Erneuerungsbewegung“ aktiv war, verzeichnete hingegen eine Zunahme um 748 auf 10.479 deutschstämmige Bewohner. ${ }^{247}$

Zur Illustration sind in der folgenden Grafik die Ergebnisse von 1931 und 1941 im Vergleich aufgeführt:

\begin{tabular}{lrrrr}
\hline Kreise & Erhebung 1931 & Erhebung Ende 1941 & Zunahme & Prozent \\
\hline Ostsyrmien & 46.124 & 49.806 & 3.682 & 8 \\
Save-Donau & 30.818 & 41.318 & 10.500 & 29,5 \\
Unterdrau & 37.072 & 51.745 & 14.673 & 39,5 \\
Mitteldrau & 13.790 & 23.456 & 9.666 & 70,5 \\
Agram-Bosnien & 23.363 & 29.717 & 6.354 & 27 \\
Nacherhebung & 3.000 & 3.000 & - & - \\
TOTAL & 154.167 & 199.042 & 44.875 & $29^{248}$ \\
\hline
\end{tabular}

Im August 1942 gab Berger die Weisung aus, dass für die in Kroatien anlaufende Werbung von „Volksdeutschen“ die bereit gestellten Annahmekommissionen sowie das Begleitkommando „zur ,Prinz Eugen“ in Marsch gesetzt werden“ sollten, um dort bei der Musterung bzw. beim Ausstellen der Wehrpapiere mitzuhelfen. Berger hoffte, dass auf diese Weise die Rekrutierung bis am 10. September 1942 abgeschlossen wäre. ${ }^{249}$ Im selben Monat sollten in die neu aufgestellte Division auch Kroaten übernommen werden, die vorher verteilt auf verschiedene Verbände an

246 Berger an Himmler, betr. „Kroatische Führer“, 31.1.1942, BArchB NS19/319, Bl. 11.

247 Vgl. Leiter Volksdeutsche Mittelstelle Werner Lorenz an Himmler, betr. „Bestandesaufnahme der Deutschen Volksgruppe in Kroatien“, 31.3.1942, BArchB NS19/319, Bl. 18.

248 Vgl. ebd., Bl. 17.

249 Berger an SS-Obersturmbannführer Nageler, 26.8.1942, BArchB, NS19/319, Bl. 45. 
der Ostfront gedient hatten. Hitler persönlich hatte befohlen, diese „kroatischen Truppenteile“ nun in eine eigenständige „kroatische Division“, damit meinte er die „Prinz Eugen“, zu integrieren. Obwohl diese von Alfred Jodl am Briefanfang als Kroaten bezeichnet wurden, meinte er exklusiv kroatische „Volksdeutsche“. Das OKW erklärte sich zur Herausgabe dieser „Volksdeutschen“ im Hinblick auf eine „beschleunigte Aufstellung“ bereit. Auch das Landwehrministerium in Zagreb stellte 350 „Volksdeutsche“ für die neue Division bereit. ${ }^{250}$

Die Werbung der „volksdeutschen“ Rekruten im NDH sollte ganz in der Verantwortung des „Volksgruppenführers“ im NDH, Altgayer, stehen. Berger verlangte, dass er „mit Propagandamaterial, Aufrufen usw. in jeder Form“ auszustatten und zu unterstützen sei. ${ }^{251}$ Anders verhielt es sich für die neuen Ansiedler aus Bosnien, welches auch zum NDH gehörte, unter welchen vorerst nicht geworben werden durfte. ${ }^{252}$ Ähnlich wie im Banat sollten aber alle, auch ältere „volksdeutsche“ Männer zumindest untersucht und karteimäßig erfasst werden. Letztere sollten, wie später auch im Falle der bosnischen Muslime sowie derjenigen aus dem Sandžak, bei Bedarf für „Selbstschutz“-Einheiten herangezogen werden. Hingegen waren sie weder für einen Einsatz innerhalb der „Prinz Eugen“ noch für Arbeitseinsätze im „Reich“ vorgesehen. ${ }^{253}$

Dass diese Rekrutierungen bei den Vertretern des Auswärtigen Amtes nicht unbedingt auf Gegenliebe stießen, zeigt ein Schreiben des Unterstaatssekretärs Martin Luther, der Berger am 24. August 1942 meldete, dass mit der Werbung von „Volksdeutschen“ vor Ort begonnen worden sei, ohne sich an gemachte Absprachen zu halten. Sowohl Kasche als Luther ärgerten sich, dass sie bei diesen bereits laufenden Werbemaßnahmen übergangen worden waren. So hatte Kasche Luther gemeldet, dass Landesmannschaftsführer Lichtenberger Werbeplakate aufgehängt, und SS-Obersturmführer Herrmann die Weisung ausgegeben habe, solche Werbemaßnahmen sollten parallell zu den Aushebungen erfolgen. Luther klagte außerdem, dass das Höchstalter auf 35 Jahre heraufgesetzt worden sei, obwohl dieses bei bisherigen Besprechungen auf 30 Jahre festgelegt worden war. ${ }^{254}$

Luther war zudem erbost über die verfrühte Aufnahme der Werbung. Bergers „Unterführer“ [sic] würden sich nicht an die Vereinbarung halten, dass mit der Werbung solange gewartet werden sollte, bis „die Umsiedler aus Bosnien abmarschbereit“ wären. Nach Luthers Meinung konnte das Auswärtige Amt ein

250 Chef des Oberkommandos der Wehrmacht, Alfred Jodl, an Himmler und SS-Obergruppenführer Karl Wolff, 21.8.1942, BArchB, NS19/319, Bl. 42.

251 Berger an SS-Obersturmbannführer Nageler, 26.8.1942, BArchB, NS19/319, Bl. 45.

252 Vgl. ebd.

253 Vgl. ebd., Bl. 46.

254 Vgl. Unterstaatssekretär Martin Luther an Berger, 24.8.1942, BArchB, NS19/319, Bl. 43. 
solches Vorgehen der Waffen-SS-Werber auf keinen Fall dulden, es sei denn, den Verantwortlichen würden Gründe für die Beschleunigung des Werbebeginns vorliegen. ${ }^{255}$ Es schien ihm „auf die Dauer unerträglich, wenn trotz aller Besprechungen und Vereinbarungen das Auswärtige Amt, wie dies jetzt in Kroatien wiederum der Fall ist, vor vollendete Tatsachen gestellt wird, die unerwünschte außenpolitische Rückwirkungen haben““. ${ }^{256}$ Lorenz wies Berger daher an, sicherzustellen, dass sich seine Leute vor Ort strikt an die Abmachungen hielten, welche hinsichtlich „der Zusammenarbeit in Volkstumsfragen“ zwischen dem Reichsaußenminister und dem Reichsführer SS getroffen worden waren. ${ }^{257}$ Gegenüber Wolff beschwerte sich Luther, dass nicht nur das Auswärtige Amt, sondern auch Kasche sich ,auf ausdrücklichen Befehl des Herrn Reichsaußenministers darum bemüht [hätten], der Waffen-SS jeden nur irgendwie freizumachenden volksdeutschen Freiwilligen zur Verfügung zu stellen.“258 Daher war er überzeugt, dass die Probleme bei den bisherigen Werbeanstrengungen nicht bei den Vertretern des Auswärtigen Amtes zu suchen wären, sondern bei der SS selbst bei Lorenz und Berger. ${ }^{259}$

Außerdem habe Herrmann als Leiter der Musterungskommission anscheinend die Weisung seines Vorgesetzten im SS-Ergänzungsamt nicht erhalten, vor Ort nur in Absprache mit Kasche zu rekrutieren. ${ }^{260}$ Herrmann war mit 20 bis 25 SS-Führern in Kroatien herumgereist und hatte, ohne Kasche $\mathrm{zu}$ informieren, Rekrutierungen durchgeführt. In der Tat führten in Kroatien solche Interessenkonflikte zwischen Kasche und Herrmann zu längeren Auseinandersetzungen, welche nach Ansicht Luthers gar von „Reichsinteresse“ waren. ${ }^{261}$ Vier Tage später erstattete er auch Lorenz Meldung über die unautorisierten Rekrutierungsvorgänge in Kroatien. Herrmann habe 556 Arbeitsdienstmänner gemustert und davon 327 einberufen. ${ }^{262}$ Diese würden zwar in Anbetracht der Gesamtzahl von 4.600 bisher Einberufenen keine entscheidende Rolle spielen, problematisch dabei sei aber, dass sie nun bei entscheidenden Aufbauarbeiten fehlen würden. ${ }^{263}$

255 Vgl. ebd. $43 \mathrm{f}$.

256 Ebd., Bl. 44.

257 Ebd.

258 Luther an SS-Obergruppenführer Wolff, 5.11.1944, BArchB, NS19/319, Bl. 61.

259 Vgl. ebd.

260 Vgl. ebd.

261 Vgl. ebd., Bl. 62. Vgl. zu den Auseinandersetzungen zwischen Herrmann und Kasche auch: Lorenz an Berger, betr. „Werbung von Volksdeutschen zur Waffen-SS in Kroatien“, BArchB, NS19/319, Bl. $83 \mathrm{f}$.

262 Vgl. Luther an SS-Obergruppenführer Lorenz, 9.11.1944, BArchB, NS19/319, Bl. 63.

263 Vgl. ebd., Bl. $63 \mathrm{f}$. 
In einem Telegramm vom 12. November 1942 meldete Kasche aus Zagreb, dass die Waffen-SS von August bis November folgende Kontingente gemustert bzw. geworben habe: Insgesamt seien 25.000 Mann gemustert worden, davon seien bis Ende Oktober 4.000 „Volksdeutsche“ eingerückt; „Volksgruppenführer“ Altgayer gab sogar eine Zahl von 4.600 an. Obergruppenführer Lorenz hatte Herrmann außerdem befohlen, alle SS-tauglichen Männer des Arbeitsdienstes für die geplante Division einzuziehen, sowie die gesamte Einsatzstaffel und die „volksdeutschen“ Jägerbataillone durchzumustern. ${ }^{264}$

Wie aus diesen Schreiben hervorgeht, war Kasche mit dem Vorgehen der Waffen-SS ganz und gar nicht einverstanden. Aus seiner Sicht waren er und das Auswärtige Amt nicht ausreichend über die Rekrutierungsvorhaben der Waffen-SS informiert worden. Insbesondere die geplante SS-Dienststelle zur „weiteren Wehrüberwachung“ erregte Kasches Gemüt. ${ }^{265}$ Auch Luther äußerte sich besorgt, dass die von der Waffen-SS geplante „Durchmusterung“ der Einsatzstaffeln und „volksdeutschen“ Jägerbataillone ohne Absprache mit der kroatischen Regierung negative Konsequenzen haben würde. ${ }^{266}$

Am 17. November meldete sich schließlich der von Kasche angeschwärzte Lorenz zu Wort und beteuerte, dass die „Durchmusterung“ nur als „Überblick über die Wehrtauglichkeit“ gedacht gewesen sei. Über eine geplante Einrichtung einer Dienststelle in Osijek/Essegg sei er nicht informiert. ${ }^{267}$ Anfang Dezember 1942 wollte SS-Obergruppenführer Wolff schließlich von Berger wissen, wie er zu den Vorwürfen gegen Herrmann und ihn, Lorenz, stehe. ${ }^{268}$ Berger antwortete salopp und im Wissen darum, dass sich die Waffen-SS längst zu einer ernstzunehmenden Größe im nationalsozialistischen System gemausert hatte:

Liebes Wölfflein! Der Brief des Herrn Unterstaatssekretärs Luther vom 9.11.42 hat mir viel Freude gemacht, rein darum, weil ich an mir selbst feststellen konnte, dass ich über derartige Verdrehungen mich nicht mehr ärgere, sondern zur Tagesordnung übergehe. Ich habe den gesamten Vorgang dem Leiter des Ersatzkommandos Südost, SS-Ostubaf. Letsch, übersandt mit dem Befehl, sich ins eingehendeste zu diesen Anschuldigungen [gegen die Rekrutierungen im Allgemeinen und Herrmann im Speziellen] zu äußern. [...] Im übrigen muss sich eben der Herr Unterstaatssekretär Luther daran gewöhnen, dass ein SS-Gruppenführer kein kleines Würstchen ist, mit dem man spielen kann. ${ }^{269}$

264 Vgl. Kasche an AA, 12.11.1942, BArchB, NS19/319, Bl. 87.

265 Vgl. ebd., Bl. 88.

266 Vgl. Luther an Volksdeutsche Mittelstelle, Lorenz, betr. „Musterung von Volksdeutschen zur Waffen-SS in Kroatien“, 14.11.1942, BArchB, NS19/319, Bl. 86.

267 Vgl. Lorenz an Luther, betr. „Einberufung zur Waffen-SS in Kroatien“, 17.11.1942, BArchB, NS19/319, Bl. 88.

268 Vgl. SS-Obersturmführer an Chef des SS-Hauptamtes, Berger, BArchB, NS19/319, Bl. 89.

269 Berger an Wolff, 5.12.1942, BArchB, NS19/319, Bl. 90. 
Über die Werbung im bosnisch-kroatischen Grenzgebiet im Herbst 1942 berichtet der „Volksdeutsche“ Bernwald aus Sicht der Rekrutierten in seinen Memoiren:

Im Oktober 1942 wurde eine große Werbeveranstaltung seitens der Führung der deutschen Volksgruppe in Kroatien durchgeführt; ihr Zweck war die Werbung von Freiwilligen für die Waffen-SS. Aus meiner Klasse [Gymnasium] meldeten sich etwa fünf bis acht Kameraden. Ich kam mit Joschka und Hansi Oppermann sowie Fritz Florschütz zur LSSAH [Leibstandarte Adolf Hitler] nach Berlin-Lichterfelde-West. ${ }^{270}$

Die Werber der Waffen-SS zielten ganz bewusst auf die Jüngsten, die am einfachsten $\mathrm{zu}$ beeinflussen waren. Bernwalds ältester Bruder hingegen, der als Schriftsetzer in Zagreb bereits politisch organisiert war, entschloss sich, zu den Partisanen zu gehen. ${ }^{271}$ Eine andere Art von Vorgehen stellt die Aufforderung Lorenz' an Altgayer im November 1942 dar, aus dem „volksdeutschen“ Arbeitsdienst im NDH sieben Führer und 100 Mann für die Waffen-SS freizugeben. ${ }^{272}$ Lorenz ging auf den von Kasche stammenden Vorschlag ein, diesen neu aufgebauten Arbeitsdienst nicht ganz in die Waffen-SS zu integrieren, sondern nur einen Teil zu versetzen und den Rest fortbestehen zu lassen. Er hatte Bedenken, dass die kroatische Regierung andernfalls zukünftigen Rekrutierungen - auch einem Aufbau weiterer Waffen-SS-Verbände - ablehnend gegenüberstehen würde. ${ }^{273}$ Lorenz sollte mit seiner Einschätzung, bei der angestrebten Rekrutierung Vorsicht walten zu lassen, um Kasche keine Möglichkeit zur Intervention zu geben, richtig liegen. Im Laufe weiterer Rekrutierungsanstrengungen der SS, gerade in Bezug auf bosnische Muslime, behinderte Kasche das Vorhaben der Schutzstaffel konsequent und wandte sich diesbezüglich auch mehrmals an das Auswärtige Amt. ${ }^{274}$

\subsubsection{Rekrutierungen in Rumänien}

Die Massenrekrutierungen in Rumänien sollten in einem zeitlichen Rahmen von gut drei Monaten, vom 24. April bis 31. Juli 1943 stattfinden und danach beendet sein. Doch die deutschen SS-Werber hielten sich weder an den Anfangszeitpunkt die Rekrutierungen liefen bereits am 14. April an - noch an das abgemachte Ende der Rekrutierungen. ${ }^{275}$ Obwohl das Werbeabkommen zwischen Waffen-SS und

270 Bernwald, Muslime, S. 36.

271 Vgl. ebd.

272 Vgl. Abschrift Lorenz an Volksgruppenführer Altgayer, 11.11.1942, BArchB, NS19/319, Bl. 82.

273 Lorenz an Berger, betr. „Werbung von Volksdeutschen zur Waffen-SS in Kroatien“, BArchB, NS19/319, Bl. 83.

274 Vgl. Kapitel „Auseinandersetzungen zwischen Auswärtigem Amt und SS“ im Teil zur Division „Handschar“.

275 Vgl. Milata, Zwischen Hitler, Stalin und Antonescu, S. 165. 
rumänischer Regierung Propagandamedien nicht explizit ausschloss, hatte die rumänische Regierung darum gebeten, Diskretion walten zu lassen, da es sich innenpolitisch um ein brisantes Thema handelte. ${ }^{276}$ Somit fand die Anwerbung Rumäniendeutscher oft auf mündlichem Wege statt. Die Führung der „Deutschen Volksgruppe in Rumänien“ unter Schmidt ließ Aufrufe, Nachrichten und Befehle per Motorad oder Auto in die deutschen Siedlungsgebiete bringen und direkt an die jeweiligen Kreis- und Ortsgruppenleiter aushändigen. In diesen Werbeunterlagen wurde die Aktion unumwunden als „Aushebung“ bezeichnet. ${ }^{277}$ Obwohl die Rekrutierungen erst im Sommer anliefen, ließ Schmidt an einer Massenkundgebung zur Feier von Hitlers 10-jähriger Machtergreifung am 31. Januar 1943 bereits verlauten, „dass ab sofort der höchstmögliche Einsatz an der Heimat- und Waffenfront geleistet werden müsse. ${ }^{278}$ Bis Sommer 1943 würde er an die 50.000 Rumändiendeutsche geworben haben. ${ }^{279}$

Zahlreiche Hinweise deuten darauf hin, dass die Rekrutierungen von Beginn an als Zwansgaushebungen und nicht als Freiwilligenaktion gedacht waren. ${ }^{280} \mathrm{Am}$ 20. April 1943, Hitlers Geburtstag, ließ Schmidt die Rumändiendeutschen wissen, dass die „verbotene Freiwilligkeit“ bald ein Ende haben würde, und am 24. April veröffentlichte Walter May, Leiter des „Presse und Propaganda“-Amtes, einen Artikel zu bereits stattgefundenen „frühen“ Rekrutierungen und jenen, die folgen würden. Die Waffen-SS blieb in solchen Wortmeldungen gänzlich unerwähnt, die Aufgabe der Rekrutierten wurde unpräzise als „Fronteinsatz“ umrissen. ${ }^{281}$ Obwohl erst am 12. Mai 1943 ein offizielles Abkommen zur Werbung Rumäniendeutscher für die Waffen-SS zustande kam, zeigen verschiedene Schreiben deutscher Dienststellen, dass die SS-Führung bereits Ende März auf eine flächendeckende Werbung drängte. ${ }^{282}$ Rumäniendeutschen, welche auf der Krim und ostwärts des Dons stationiert waren, war aber ein Wechsel von der rumänischen Armee zur Waffen-SS oder Wehrmacht immer noch untersagt. Somit fanden im Sommer 1943 in diesem Gebiet weiterhin Desertionen statt, wobei die Waffen-SS Desertionswillige bei diesem Schritt nach wie vor unterstützte. ${ }^{283}$

276 Vgl. ebd., S. 167. Vgl. Casagrande, Volksdeutsche SS-Division, S. 208.

277 Vgl. Milata, Zwischen Hitler, Stalin und Antonescu, S. 167.

278 Vgl. ebd., S. 168.

279 Vgl. ebd.

280 Vgl. ebd., S. 166.

281 Vgl. ebd., S. 169. Vgl. zu verbotenen Beitritten zur Waffen-SS bzw. Desertionen aus der rumänischen Armee vgl. auch Casagrande, Volksdeutsche SS-Division, S. 209.

282 Vgl. ebd., S. 210.

283 Vgl. Deutsche Gesandtschaft in Bukarest, 20.7.1943, PAAA, Inland IIg 17a/1755, E024781, E27923, 327924, nach: Casagrande, Volksdeutsche SS-Division, S. 210. 
Innenansichten zu den Rekrutierungen in Rumänien im Frühjahr und Sommer 1943 liefert das Buch von Anna Wittman über das Leben Friedrich Umbrichs. Wie Bernwald zeichnet auch Umbrich ein Bild von Jugendlichen, die leicht zu überzeugen waren. ${ }^{284}$ Er und seine Freunde aus Belleschdorf lasen die Aufforderung, sich rekrutieren zu lassen, an einer Scheunentür: „Rumänische Staatsbürger deutscher Herkunft, die am 1. April 1943 das 17. Lebensjahr vollendet haben, können sich freiwillig in die deutsche Wehrmacht-SS [sic] einreihen lassen.“285 Umbrich betont aber auch, dass es während der Rekurtierungen durchaus kritische Stimmen in der „volksdeutschen“ Bevölkerung gegeben habe. In seinen Memoiren ist dies beispielsweise Herr Breit, der die Jugendlichen mehrmals $\mathrm{zu}$ warnen versucht hatte und eine dezidiert antifaschistische Haltung an den Tag legte. Er verteilte Bücher, welche die Kriegspropaganda des Dritten Reiches demaskieren sollten und sagte den Jungen wörtlich, dass sie als Kanonenfutter enden würden. ${ }^{286}$ Auch sein eigener Großvater habe, so Umbrich, kein gutes Wort für die Nazis übriggehabt. ${ }^{287}$ Umbrich weist daraufhin, dass zwar die Entscheidung, ob man in der rumänischen oder der deutschen Armee Dienst leisten wollte, noch freiwillig war, dass es aber danach keine Wahl zwischen deutscher Wehrmacht und Waffen-SS gegeben habe. ${ }^{288}$

Außerdem sollten wie in anderen Gebieten und für andere Waffen-SS-Verbände auch in Rumänien „volksdeutsche“ Gefangene vor die Wahl gestellt werden, weiter im Gefängnis auszuharren oder in der Waffen-SS Dienst zu leisten. ${ }^{289}$ Auf dem ausgestellten Annahmeschein, den jeder für tauglich Befundene nach der Aushebung erhielt, fehlte denn auch jeder Hinweis auf die „Freiwilligkeit“ des Beitritts. 290

284 Vgl. Wittmann, Umbrich, Alptraum Balkan, S. 68.

285 Vgl. ebd., S. 66.

286 Vgl. ebd., S. 68.

287 Vgl. ebd., S. 73.

288 Vgl. ebd., S. 66.

289 Vgl. Milata, Zwischen Hitler, Stalin und Antonescu, S. 169 f.

290 Vgl. ebd., S. 174. 


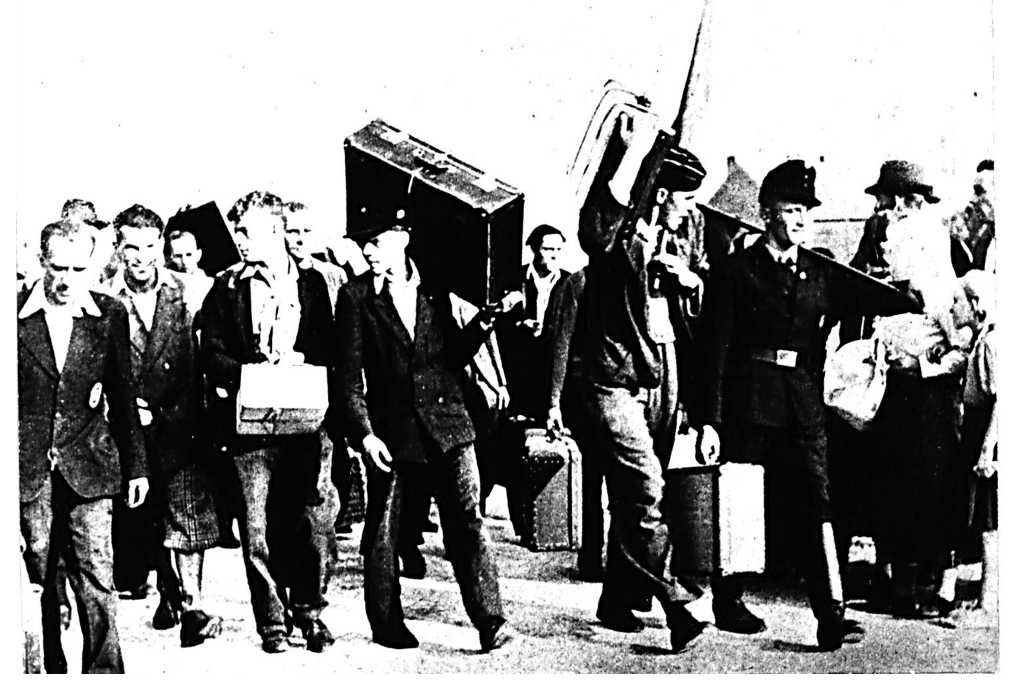

Abb. 7: „Volksdeutsche“ Rekruten, wahrscheinlich aus Ungarn, Bildunterschrift: „Auf dem Marsch zum Bahnhof“. 291

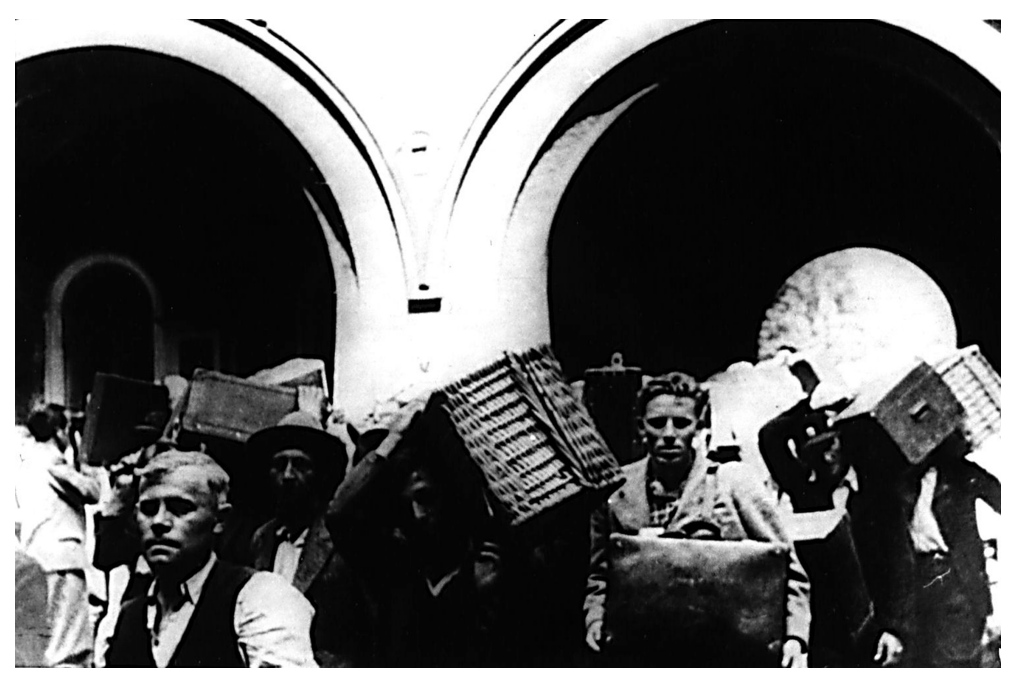

Abb. 8: „Freiwillige aus Siebenbürgen rücken ein“. 292

291 BArchF, Nachlass Vopersal, N756/149b.

292 Ebd. 


\subsubsection{Stationierung und Einsatzräume}

Anfang Oktober 1942 gelangte die Division „Prinz Eugen“ in den südserbischen Raum Užice-Čačak-Novi Pazar-Mitrovica. Bevor die neue Division allerdings untergebracht werden konnte, mussten die für sie vorgesehenen Unterkünfte aus der österreichisch-ungarischen Zeit instandgesetzt werden, da sie sich in einem miserablen Zustand befanden. ${ }^{293}$ In diesem serbisch-montenegrinisch-bosnischalbanischen Grenzgebiet kam die „Prinz Eugen“ zum ersten Mal gegen lokale Partisaneneinheiten zum Einsatz. In der Region, welche auch Teile des Sandžak und die unter deutscher Militärherrschaft verbliebenen Teile Kosovos umfasste, wurden die Rekrutierungen fortgesetzt. ${ }^{294} \mathrm{Zu}$ diesem Zeitpunkt erhielt die 7. SSFreiwilligen-Gebirgs-Division schließlich auch ihren heute bekannten Namenszusatz „Prinz Eugen“. 295

Brisant an diesem Einsatzgebiet ist die Tatsache, dass dort genau ein Jahr zuvor bereits ein blutiger Krieg zwischen Wehrmacht und Partisanen gewütet hatte: Ende September bis Anfang Oktober 1941 war es Partisaneneinheiten gelungen, Užice, Pozega, Gornji Milanovac und Čačak zu befreien. Auch Valjevo und Kraljevo waren damals gefährdet gewesen. ${ }^{296}$ Wie unüberschaubar sich die Einsätze in diesem Gebiet gestalteten, zeigt sich etwa an der Befehlsgebung für die „Prinz Eugen“ Anfang Oktober 1942. Darin wird einerseits festgehalten, wie mit Partisanen, Četniks und antideutschen Zivilisten umzugehen sei, andererseits aber auch darauf hingewiesen, dass sich im Raum verbündete Banden, ebenfalls Četniks unter dem Kommando von M. Djurović befänden, die ebenfalls gegen Partisanen vorgehen würden. ${ }^{297}$

An diesen Standorten war die „Prinz Eugen“ im Herbst 1942 im serbischmontenegrinisch-bosnisch-albanischen Grenzgebiet stationiert:

293 Vgl. Kumm, Vorwärts Prinz Eugen, S. 38.

294 Vgl. Klietmann, Waffen-SS: eine Dokumentation, S. 152. Vgl. Casagrande, Volksdeutsche SS-Division, S. 229. Zur Stationierung in Mitrovica vgl. Alfred Graf, Kriegsgefangenenbericht, 9.11.1948, VA HEM.OK.BOJCKA, 72/2-1/32.

295 Vgl. Tessin, Verbände, Bd. 3, S. 83.

296 Vgl. Schmider, Partisanenkrieg, $64 \mathrm{f}$.

297 Vgl. Casagrande, Volksdeutsche SS-Division, S. $231 \mathrm{f}$. 


\begin{tabular}{ll}
\hline Div.-Stabs-Quartier & Kraljevo \\
\hline Stab Art.-Rgt. & \\
Pi.-Btl. & \\
Na.-Abt. & \\
San.-Abt. & Usice \\
\hline Stab Rgt. 1 & \\
\hline II./1 & \\
IV./1 (+ Pozega) & Ivanjica \\
I./Art.Rgt. & \\
\hline 1/1 & Čačak \\
III./I & \\
\hline III./Art.Rgt. & \\
\hline Stab Rgt.2 & Raška \\
\hline II./2 IV./2 & Mitrovica \\
1/2 & Novi Pazar \\
III./2
\end{tabular}

Im Winter 1942/1943 wurde die Division nach Zagreb-Karlovać verlegt und kam vom 8. Januar bis Mitte März 1943 beim Unternehmen „Weiß“ zum Einsatz, das die Bekämpfung der Partisanen im Gebiet Slunj-Bihać-Petrovac zum Ziel hatte. ${ }^{298}$ In Bihać hatte Ende November 1942 der erste Kongress der Kommunistischen Partei Jugoslawiens stattgefunden. ${ }^{299}$ Neben der „Prinz Eugen“ standen auch italienische und kroatische Verbände im Einsatz. Bei diesem Großunternehmen sollen in der Region zwischen Bihać, Slunj und Karlovać zahlreiche Dörfer zerstört worden sein. Obwohl Titos Partisanenarmee durch Hunger und die Ausbreitung von Typhus schwer bedroht war, gelang es ihr schließlich, Richtung Montenegro vorzustossen und bei der Schlacht von Neretva den ebenfalls eingesetzten Četnik-Verbänden eine schwere Niederlage zuzufügen. Unternehmen „Weiß“ dauerte bis März 1943, erzielte jedoch nicht den gewünschten Erfolg, sprich die „Vernichtung“ der Partisanen in diesem Raum. ${ }^{300}$ Auch am nächsten Großeinsatz, dem Unternehmen „Schwarz“, welches Mitte Mai 1943 im westlichen Montenegro anlief und Mitte Juni endete, war die „Prinz Eugen“ beteiligt. ${ }^{301}$

298 Vgl. ebd., S. 241-251. Vgl. Böhm, Die deutschen Volksgruppen, S 403. Vgl. Alfred Graf, Kriegsgefangenenbericht, 9.11.1948, VA HEM.OK.BOJCKA, 72/2-1/32.

299 Vgl. Casagrande, Volksdeutsche SS-Division, S. 241.

$300 \mathrm{Vgl}$. Böhm, Die deutschen Volksgruppen, S. $404 \mathrm{f}$.

301 Vgl. Casagrande, Volksdeutsche SS-Division, S. 251-261. 
Dabei ging es in erster Linie darum, die deutschen Bauxitabbaugebiete westlich von Mostar zu schützen, da dort ein blutiger Bürgerkrieg zwischen Partisanenverbänden Titos und Četnikverbänden tobte, und die Partisanen in diesem Gebiet zu „vernichten“. Die „Prinz Eugen“ hatte die Aufgabe, aus dem Narenta-Abschnitt Prigedjani, östlich von Mostar, und Capljina Richtung Osten vorzustoßen. ${ }^{302}$ Weitere kleinere Einsätze in der Nähe von Sarajevo in Bataillonsstärke folgten. ${ }^{303}$

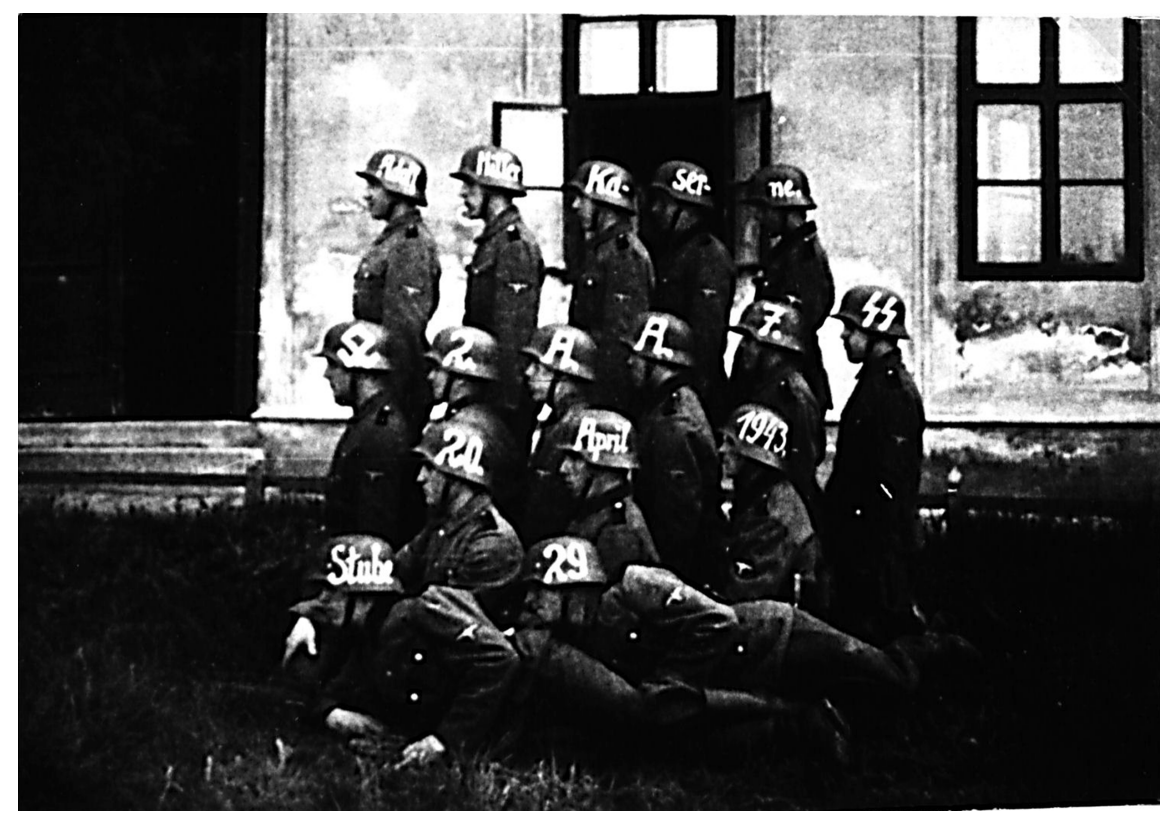

Abb. 9: 20. April 1943, Geburtstagsglückwünsche für den Führer, Bildunterschrift: „Stube 292./SS-Frw.Geb.Jg.Aufkl.Abt.7 in ,voller Kriegsbemalung““. 304

Im Sommer 1943 gelangten auch die in Rumänien geworbenen Rekruten über den Umweg Wien nach Bela Crkva/Weißkirchen im serbischen Banat. ${ }^{305}$ Der Zug von Umbrich traf dadurch erst nach zehn Tagen im dortigen Ausbildungslager ein. Ihre Ankunft war jedoch nicht vorbereitet, und die erschöpften, schmutzigen und hungrigen Rekruten mussten weitere zwei Tage warten, bis im Lager genü-

302 Vgl. Böhm, Die deutschen Volksgruppen, S 406.

303 Vgl. Klietmann, Waffen-SS: eine Dokumentation, S. 152.

304 BArchF, Nachlass Vopersal, N756/149b.

305 Vgl. Wittmann, Umbrich, Alptraum Balkan, S. 79. 
gend Platz vorhanden war. Ein wichtiges Detail dabei war die ständige Überwachung durch deutsche Wachposten während ihrer Wartezeit. ${ }^{306}$

Im Juli 1943 lag die Division weiterhin in der Nähe von Mostar. ${ }^{307}$ Im Herbst 1943 war die „Prinz Eugen“ nach der Kapitulation Italiens am 8. September 1943 maßgebend an der Entwaffnung und Hinrichtung italienischer Soldaten im Dreieck Ragusa-(heute: Dubrovnik)-Metković-Split beteiligt, darunter auch bei der Eroberung der Inseln Brač, Hvar, Korčula und der Halbinsel Pelješac. ${ }^{308}$

Zum Desaster geriet eine großangelegte Verhaftungsaktion in Mostar Anfang September 1943: Obwohl nach dem zu dieser Zeit geltenden Kriegsvölkerrecht Geiselnahmen erlaubt waren, warf die Festnahme von rund 1.000 Zivilisten, darunter auch Muslime, in Mostar hohe Wellen. Phleps verteidigte sich damit, dass in dieser Stadt über 50 Prozent der Muslime zu den Kommunisten halten würden und somit die Festnahmen gerechtfertigt gewesen seien. Weiter argumentierte er, dass durch diese Festnahmewelle zehn Partisanen und zehn Kommunisten ergriffen werden konnten. Es stellte sich aber heraus, dass die Angehörigen der „Prinz Eugen“ aus Versehen nicht nur Partisanen bzw. Kommunisten, sondern auch den Bürgermeister von Mostar festgenommen hatten. Der bereits bekannte und zu dieser Zeit in

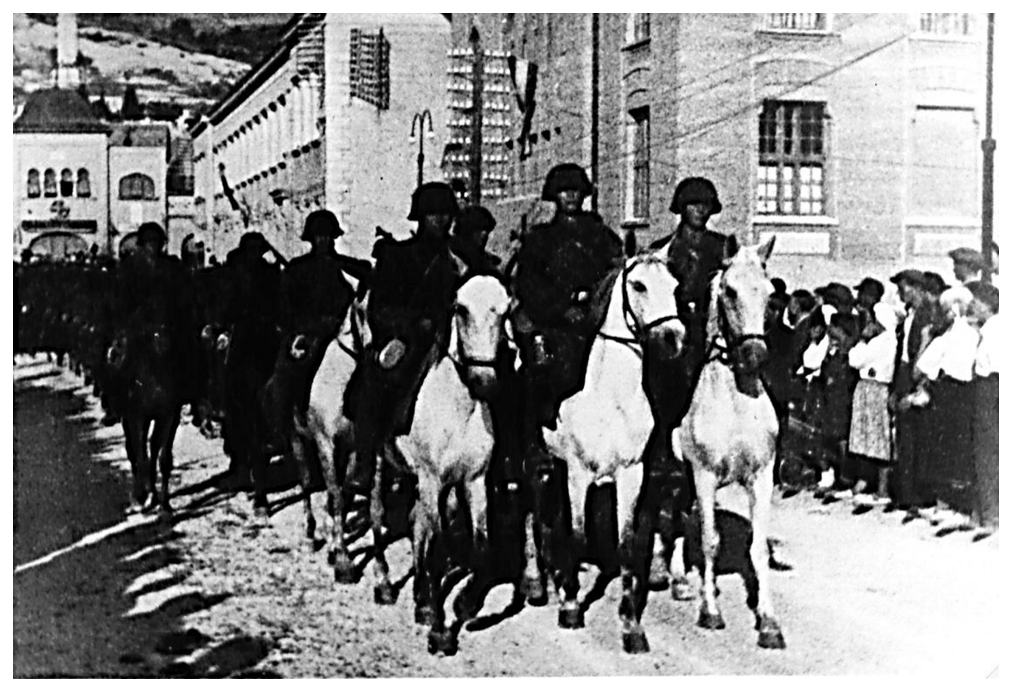

Abb. 10: Die Division „Prinz Eugen“ in Mostar. ${ }^{309}$

306 Vgl. ebd., S. 81.

307 Vgl. Klietmann, Waffen-SS: eine Dokumentation, S. 152.

308 Vgl. ebd.

309 Vgl. Nachlass Vopersal, BArchF, N 756/149b. 
Mostar als Standortkommandant eingesetzte Schmidhuber musste sich am nächsten Tag beim Bürgermeister persönlich entschuldigen. Von Oberkamp, zu diesem Zeitpunkt Kommandeur der „Prinz Eugen“, musste sich nach der Aktion mehrmals mit Vertretern der muslimischen Bevölkerung treffen, um die Situation zwischen Waffen-SS und lokalen Eliten zu entschärfen und zu bereinigen. ${ }^{310}$

Ab Dezember 1943 kämpfte die Division im montenegrinischen RogaticaGoražde gegen Titos Partisanen und war auch bei deren Verfolgung im Unternehmen „Schneegestöber“ (auch: „Schneesturm“) im Einsatz. ${ }^{311}$

Ab Februar 1944 kehrte die „Prinz Eugen“ zum Abschnitt Split-Ragusa zurück. Erst dort fand die Ausbildung ihren Abschluss. ${ }^{312}$ Im März 1944 folgte ihre Verlegung in den bosnischen Raum um Mirkonjić Grad-Jaice-Bugojno-Travnik-SarajevoRogatica-Goražde-Višegrad. Auch hier kam die „Prinz Eugen“ gegen Partisanen im Einsatz. Von Mai bis Juni 1944 war die „Prinz Eugen“ eine der führenden Einsatzkräfte im Großunternehmen „Rösselsprung“ gegen Titos Hauptquartier bei Drvar. Sie zerschlug die 1. Partisanendivision, nachdem sie diese Richtung Südosten bis nach Foča verfolgt hatte. ${ }^{313}$

Danach wurde die Division nach Prijepolje-Plevlje im Sandžak verlegt. Im Spätsommer 1944 sollten die noch im serbischen Teil Kosovos verbliebenen Wehrmachtseinheiten abrücken und durch Einheiten der Divsion „Prinz Eugen“ ersetzt werden. Günther Hausding meldete zu diesem Vorhaben am 27. August 1944 besorgt:

Der Kreis Kosovska-Mitrovica muss mit einer weit stärkeren Belegung durch die SS-Truppen rechnen, weshalb die Unterbringung der Offiziere und Mannschaften mit Troß bei den äußerst beschränkten Unterbringungsmöglichkeiten große Schwierigkeiten bereiten wird. Andeutungsweise wurde zum Ausdruck gebracht, dass das von mir verwaltete Polizeigefängnis hier, das am Rande des Kasernenkomplexes liegt, ebenfalls als Unterkunft herangezogen werden soll. Dies würde den Ausfall und damit das Fehlen jeglicher Unterbringungsmöglichkeit für Häftlinge bedeuten [...]. ${ }^{314}$

Was mit den Häftlingen geschehen würde, ließ Hausding offen. Aus diesem Gebiet folgten nach einer etwas ruhigeren Zeit im Herbst 1944 Einsätze gegen vorrückende

310 Vgl. Phleps an Reichsführer SS Himmler, 7.9.1943, BarchB NS19/1434, Bl. 17.

311 Vgl. ebd. Vgl. Alfred Graf, Kriegsgefangenenbericht, 9.11.1948, VA HEM.OK.BOJCKA, 72/21/32. Der Stab des V. Gebirgskorps war zu jener Zeit in Sarajevo stationiert. Vgl. ebd.

312 Vgl. Klietmann, Waffen-SS: eine Dokumentation, S. 152.

313 Vgl. ebd., S. 152.

314 Lagebericht des Außenkommandos Kosovska-Mitrovica für August 1942, Hausding, 27.8.1942, USHMM/BArchL, B162/15.668, Bl. 37. 
bulgarische und sowjetische Verbände. Schließlich sicherte die „Prinz Eugen“ die aus Griechenland zurückflutenden Wehrmachtsteile der Heeresgruppe E. ${ }^{315}$ Bei Niš stand sie in neuen Kämpfen wieder bulgarischen und sowjetischen Truppen gegenüber, gegen die sie schwere Verluste erlitt. Diejenigen Soldaten, die überlebten, wurden nach Kraljevo gebracht und waren dort im Brückenkopf für die Sicherung des Rückzugs der Heeresgruppe F unter Generaloberst Alexander Löhr bis zur Räumung im November 1944 zuständig. ${ }^{316}$ Danach zogen sich auch die Reste der „Prinz Eugen“ - gemeinsam mit Teilen der Wehrmacht und dem, was von der Division „Skanderbeg“ übriggeblieben war, über Čačak, Uziče, Banja Bosta, Ljubovija, Zvornik, Bijelijina und Brčko und schließlich über die Drina zurück. ${ }^{317}$

Im Januar 1945 folgten letzte Kämpfe gegen Partisanen bei Otok, Mitte des Monats gelangte die „Prinz Eugen“ in Eilmärschen in das Gebiet südlich von Vukovar. Als Teil des XXXIV. Armeekorps waren noch Reste der „Prinz Eugen“ bis zum Schluss im Westbalkan im Einsatz. ${ }^{318}$ Nach letzten Gefechten gegen die nun vereint kämpfenden bulgarisch-sowjetischen Verbände und Tito-Partisanen zogen sie sich zuerst in den Raum Zagreb zurück. ${ }^{319}$ In den Frühlingsmonaten des Jahres 1945 kämpften Teile der „Prinz Eugen“ immer noch in Westbosnien: Am 28. März 1945 nahmen die Partisanen Bihač ein. Der Versuch, im Unternehmen „Maigewitter“ vom 24. bis 31. März 1945, bei welchem auch die „Prinz Eugen“ ein Regiment stellte, die nordostbosnische Stadt Tuzla wieder unter deutsche Kontrolle zu bringen, scheiterte. ${ }^{320}$ Zur gleichen Zeit, am 28. März, leitete die 2. Jugoslawische Armee einen Großangriff gegen Sarajevo ein, welches bis zu diesem Zeitpunkt insbesondere von Einheiten der „Prinz Eugen“ gehalten worden war, indem die Waffen-SS-Division die Front im Süden Sarajevos stabilisierte und die Nachschubwege im Norden offenhielt. ${ }^{321}$ Schmidhuber machte in Kriegsgefangenschaft zum Zeitraum Februar bis Mai 1945 ziemlich genaue Angaben, über die letzten Einsatzorte der Division: Noch im Februar 1945 stand sie im Papuk-Gebirge, im März 1945 befand sie sich im Raum Zenica, danach im Raum Trnovo, von da tat sie den Rückzug zuerst dieselbe Strecke zurückgehend über Sarajevo nach Doboj und Brod,

315 Vgl. Klietmann, Waffen-SS: eine Dokumentation, S. 153.

316 Vgl. ebd.

317 Vgl. ebd.

318 Vgl. ebd.

319 Vgl. ebd.

320 Vgl. Schmider, Jugoslawischer Kriegsschauplatz, S. 1065.

321 Vgl. ebd., S. 1066. 
danach Richtung Korzo, Karlovać, Sobobor bis nach Celje/Cilli an. ${ }^{322}$ Schließlich mussten große Teile der Division im Raum um Celje/Cilli kapitulieren; die Soldaten gerieten größtenteils in jugoslawische Kriegsgefangenschaft. ${ }^{323}$

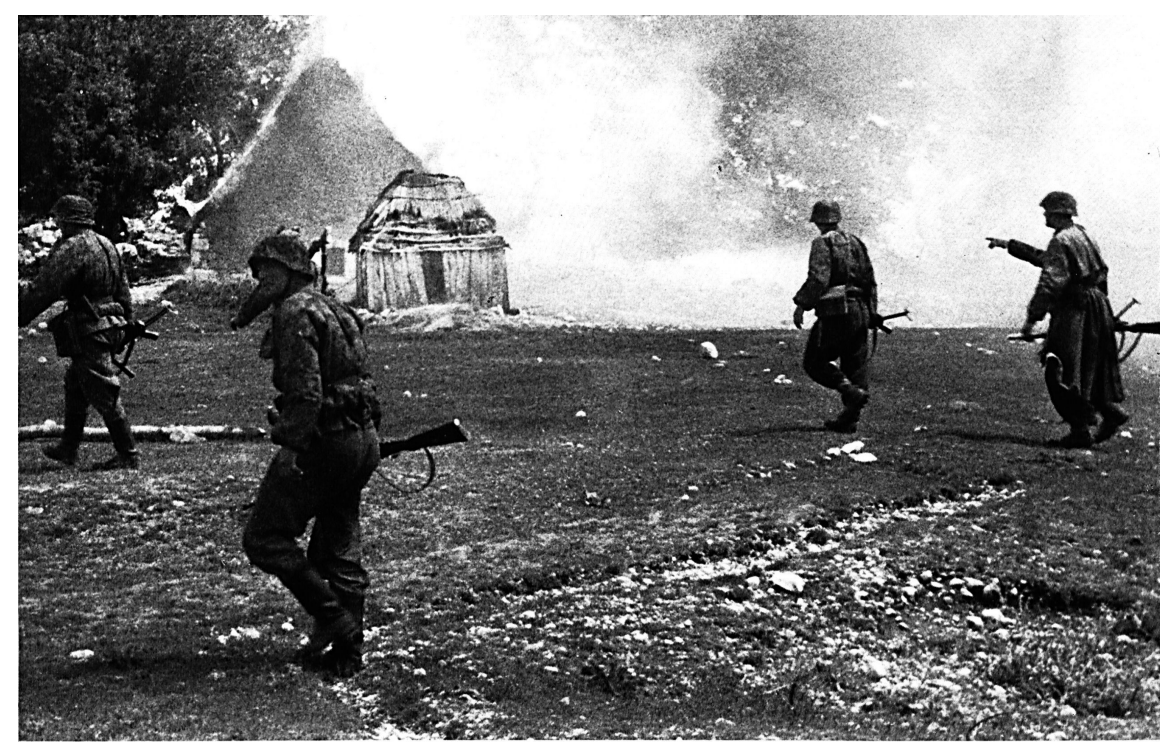

Abb. 11: Brennendes Dorf, ev. Südserbien. Bildunterschrift Voprsal: „Der lange Marsch Kupa, Slunj, Bihać, Vroče, Petrovac, Grahovo, Livno, Lise, Mostar, Nevesinje, Gacko, Bileca, Nikšić, Gvozd, Savnik“. Bildüberschrift bei Kumm: „Der Feind ist niedergekämpft““ ${ }^{324}$

\subsection{Aufbau und Struktur}

Der Name dieser ersten südosteuropäischen „volksdeutschen“ Division macht die Bemühungen deutlich, auf alte Traditionen zurückzugreifen: „Prinz Eugen“ meinte Prinz Eugen von Savoyen, der, nachdem er die Osmanen zurückgeschlagen hatte, im 18. Jahrhundert auch die ersten Deutschen in Südosteuropa ansiedeln ließ. Er galt dadurch als Befreier des Balkans von der osmanischen Herrschaft. ${ }^{325}$ Nach Janko und Kumm wurde dieser Name von Phleps vorgeschlagen, um an die alte

322 Vgl. Kriegsgefangenenbericht III, August Schmidhuber, 7.1946, VA HEM.OK.BOJCKA, 72/ 2/1-33.

323 Vgl. Klietmann, Waffen-SS: eine Dokumentation, S. 153.

324 BArchF, Nachlass Vopersal, N756 149a. Kumm, Vorwärts, Prinz Eugen, ohne Seitenangabe. 325 Vgl. Casagrande, Volksdeutsche SS-Division, S. 89, 188. 
Tradition der so genannten Grenzer-Regimenter anzuschließen, welche sich, wie die „Prinz Eugen“, vor allem aus Soldaten aus dem Bauernstand deutscher Auswanderer zusammengesetzt hatten. ${ }^{326}$ Auch die Kragenspiegel, die Odalrune als Zeichen von Besitz, und der Wahlspruch „Ehre, Blut und Boden“ sollten die Nähe der Division zu den Herkunftsregionen ihrer Angehörigen verdeutlichen. ${ }^{327}$ Dabei wurde von den Werbern und ihren vorgesetzten Stellen gezielt auf eine Betonung des Ethnischen geachtet, wie Casagrande feststellte. ${ }^{328}$ Im Februar 1944 hatte die Division schließlich einen Anteil von über 90 Prozent „Volksdeutschen“. Davon kamen 53,6 Prozent aus dem Banat und Serbien, 21,3 Prozent aus Rumänien, 11,2 Prozent aus Kroatien, 2,9 Prozent aus der Slowakei, 2,6 Prozent aus Ungarn sowie weitere einzelne „Volksdeutsche“ aus anderen kulturellen Zusammenhängen. ${ }^{329}$ Die „Prinz Eugen“ stellte somit die Division mit dem höchsten Prozentsatz in einem Verband kämpfender „Volksdeutscher“ aus dem serbischen Banat und Serbien, sowie aus dem rumänischen Banat und anderen Gebieten Rumäniens dar. ${ }^{330}$

Als erster Divisionskommandeur wurde Artur Phleps eingesetzt, der als Rumäniendeutscher auf die Rekrutierungswilligkeit „Volksdeutscher“ in Südosteuropa einen positiven Einfluss ausübte. ${ }^{331}$ Im Frühjahr 1943 sollte SS-Brigadeführer Carl von Oberkamp als neuer Divisionskommandeur der „Prinz Eugen“ SS-Gruppenführer Phleps „zur Verwendung im Rahmen seines Befehlsbereiches unterstellt“ werden, denn Himmler plante die Unterstellung der „Prinz Eugen“ sowie der sich in Aufstellung befindenden „Handschar“ unter das V. SS-Gebirgskorps. Phleps sollte dieses befehligen und den als Divisionskommandeur vorgesehenen von Oberkamp in seiner ersten Zeit als Divisionskommandeur unterstützen. Konkret waren damit vor allem die Vorbereitung geplanter Operationen, die Vertretung der Führung und Unterstützung bei der weiteren Aufstellung der Division gemeint. ${ }^{332}$ Von Oberkamp würde diese Zeit „ohne abgegrenztes selbständiges Kommando“ zur Eingewöhnung in die lokalen Verhältnisse und zum „Kennenlernen von Land und Leuten“ nutzen. ${ }^{333}$ Schließlich ging es auch darum, so Himmler, dass von Oberkamp in diesen ersten Wochen seine Eignung beweisen musste, bevor er endgültig als Divisionskommandeur der „Prinz Eugen“ eingesetzt würde, damit sich

326 Vgl. Janko, Weg und Ende der deutschen Volksgruppe, S. 220 und Kumm, Vorwärts Prinz Eugen, S. 40. Vgl. Casagrande, Volksdeutsche SS-Division, S. 188.

327 Casagrande, Unsere Gegner, S. 167.

328 Vgl. Casagrande, Volksdeutsche SS-Division, S. 188.

329 Vgl. ebd., S. 211.

330 Vgl. Milata, Zwischen Hitler, Stalin und Antonescu, S. 241.

331 Vgl. ebd., S. 53 f. und Casagrande, Volksdeutsche SS-Division, S. 189.

332 Vgl. Himmler an SS-Führungshauptamt, SS-Personalhauptamt, SS-Hauptamt, SS-Gruppenführer Phleps und SS-Brigadeführer von Oberkamp, 31.3.1943, BArchB NS19/2601, Bl. 6.

333 Vgl. ebd. 
Phleps ganz dem Aufbau des neuen Armeekorps widmen und einen geeigneten Kommandeur für die bosnisch-muslimische Division finden konnte. ${ }^{334}$

Die frisch aufgestellte Division sollte aus zwei Gebirgsjäger-Regimentern zu vier Bataillonen, einer Panzerkompanie, einem Artillerieregiment, einer Flakabteilung, einer Reiterschwadron, einem Pionierbataillon, einem Radfahrbataillon und einer Nachrichtenabteilung bestehen. Hinzu kamen ein Wirtschaftsbataillon, eine Werkstattkompanie, eine Sanitäts- und eine Veterinärabteilung. Von Anfang an war auch eine Propagandaabteilung vorgesehen, um die Grundwerte des Nationalsozialismus im weiteren und der Waffen-SS im engeren Sinne vermitteln zu können. Die Herausgabe divisionsinterner Zeitungen wie die „Volkswacht“ und der „Banater Beobachter“ sowie das Herstellen von Flugblättern und anderem Propagandamaterial waren ebenfalls Aufgabe dieser Abteilung. ${ }^{335}$

\subsubsection{Rahmenpersonal}

Durch das SS-Führungshauptamt erfolgten bei der Stellenbesetzung keine Zuweisungen. Dies stellte Phleps vor allem hinsichtlich des Führer- und Unterführerkorps vor Probleme. Denn diese wurden nicht wie üblich bei einer Neuaufstellung aus bereits bestehenden Einheiten bzw. Ersatzeinheiten gestellt, sondern mussten von ihm selbst geworben werden, so etwa Kommandeure in seinem Bekanntenkreis ehemaliger k.u.k. Offiziere. Führer und Unterführer waren gemäß Kumm „aus den in fremden Armeen Ausgebildeten heranzuziehen“. ${ }^{336}$ Phleps bestand aber darauf, einige seiner Meinung nach ausgezeichneten Führer aus der Division „Wiking“ zu erhalten. ${ }^{337}$

Bereits vor der Aufstellung stand fest, dass für die „Prinz Eugen“ auch „reichsdeutsches“ Personal benötigt würde, da unter den „Volksdeutschen“ Führungspersonal und Spezialisten fehlten und erst ausgebildet werden mussten. ${ }^{338}$ Soweit möglich sollte aber bei der Besetzung der Stellen auf Offiziere, Unteroffiziere und Mannschaften aus dem serbischen Raum zurückgegriffen werden, wie vom SS-Führungshauptamt am 1. März 1942 angeordnet wurde. ${ }^{339}$ Auch „Volks-

334 Vgl. ebd., Bl. 7.

335 Vgl. Casagrande, Volksdeutsche SS-Division, S. 222. Vgl. auch Casagrande, Unsere Gegner, S. 167.

336 Vgl. Kumm, Vorwärts Prinz Eugen, S. 27. Siehe auch Casagrande, Volksdeutsche SS-Division, S. 213.

337 Vgl. Kumm, Vorwärts Prinz Eugen, S. 39.

338 Vgl. Casagrande, Volksdeutsche SS-Division, S. 187, 213.

339 Vgl. Casagrande, Unsere Gegner, S. 166. 
deutsche“ aus Nordsiebenbürgen, das zu diesem Zeitpunkt zu Ungarn gehörte, waren für Offiziersränge vorgesehen. ${ }^{340}$ Im April 1943 wurde schließlich „eine große Zahl an Offizieren und Unteroffizieren der früheren jugoslawischen Armee“ in Umschulungslehrgängen zusammengefasst, um das Rückgrat der Division zu bilden. ${ }^{341}$ Das Verhältnis zwischen Deutschen und „Volksdeutschen“ sah innerhalb der „Prinz Eugen“ wie folgt aus: Von drei Regimentskommandeuren waren zwei „Volksdeutsche“. Bei Kompanie- und Zugführern kamen auf einen „Reichsdeutschen“ drei „Volksdeutsche“; auch bei den Bataillonskommandeuren war das Verhältnis ungefähr eins zu drei. Bei den Unterführern entfielen fünf „Volksdeutsche“ auf einen „Reichsdeutschen“. ${ }^{442}$

Im Allgemeinen galt die Versetzung zur „Prinz Eugen“ bei den „reichsdeutschen“ Unteroffizieren und Offizieren oft als Strafversetzung. ${ }^{343}$ Bei dem Teil des Rahmenpersonals, welches schließlich nicht vor Ort geworben werden konnte und für den Dienst in der „Prinz Eugen“ nach Südosteuropa versetzt wurde, finden sich drei Merkmale, die besonders auffallen: Zum einen stellten „eingedeutschte“ Österreicher, die bereits im Ersten Weltkrieg in dieser Region gekämpft hatten, einen großen Teil der Division. Zweitens dienten in den Kaderrängen vor allem auch „Volksdeutsche“, die teilweise bereits in zwei Nationalarmeen, der österreichisch-ungarischen und der jugoslawischen, gedient hatten, und außerdem der serbokroatischen Sprache mächtig waren. Drittens hat Stefan Hördler in seinem Aufsatz „KZ-System und Waffen-SS. Genese, Interdependenzen und Verbrechen“, herausgearbeitet, dass eine große Anzahl hoher Führungspersonen direkt aus den KZ-Systemen abgezogen und zur neu aufgestellten „Prinz Eugen“ versetzt wurden. ${ }^{344}$ Hördler zählt folgende hochrangige SS-Führer auf, die vorher in verschiedenen europäischen Konzentrationslagern Dienst getan hatten: Die Kommandanten des KZ Flossenbürg, Karl Künstler und Egon Zill, der Schutzhaftlagerführer der KZ Dachau und Buchenwald, Norbert Scharf, der Kommandant der KZ Buchenwald und Lublin, Hermann Hackmann, der Beauftragte für den Häftlingseinsatz bei der Inspektion der Konzentrationslager (IKL), Wilhelm Burböck, der Verwaltungsführer der KZ Groß-Rosen und Warschau Waldemar Henneberg, zahlreiche Kompanie- und Bataillonsführer der KZ-Wachverbände wie Heinrich Petersen, Eberhard Quirsfeld und Alfons Zeitler sowie eine höhere Zahl von SS-Ärzten. ${ }^{345}$ Zeitler war

340 Klietmann, Waffen-SS: eine Dokumentation, S. 151.

341 Vgl. Kumm, Vorwärts Prinz Eugen, S. 40.

342 Vgl. ebd., S. 40.

343 Vgl. ebd., S. 39.

344 Vgl. Stefan Hördler, KZ-System und Waffen-SS. Genese, Interdependenzen und Verbrechen, in: Lieb, Schulte, Wegner (Hgg.), Die Waffen-SS. Neue Forschungen, S. 80-98.

345 Hördler, KZ-System und Waffen-SS, S. 94. 
Divisionsadjutant, Quirsfeld und Petersen Regimentskommandeure, Zill und Künstler zeichneten für den Divisionsnachschub verantwortlich, die übrigen waren Kompanieführer oder beim Divisionsstab eingesetzt. ${ }^{346}$

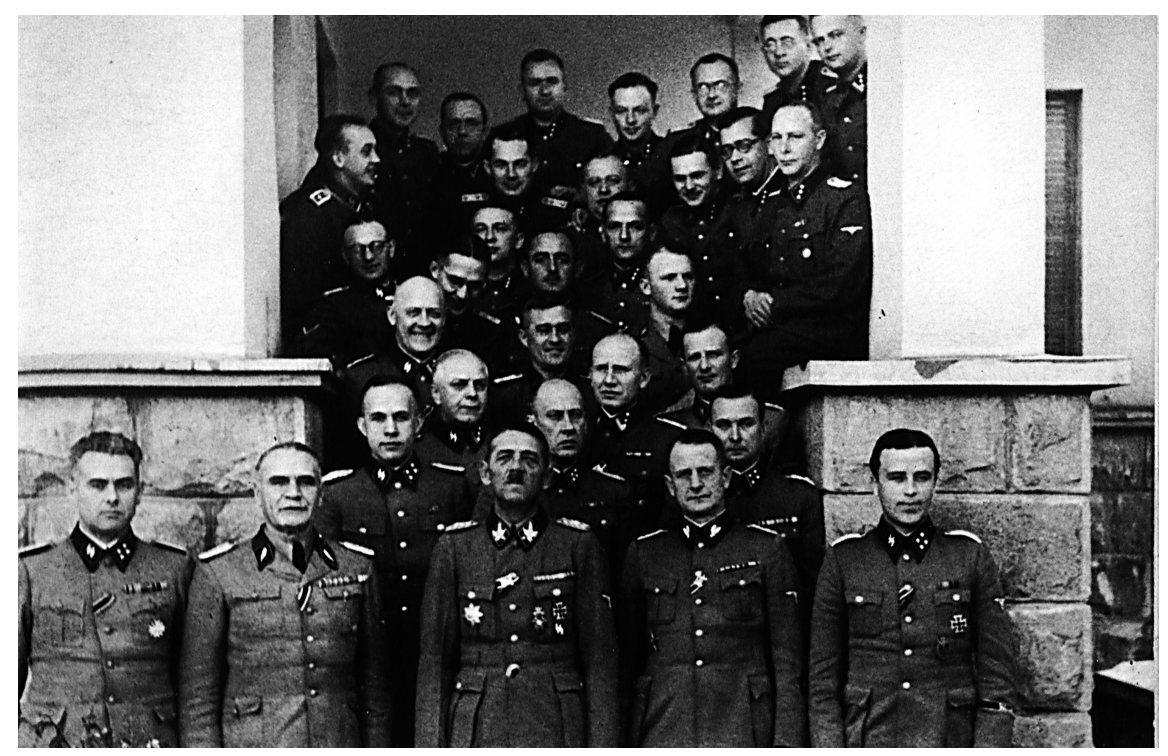

Abb. 12: Stab der „Prinz Eugen“. ${ }^{347}$

\subsubsection{Zu den Divisionskommandeuren}

Da die Divisionskommandeure auf die Entwicklung und Ausgestaltung der Division als auch auf das Verhalten der Soldaten im Partisanenkrieg einen wesentlichen Einfluss ausübten, sollen die vier Kommandeure hier kurz vorgestellt werden.

\subsubsection{Divisionskommandeur Artur Phleps}

Artur Phleps war der erste Kommandeur der „Prinz Eugen“. Kumm attestierte ihm, in dieser Funktion zu einer der entscheidendsten Persönlichkeiten des Balkans unter deutscher Besatzung geworden zu sein. ${ }^{348}$ Phleps als Person war für die Aufstellung dieser ersten „volksdeutschen“ Division gewissermaßen pro-

346 Vgl. ebd.

347 BArchF, Nachlass Vopersal, N756 149b.

348 Vgl. Kumm, Vorwärts Prinz Eugen, S. 27. 
grammatisch, da er genau dem Zielpublikum entsprach, welches die Deutschen ansprechen wollten. Artur Phleps wurde am 29. November 1881 in Birthälm geboren - ein Rumäniendeutscher bzw. sogenannter Siebenbürger Sachse. Wie viele andere, die später in der Waffen-SS kämpften, diente er als k.u.k. Offizier in Bosnien-Herzegowina und war schließlich im Rang eines Majors und in der Funktion eines Generalstabschefs im Ersten Weltkrieg an Kämpfen in Serbien, Siebenbürgen sowie in Ungarn und Polen beteiligt. ${ }^{349}$ In der Zwischenkriegszeit kommandierte er die „Sächsische Nationalgarde“ in Siebenbürgen bei der Aufstandsbekämpfung, als revolutionäre Unruhen ausbrachen. Schließlich trat Phleps 1941 aus der rumänischen Armee aus, um fortan Dienst in der Waffen-SS zu leisten. Im Rang eines SS-Standartenführers und später eines SS-Oberführers nahm er am Überfall auf die Sowjetunion im Sommer 1941 teil. ${ }^{350}$

Von Otto Kumm wird er in dessen apologetischem Werk „Vowärts, Prinz Eugen“ retrospektiv als „Papa Phleps“ bezeichnet und mit Attributen wie „strahlendem Charme“, „vollendeter Höflichkeit“, „nie versagendem Humor und tiefer väterlicher Güte“ beschrieben. ${ }^{351}$ Dass Phleps auch noch andere Charaktereigenschaften besaß, zeigen die unzähligen Kriegsverbrechen, die er in Südosteuropa zu verantworten hatte. Er hatte drei verschiedene Gesichter: Auf der einen Seite verstand er es, das Stammpersonal der verschiedenen ihm unterstellten Divisionen für sich zu gewinnen, hatte auf der anderen Seite aber zahlreiche Auseinandersetzungen mit deutschen und lokalen Autoritäten, etwa dem Gesandten in Agram, Siegfried Kasche, oder der kroatischen Regierung. Und er war gnadenlos, wenn es um die „Vernichtung der Partisanen“ ging. Bereits am 27. April 1942 legte Phleps mit der Veröffentlichung seiner „Taktischen Grundsätze zur Führung des Kleinkriegs“ die Basis für den brutalen Krieg gegen Partisanen alle Couleur und gegen die Zivilbevölkerung im ehemaligen Königreich Jugoslawien. ${ }^{352}$

Im Juli 1943 wurde Phleps befördert und mit dem Aufbau des V. SS-Gebirgskorps betraut; somit unterstand ihm nun auch die neu aufgestellte Division „Handschar“. ${ }^{353}$ Am 21. September 1944 kam er mit einem Flugzeug aus dem Sandžak im Gebiet von Arad, im rumänischen Teil des Banats, an und soll dort von der Roten Armee gefangengenommen und erschossen worden sein. Erst Tage später fand ein ungarischer Oberleutnant Phleps’ Erkennungsmarke und weitere persönliche

349 Ausführlich vgl.: Kumm, Vorwärts Prinz Eugen, S. 24 f. Vgl. Casagrande, Volksdeutsche SS-Division, S. 189.

350 Vgl. Casagrande, Volksdeutsche SS-Division, S. 189.

351 Kumm, Vorwärts Prinz Eugen, S. 23.

352 Vgl. Casagrande, Unsere Gegner, S. 170.

353 Vgl. Himmler an SS-Führungshauptamt, SS-Personalhauptamt, SS-Hauptamt, SS-Gruppenführer Phleps und SS-Brigadeführer von Oberkamp, 31.3.1943, BArchB NS19/2601, Bl. 6. 
Gegenstände und meldete seinen Tod nach Berlin. Sein Grab soll von Bewohnern der Gegend noch bis 1946 gepflegt worden sein, galt danach als verschollen und soll laut Schulz und Zinke von seiner Tochter ausfindig gemacht worden sein. ${ }^{354}$ Kumm hingegen verklärte Phleps“ Tod als Heldentod im Dienste des Vaterlands. ${ }^{355}$ Am 24. November 1944 wurde Phleps posthum das Eichenlaub verliehen. ${ }^{356}$

\subsubsection{Divisionskommandeur Carl von Oberkamp}

Carl von Oberkamp wurde 1893 in München geboren und hatte somit keinen direkten Bezug zu Südosteuropa vorzuweisen. Nach dem Abitur 1912 trat er in Straßburg der Preußischen Armee bei. Er wurde rasch befördert und kletterte kontinuierlich die militärische Karriereleiter nach oben. Im Ersten Weltkrieg diente er zuerst an der Westfront in Lothringen und an der Somme. Danach konnte er, ähnlich wie Phleps, bereits Erfahrungen in Südosteuropa sammeln, wo er in Serbien und verschiedenen Regionen der Karpaten stationiert war. ${ }^{357}$ Als Oberleutnant kehrte er nach dem Krieg zu seinem Stammregiment zurück, wurde aber infolge einer Krankheit auf eigenen Wunsch aus der Armee entlassen. Oberkamp nahm als NS-Anhänger der ersten Stunde bereits am Hitlerputsch 1923 teil. 1933 trat er der NSDAP und Anfang Mai 1934 der SA bei. Am 1. April 1935 kehrte er als Oberleutnant in die Armee zurück, wo er in verschiedenen Einheiten diente und in den Rängen weiter aufstieg. 1938 trat er schließlich als SS-Sturmbannführer der SS-Verfügungstruppe bei und unterrichtete als Taktiklehrer an der Junkerschule Bad Tölz. Beim Überfall auf Polen im September 1939 kommandierte er den II. Sturmbann der „Leibstandarte Adolf Hitler“ und beim Westfeldzug 1940 war er als Bataillonskommandeur der SS-Verfügungsdivision im Einsatz. Als SS-Obersturmbannführer kommandierte er das Regiment „Germania“. 1941 nahm er, bereits SS-Standartenführer, als Angehöriger der Division „Wiking“ am Russlandfeldzug teil. Am 1. Oktober 1941 wurde er zum SS-Oberführer ernannt, kam aber nach Meinungsverschiedenheiten mit dem Divisionskommandeur Felix Steiner als Inspektionschef zum SS-Führungshauptamt. ${ }^{358}$ Ende April 1943 traf Oberkamp bei der Division „Prinz Eugen“ ein, um von Phleps „eingehend in die bisherigen Kämpfe und die derzeitige Lage eingewiesen“ zu werden. ${ }^{359}$ Im Juli 1943 ersetzte Oberkamp Phleps als Divisionskommandeur. ${ }^{360}$

354 Vgl. Schulz, Wegmann, Zinke, Die Generale der Waffen-SS und der Polizei, Bd. 3, S. 511.

355 Vgl. Kumm, Vorwärts Prinz Eugen, S. 28.

356 Vgl. Schulz, Wegmann Zinke, Die Generale der Waffen-SS und der Polizei, Bd. 3, S. 511.

357 Vgl. ebd., Bd 3. S. 380.

358 Vgl. ebd., Bd. 3, S. 383. Vgl. Kumm, Vorwärts Prinz Eugen, S. 162.

359 Vgl. Kumm, Vorwärts Prinz Eugen, S. 70.

360 Vgl. Schulz, Wegmann, Zinke, Die Generale der Waffen-SS und der Polizei, Bd 3. S. 380. 


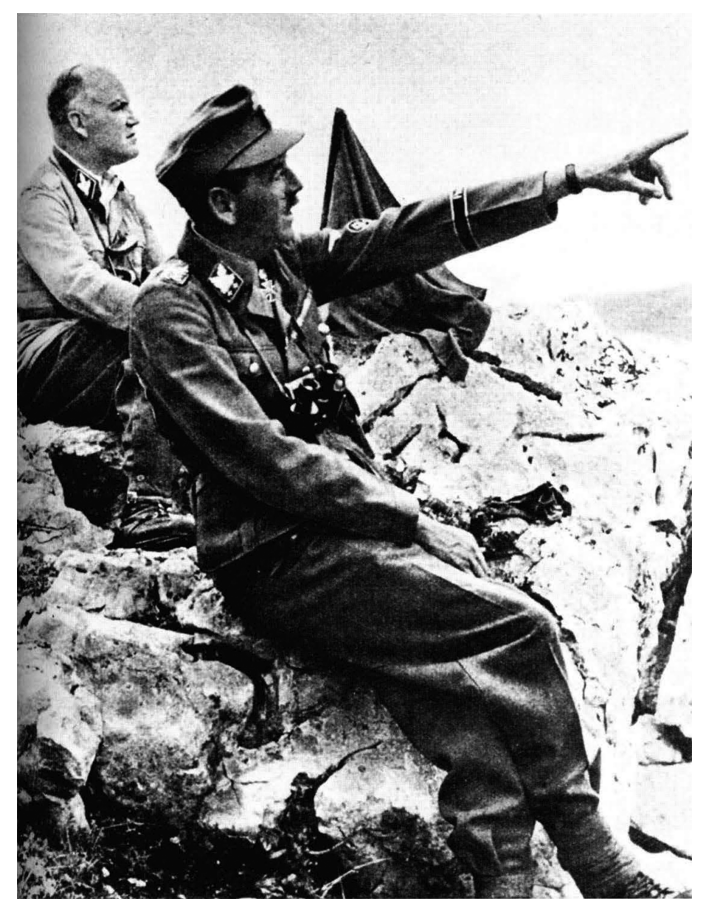

Abb. 13: Carl von Oberkamp und Artur Phleps auf der Halbinsel Pelješac. ${ }^{361}$

\subsubsection{Divisionskommandeur Otto Kumm}

Auch Otto Kumm stammte nicht aus Südosteuropa. Er wurde 1909 als Sohn eines Kaufmanns in Hamburg geboren, von 1925 bis 1929 absolvierte er eine Ausbildung zum Schriftsetzer und trat bereits 1931 mit 22 Jahren der SA bei. Nur ein paar Monate später wurde er aus der SA entlassen und noch im selben Jahr Mitglied der SS. 1934 meldete er sich freiwillig für die neu gegründete SS-Verfügungstruppe. 1936 wurde er zum SS-Hauptsturmführer befördert und befehligte die 2. Kompanie der SS-Standarte „Deutschland“. Als Kommandeur des III. Bataillons des SS-Regiments „Der Führer“ nahm Kumm im April 1941 am Angriff auf Jugoslawien teil. Kurz darauf übernahm er die Führung des SS-Regiments „Der Führer“, mit welchem er am Russlandfeldzug teilnahm, darunter auch an der Schlacht von Rschew. ${ }^{362}$

361 Nachlass Vopersal, BArchF, N 756/149b.

362 Vgl. Kaltenegger, Totenkopf und Edelweiss, S. 239. Schulz, Wegmann, Zinke, Die Generale der Waffen-SS und der Polizei, Bd. 2, S. $651 \mathrm{f}$. 
Ab Juli 1943 kam Kumm als Chef des Stabes des sich in Aufstellung befindenden V. SS-Gebirgskorps unter das Kommando von Phleps nach Südosteuropa. In Phleps' Stab und vom 30. Januar 1944 bis zum 20. Januar 1945 als Kommandeur der „Prinz Eugen“ verantwortete Kumm zahlreiche Kriegsverbrechen, die unter seinem Kommando begangen wurden. ${ }^{363}$

Als Kommandeur der „Leibstandarte Adolf Hitler“ hatte er bei der Operation „Frühlingserwachen“ vom 6. bis 16. März 1945 einen seiner letzten großen Einsätze. Kumm geriet in US-Kriegsgefangenschaft. In Nürnberg wurde er mehrere Monate verhört und schließlich in das Internierungslager Dachau zurückgeschickt. Er entging der jugoslawischen Kriegsgefangenschaft und somit seiner sicheren Hinrichtung durch seine Flucht aus Dachau. ${ }^{364}$

Anfang der 1950er Jahre konnte er bereits wieder in das Berufsleben einsteigen. Als Mitbegründer der HIAG wurde er zu deren erstem Vorsitzenden. ${ }^{365} 1978$ veröffentlichte er seine umfangreiche und apologetische Divisionsgeschichte zur „Prinz Eugen“ im einschlägig bekannten Munin-Verlag. Kumm starb 2004 im Alter von 95 Jahren in Offenburg. ${ }^{366}$

\subsubsection{Divisionskommandeur August Schmidhuber}

August Schmidhuber war der letzte Kommandeur der „Prinz Eugen“ und befehligte die Division vom 20. Januar bis zu ihrer Auflösung am 8. Mai 1945. Zwischen 1942 und 1944 kommandierte er das SS-Gebirgsjäger-Regiment 2 und übernahm ad interim das Divisionskommando für zwei Großoperationen in den Wintermonaten 1943/44, da Kumm aufgrund einer Krankheit ausfiel. Im Frühjahr 1944 wurde er zum Kommandeur der Division „Skanderbeg“ ernannt. Schließlich übernahm er im Januar 1945 erneut das Kommando über die „Prinz Eugen“, in welche auch die Reste der „Skanderbeg“ eingegliedert wurden, und blieb bis zu ihrer Auflösung im Mai 1945 ihr Divisionskommandeur. Wie Kumm und Phleps war auch Schmidhuber verantwortlich für zahlreiche Kriegsverbrechen, die während der deutschen Besatzung auf dem Balkan begangen wurden. Er wurde 1947, nach zweijähriger

363 Unter anderem die als „Sühnemaßnahmen“ getarnten Kriegsverbrechen in Otok. Vgl. Schulz, Wegmann, Zinke, Die Generale der Waffen-SS und der Polizei, Bd. 2, S. 653.

364 Vgl. Kumm, Vorwärts Prinz Eugen, S. 388. Vgl. Schulz, Wegmann, Zinke, Die Generale der Waffen-SS und der Polizei, Bd. 2, S. 654.

365 Wilke, Hilfsgemeinschaft auf Gegenseitigkeit, S. 37 f., 329.

366 Kumm, Vorwärts Prinz Eugen, Originalausgabe Osnabrück: Munin-Verlag 1978, Neuauflage Dresden: Winkelried Verlag 2007. Vgl. Schulz, Wegmann, Zinke, Die Generale der WaffenSS und der Polizei, Bd. 2, S. $654 \mathrm{f}$. 
Haft, in Belgrad hingerichtet. ${ }^{367}$ Von ihm wird im Kapitel zur Division „Skanderbeg“ noch die Rede sein.

\subsubsection{Truppe}

Innerhalb der Division „Prinz Eugen“ dienten auf Mannschaftsebene mit Stand vom Januar 194418.985 „Volksdeutsche“ sowie 1.381 Hilfswillige. Nach einer statistischen Aufstellung von Ende 1943 stammten zu diesem Zeitpunkt 12.145 Divisionsangehörige aus dem Banat und Serbien. Weitere 2.539 Mann kamen aus den Gebieten des NDH, 4.826 aus Rumänien, 662 aus der Slowakei und 582 aus Ungarn. ${ }^{368}$ Die meisten Soldaten waren somit in ihrem Heimatgebiet bzw. in direkt angrenzenden Gebieten eingesetzt. Dennoch darf nicht vergessen werden, dass sich diese deutschen Volksgruppen den jeweiligen Staaten, in welchen sie lebten, angepasst hatten, und somit ein „Volksdeutscher“ aus dem serbischen Banat aufgrund anderer Motive in die Waffen-SS eingetreten sein konnte als einer aus Rumänien. ${ }^{369}$

\subsubsection{Zusammenarbeit mit Hilfstruppen}

Sowohl die italienischen als auch die deutschen Besatzer gingen im Kampf gegen Partisanenformationen mannigfache Allianzen ein, was bereits in den frühen Operationszyklen „Weiss I“, „Weiss II“ und „Schwarz“ sichtbar wird. ${ }^{370}$ Dass die „Prinz Eugen“ auch ganz direkt Allianzen einging, bestätigt etwa ein Verhandlungsprotokoll vom 7. Juli 1944 zwischen dem Četnik-Führer Radivoj Kosorić und SS-Obersturmführer Balthasar Kirchner als Vertreter der SS-Division „Prinz Eugen“. Kosorić verpflichtete sich darin, den feindlichen politischen Gruppierungen und illegalen militärischen Verbänden abzuschwören, sowie außerdem anstelle nationaler serbischer Kokarden einen Doppeladler mit Totenkopf in der Mitte einzuführen. Die „Prinz Eugen“ hingegen verpflichtete sich, die Verpflegung, Munitionierung sowie sanitäre Betreuung nach ,den in der deutschen Wehrmacht geltenden Bestimmungen“ für Kosorićs rund 600 Mann zu übernehmen. Außerdem versprach die Deutsche Wehrmacht, den Schutz „aller Familien, deren männliche

367 Vgl. Schulz, Wegmann, Zinke, Die Generale der Waffen-SS und der Polizei, Bd. 5, S. 48-51. 368 Vgl. Casagrande, Volksdeutsche SS-Division, S. $211 \mathrm{f}$.

369 Vgl. hierzu Kapitel „Ausgangslage und Absichten auf ,volksdeutscher“ Seite“.

370 Vgl. Schmider, Der jugoslawische Kriegsschauplatz, S. 1015, 1017-1021. Vgl. Korb, Im Schatten des Weltkriegs, S. 89. 
Vertreter Angehörige der Abteilung sind, gegenüber Übergriffen von welcher Seite sie auch kommen mögen“, zu garantieren. ${ }^{371}$

\subsubsection{Gliederung und Unterstellung}

Unter den Bezeichnungen SS-Freiwilligen-Gebirgs-Division „Prinz Eugen“ und 7. SS-Freiwilligen-Gebirgs-Division „Prinz Eugen“ war diese „volksdeutsche“ und erste in Südosteuropa aufgestellte Division wie folgt gegliedert:

\section{Gliederung}

SS-Geb.Jäger-Rgt. 1 (Pr. Eugen) I.-IV.

SS-Geb.Jäger-Rgt. 2 (Pr. Eugen) I.-IV.

SS-Radf.Btl. (Pr. Eugen) $3 \mathrm{Kp}$.

SS-Kav.Abt. (Pr. Eugen) 2 Schw. ohne Stab

SS-Panzer-Abt. (Pr. Eugen) nur $1 \mathrm{Kp}$.

SS-Geb.Art.Rgt. (Pr. Eugen) I-III., seit Winter auch IV. (schw.) Abt.

SS-Pion.Btl. (Pr. Eugen) 2, seit $19433 \mathrm{Kp.}$

SS-Nachr.Abt. (Pr. Eugen) 4 Kp., später 5 Kp.

sowie Versorgungstruppen Pr. Eugen

Ab Winter 1942/43 kamen weitere Verbände hinzu:

SS-Aufkl.Abt. (Pr. Eugen) 4 Schw.

SS-Panzerjäger-Abt. (Pr. Eugen) $3 \mathrm{Kp}$.

SS-Kradschützen-Btl. (Pr. Eugen) 3 Kp.

SS-Flak-Abt. (Pr. Eugen) $3 \mathrm{Kp}$.

Im Sommer 1943 wurde das Kradschützen-Bataillon aufgelöst und daraus die 22. und 23. Kompanie im SS-Gebirgs-Jäger-Regiment 1 gebildet. ${ }^{372}$

371 Verhandlungsprotokoll zwischen Četnik-Führer Radivoj Kosorić und SS-Obersturmführer Kirchner über die Zusammenarbeit der „Prinz Eugen“ mit Četnik-Verbänden, 7.7.1944, BArchF, RS3/7-16, Bl. $27 \mathrm{f}$.

372 Nach Tessin, Truppen und Verbände, Bd. 3, S. 83. 
Zwischen November 1942 und Mai 1945 war die Division unter dem Kommando folgender Formationen:

\begin{tabular}{|c|c|c|c|c|c|}
\hline Jahr & Monat & $\begin{array}{l}\text { Befehlshaber/ } \\
\text { Korps }\end{array}$ & Armee & $\begin{array}{l}\text { Armee/ } \\
\text { Heeresgruppe }\end{array}$ & Land \\
\hline 1942 & $\begin{array}{l}\text { November- } \\
\text { Dezember }\end{array}$ & General Serbien & $\rightarrow$ & 12. Armee & Serbien \\
\hline \multirow[t]{4}{*}{1943} & Januar & $\begin{array}{l}\text { Befehlshaber } \\
\text { Serbien }\end{array}$ & $\rightarrow$ & 12. Armee & Serbien \\
\hline & Februar-August & $\begin{array}{l}\text { Befehlshaber } \\
\text { Kroatien }\end{array}$ & - & Heeresgruppe $\mathrm{E}$ & Kroatien \\
\hline & $\begin{array}{l}\text { September- } \\
\text { November }\end{array}$ & XV. Gebirgskorps & 2. Panzerarmee & Heeresgruppe $\mathrm{F}$ & Split \\
\hline & Dezember & $\begin{array}{l}\text { V. SS- } \\
\text { Gebirgskorps }\end{array}$ & 2. Panzerarmee & Heeresgruppe $F$ & Sarajewo \\
\hline \multirow[t]{6}{*}{1944} & Januar-März & $\begin{array}{l}\text { V. SS- } \\
\text { Gebirgskorps }\end{array}$ & 2. Panzerarmee & Heeresgruppe $\mathrm{F}$ & Kroatien \\
\hline & April-Juli & $\begin{array}{l}\text { V. SS- } \\
\text { Gebirgskorps }\end{array}$ & 2. Panzerarmee & Heeresgruppe $\mathrm{F}$ & Kroatien \\
\hline & $\begin{array}{l}\text { August- } \\
\text { September }\end{array}$ & $\begin{array}{l}\text { V. SS- } \\
\text { Gebirgskorps }\end{array}$ & 2. Panzerarmee & Heeresgruppe $\mathrm{F}$ & Serbien \\
\hline & Oktober & Korps Müller & Serbien & Heeresgruppe $\mathrm{F}$ & Serbien (Niš) \\
\hline & November & Korps Müller & Heeresgruppe $\mathrm{E}$ & Heeresgruppe $\mathrm{F}$ & Kroatien \\
\hline & Dezember & $\begin{array}{l}\text { XXXIV. } \\
\text { Armeekorps }\end{array}$ & Heeresgruppe $\mathrm{E}$ & Heeresgruppe $\mathrm{F}$ & Kroatien \\
\hline \multirow[t]{4}{*}{1945} & Januar & $\begin{array}{l}\text { XXXIV. } \\
\text { Armeekorps }\end{array}$ & Heeresgruppe $\mathrm{E}$ & Heeresgruppe $\mathrm{F}$ & Kroatien \\
\hline & Feburar & $\begin{array}{l}\text { LXXXXI. } \\
\text { Armeekorps }\end{array}$ & Heeresgruppe $\mathrm{E}$ & Heeresgruppe $\mathrm{F}$ & Kroatien \\
\hline & März-April & $\begin{array}{l}\text { XXI. } \\
\text { Gebirgskorps }\end{array}$ & Heeresgruppe $\mathrm{E}$ & Heeresgruppe $\mathrm{F}$ & Kroatien \\
\hline & Mai & LXIX. Armeekorps & - & OB Südost & $\begin{array}{l}\text { Celje } \\
\text { (Cilli) }^{373}\end{array}$ \\
\hline
\end{tabular}

373 Nach Tessin, Truppen und Verbände, S. $83 \mathrm{f}$. 


\subsubsection{Stärke}

Laut einem Bericht des Divisionskommandeurs an das Generalkommando des V. SS-Gebirgskorps vom 6. Februar 1944 bestand die Division zu diesem Zeitpunkt aus 392 Offizieren, 1.901 Unteroffizieren, 18.985 Mannschaften und 1.381 Hilfswilligen und wies somit eine Gesamtstärke von 22.659 Mann auf. ${ }^{374}$

Nur zwei Monate später, im April 1944, hatte sich die Stärke der „Prinz Eugen“ um über 1.000 Mann reduziert: ${ }^{375}$

\begin{tabular}{lrrrrr}
\hline & Führer & Unterführer & Mannschaften & Davon Hilfswillige & Gesamt \\
\hline Soll & 769 & 3.793 & 23.115 & 2.720 & 27.667 \\
Ist (17.4.1944) & 393 & 2.134 & 19.001 & 1.225 & 21.528 \\
\hline
\end{tabular}

Wirft man einen Blick auf „Ist und Soll“ der Panzerjäger-Abteilung 7 Ende 1943, lassen sich ähnliche personelle Engpässe auf Ebene der Führer und Unterführer erkennen, dafür aber einen Überschuss auf Mannschaftsebene:

\begin{tabular}{lrrrrr}
\hline & Führer & Unterführer & Mannschaften & Davon Hilfswillige & Gesamt \\
\hline Soll & 24 & 106 & 352 & & 482 \\
Ist (per 25.12.1943) & 13 & 54 & 407 & +19 & $493^{376}$ \\
\hline
\end{tabular}

\subsection{Schwierigkeiten}

\subsubsection{Mangel an Führern und Unterführern}

Kumm schreibt in seiner Divisionsgeschichte, dass sich eine besondere Schwierigkeit bei der Aufstellung der Division daraus ergeben habe, dass nicht, wie sonst bei Neuaufstellungen üblich, Führer, Unterführer und Stammmannschaften zugewiesen wurden, sondern Phleps vor die Aufgabe gestellt wurde, ,aus dem großen Bekanntenkreis der früheren k.u.k.-Armee geeignete Persönlichkeiten als

374 Div.Kdo. „Prinz Eugen“ an Gen.Kdo. V. SS-Geb.korps, 6.2.1944, BArchF RS3-7/17, Bl. 449, nach: Casagrande, Volksdeutsche SS-Division, S. 211.

375 Stärkemeldung „Prinz Eugen“, 17.4.1944, BArchB, NS 19/1475, Bl. 6.

376 Bericht SS-Sturmbannführer und Abteilungskommandeur der Panzerjäger-Abteilung 7, 25.12.1943, BArchF, N 756/149a. 
Kommandeure selbst anzuwerben“. ${ }^{377}$ Da aufgrund des akuten Personalmangels nur sehr wenige Unterführer zugewiesen wurden, kamen in der ersten Zeit auf einen Unterführer 400-450 Mann. Kumm schreibt, dass sich erst im Laufe des Sommers 1942 einige Führer in der „Prinz Eugen“ eingefunden hätten, die von anderen Divisionen versetzt worden waren. Die Versetzung zur „Prinz Eugen“ war „zu diesem Zeitpunkt für Angehörige der alten Stammdivisionen der Waffen-SS keineswegs eine Auszeichnung! Auf der Führerschule wird renitenten Junkern als Strafe eine Versetzung zur „Prinz Eugen“ angedroht“, so Kumm weiter. ${ }^{378}$ Phleps stand schließlich vor einem ziemlich zusammengewürfelten Führerkorps: Zum einen waren da Führer, die auf Phleps Drängen hin von der Division „Wiking“ versetzt wurden und andere, die sich freiwillig zur „Prinz Eugen“ versetzen ließen, und schließlich diejenigen, die strafversetzt oder aus der ehemaligen jugoslawischen Armee eingezogen wurden. ${ }^{379}$

\subsubsection{Ausbildung und Sprache}

Während des Ostfeldzugs traten zunehmend Probleme bei der Belastbarkeit der „volksdeutschen“ Soldaten auf. Diese hatten weder dieselbe Ausbildung noch denselben Bildungsstand wie deutsche oder österreichische Soldaten. Zudem schienen sie Theodor Eicke im Gegensatz zu ihren deutschen Kameraden „geistig minderwertig“ und oft unterernährt. ${ }^{380}$

Wie in den muslimischen Divisionen hatten deutsche Vorgesetzte auch in der „Prinz Eugen“ mit Verständigungsschwierigkeiten zu kämpfen. Mitunter sprachen die „Volksdeutschen“ kaum Deutsch - hatte doch die Auswanderung ihrer Vorfahren oft bereits im 18. Jahrhundert stattgefunden - und konnten weder lesen noch schreiben. ${ }^{381}$ Bereits im November 1941, noch bevor die „Volksdeutschen“ in einer Division zusammengefasst wurden, beschwerte sich der Kommandeur der 3. SS-Division „Totenkopf“, Theodor Eicke, über die mangelnden Deutschkenntnisse der in seiner Division dienenden „Volksdeutschen““. ${ }^{382}$ Auch ein Schreiben Bergers an Himmler vom Januar 1942 zeigt, dass das rekrutierte Personal auf Mannschaftsebene oft nicht über die erwarteten Deutschkenntnisse verfügte. Allerdings rechnete er damit, „dass diese sprachlichen Schwierigkeiten durch den Einsatz

377 Kumm, Vorwärts Prinz Eugen, S. 39.

378 Ebd. Vgl. Kaltenegger, Totenkopf und Edelweiss, S. 117.

379 Vgl. Kumm, Vorwärts Prinz Eugen, S. 39 f.

380 Vgl. Casagrande, Volksdeutsche SS-Division, S. 184.

381 Vgl. ebd.

382 Vgl. Casagrande, Südtiroler in der Waffen-SS, S. 39. 
von Volksdeutschen aus Kroatien, die bei uns schon dienen, in kürzester Zeit beseitigt sind“. ${ }^{383}$ Auch Jodl schrieb im Sommer 1942, dass man auf die ,gemischtsprachige Zusammensetzung“ Rücksicht nehmen müsse. ${ }^{384}$ Eicke hingegen war der Meinung, dass sämtliche „Volksdeutschen“, welche die deutsche Sprache nur ungenügend beherrschten, nicht in die Waffen-SS aufgenommen werden sollten, sondern zu „Fremdenbataillonen“ zusammengestellt und besonders geschult und beobachtet werden müssten. ${ }^{385}$ Aus den Akten im Arhiv Jugoslavije wird denn auch ersichtlich, dass einige „Volksdeutsche“ aufgrund mangelnder Sprachkenntnisse von der Waffen-SS tatsächlich abgewiesen wurden. ${ }^{386}$ Schmidhuber selbst erwähnt, dass die „Volksdeutschen“ im NDH die deutsche Sprache oft nicht beherrschten: „Da sie ausschließlich von Kroaten umgeben aufwuchsen und einer der Eltern meist ein Kroate oder eine Kroatin war, sprechen sie nur die Sprache des kroatischen Volkes, das sie aufgenommen hat. Anstatt diesen Deutschen besondere Aufmerksamkeit zu widmen, wird ihr Dienst in den Truppen durch das Vorhandensein einer Sprachbarriere erschwert. Dies wird dazu führen, dass sie sich nicht wie Deutsche fühlen können, sondern sich letztendlich in Fremde verwandeln. “387 Die Demütigungen aufgrund sprachlicher Schwierigkeiten gingen soweit, dass Vorgesetzte, wie die SS-Unterscharführer Eberhardt und Strack die Mütter ihrer Untergebenen verfluchten. Andere ließen ihre Soldaten aufgrund mangelnder Deutschkenntnisse Strafexerzieren, jede Nacht Wache stehen oder den gefangenen Partisanen die Hand schütteln. ${ }^{388}$

Auch die Ausbildung im Kriegshandwerk ließ zu wünschen übrig: Obwohl das Urteil innerhalb der SS-Panzerjäger-Abteilung 7 der „Prinz Eugen“ am 25. Dezember 1943 in materieller wie auch personeller Hinsicht zufriedenstellend ausfiel, beklagte sich ihr Kommandeur Albert Landwehr über die begrenzte technische Vorbildung der ihm unterstellten „Volksdeutschen“. Die Instruktionen empfand er als zeitraubend. Immerhin würden „diese Mannschaften doch willig und interessiert an ihrer Waffe die praktischen Handhabungen durchführen“. Aber er bemängelte, dass sie sich in „techn[ischen] u[nd] taktischen Dingen“ als sehr unbeweglich erwiesen. Außerdem hätte die „derzeitige U[nter]f[ü]hr[er]-Lage (28\% der Ausbilder)

383 Berger an Himmler, betr. Kroatische Führer, 31.1.1942, BArchB NS19/319, Bl. 11.

384 Chef des Oberkommandos der Wehrmacht, Alfred Jodl, an Himmler und SS-Obergruppenführer Karl Wolff, 21.8.1942, BArchB, NS19/319, Bl. 42.

385 Vgl. Casagrande, Volksdeutsche SS-Division, S. 184.

386 Vgl. Fall Alois Gasparitsch aus Slavonski Brod, Entlassungsschein vom 21.5.1942 „weil er die deutsche Sprache nicht beherrscht“, AJ 110/702, Bl. 242.

387 Rgt. St. Qu. SS-Gebirgsjäger Regiment 2, August Schmidhuber, „Kroatische Volksdeutsche“, 29.8.1943, BArchB. NS 7/254. Bl. 1.

388 Vgl. ebd. 
besonders d[er] (Sf.)Kp. [Selbstfahrlafetten-Kompanie] große Schwierigkeiten in allen Ausbildungszweigen zu Folge. “389 Ein härteres Urteil fällte SS-Unterscharführer Stefan Helleis der Nebelwerfer-Kompanie/Rgt. 13: Man habe aus Banater Bauern nicht über Nacht „preußische Paraderösser“ formen können. ${ }^{390}$ Bernwald schreibt rückblickend, dass die Ausbildung nur zwei Monate gedauert habe, Mitte Oktober bis Mitte Dezember 1942, und die „volksdeutschen“ Rekruten danach bereits zur SS-Division „Das Reich“ nach Frankreich gekommen wären. Auch ideologisch seien sie nie geschult worden: „Einen eigentlichen ,Weltanschaulichen Unterricht' hatte es damals bei uns in der Kompanie nicht gegeben. Warum, weiß ich nicht.“391 Die Grundausbildung innerhalb der „Prinz Eugen“ war oft schon nach nur sieben Wochen beendet. ${ }^{392}$

\subsubsection{Ungleichbehandlung, Rassismus und brutale Ausbildungsmethoden}

Wie Casagrande in seiner Studie zu Südtirolern in der Waffen-SS anschaulich herausarbeitet, stellten Überheblichkeit und Rassismus „reichsdeutscher“ Ausbilder gegenüber ihren „volksdeutschen“ Rekruten ab 1942 ein grundsätzliches Problem innerhalb der Waffen-SS dar, mit dem sich schließlich auch Himmler und Berger auseinandersetzen mussten. ${ }^{393}$ Wie bei anderen Divisionen kam es auch in der „Prinz Eugen“ vor, dass „volksdeutsche“ Soldaten von ihren deutschen Vorgesetzten als minderwertig betrachtet und entsprechend behandelt wurden. ${ }^{394}$ Casagrande schreibt von Übergriffen der SS-Ausbilder gegenüber „volksdeutschen“ bzw. auch eingebürgerten Soldaten (Optanten), die bereits 1940 gemeldet wurden. Neben körperlichen Strafen waren auch Erniedrigungen, die die Herkunft der Soldaten betrafen, an der Tagesordnung. So wurden in der Ausbildung etwa die „Schwaben“, die Bezeichnung für eingebürgerte „Volksdeutsche“, für alles, was nicht in Ordnung war, verantwortlich gemacht. ${ }^{395}$ Auch Bernwald schreibt, er wäre sich nicht sicher gewesen, ob seine und die Versetzung seiner „volksdeutschen“ Kameraden nach nur zweimonatiger Ausbildungszeit zur SS-Di-

389 Bericht SS-Sturmbannführer und Abteilungskommandeur der Panzerjäger-Abteilung 7, 25.12.1943, BArchF, N 756/149a. In dieser Abteilung waren die „volksdeutschen“ Südosteuropäer im Vergleich zur Gesamtdivision sogar etwas untervertreten: 22 Prozent der Führer, Unterführer und Mannschaften stammten aus dem Reich, 78 Prozent hingegen aus Südosteuropa. Ebd.

390 Vgl. Kumm, Vorwärts Prinz Eugen, S. 39.

391 Vgl. Bernwald, Muslime in der Waffen-SS, S. 41.

392 Vgl. Milata, Zwischen Hitler, Stalin und Antonescu, S. 244.

393 Vgl. Casagrande, Südtiroler in der Waffen-SS, S. $39 \mathrm{f}$.

394 Vgl. Casagrande, Volksdeutsche SS-Division, S. 184.

395 Vgl. Casagrande, Südtiroler in der Waffen-SS, S. $38 \mathrm{f}$. 
vision „Das Reich“ nach Frankreich damit zusammenhing, „dass man bei der für die Ausbildung verantwortlichen Dienststelle den Eindruck gewann, dass aus uns ,Beutegermanen“ keine Gardesoldaten gemacht werden konnten [...].“396 Die „nationale Überheblichkeit reichsdeutscher Ausbilder“ sollte sich aber vor allem bei der Rekrutierung und Ausbildung „Volksdeutscher“ für die „Prinz Eugen“ bemerkbar machen. Himmler machte Phleps im November 1943 persönlich darauf aufmerksam, dass Beschimpfungen von „Volksdeutschen“ - diese waren als „serbischer und kroatischer Dreck“ und „kroatischer Mist“ bezeichnet worden - zu unterlassen seien. Bei Beschimpfungen, in welchen die Mutter der Betroffenen verflucht würde, sollte sogar die Todesstrafe, auch gegen SS-Unterführer, verhängt werden. ${ }^{397}$ Auch unter den Kameraden kam es in gemischten Einheiten und Verbänden zu Konflikten, denn nicht nur die Ausbilder, sondern auch die „germanischen“ Soldaten blickten auf die „Volksdeutschen“ herab. Sie wurden für primitiv gehalten und ihre „rassischen Qualitäten“ in Frage gestrellt. ${ }^{398}$ Ein „Volksdeutscher“ stellte den Antrag auf Versetzung zu einer kroatischen Einheit, nachdem er von deutschen Divisionsangehörigen als Zigeuner und Serbe bezeichnet worden war. ${ }^{399}$

Unterscharführer Stefan Helleis schrieb nach dem Krieg, dass er seine Untergebenen als „größten Sauhaufen aller Zeiten“ bezeichnet habe, und er dies seiner Meinung nach auch durfte, da er selbst ein „Donauschwabe“ war. Er räumte aber ein, dass man einem „reichsdeutschen“ Vorgesetzten eine solche Aussage wohl übelgenommen hätte. ${ }^{400}$ Der Soldat Umbrich schreibt von der großen Enttäuschung, als sein erster Gruppenführer, ein älterer Deutscher, im Ausbildungslager in Bela Crkva/Weißkirchen, über ihn und seine Kameraden aus Rumänien verächtlich sagte, sie seien „Walachen und Kriegsverlängerer“. Obwohl sie daraufhin einwandten, sie seien keine Rumänen, sondern Sachsen und eingezogen worden, wiederholte der deutsche Vorgesetzte seine Beschimpfung. Daraufhin war Umbrichs Gruppe schwer enttäuscht und einige der älteren Männer erstatteten im Büro Beschwerde. Sie erhielten keine Antwort, dafür aber einen neuen Gruppenführer. Umbrich selbst schrieb von diesem Vorfall an seine Familie, um

396 Vgl. Bernwald, Muslime in der Waffen-SS, S. 41. „Beutegermanen“ war damals die gängige Bezeichnung für „Volksdeutsche“ aus Kroatien, so Bernwald. Vgl. ebd.

397 Vgl. Himmler an Phleps, 27.11.1943, BArchB NS19/319, Bl. 148. Vgl. Rgt. St. Qu. SS-Gebirgsjäger Regiment 2, August Schmidhuber, „Kroatische Volksdeutsche“, 29.8.1943. BArchB, NS 7/ 254, Bl. $1 \mathrm{f}$.

398 Vgl. Sørlie, Sonnenrad und Hakenkreuz, S. 351.

399 Rgt. St. Qu. SS-Gebirgsjäger Regiment 2, August Schmidhuber, „Kroatische Volksdeutsche“, 29.8.1943, BArchB. NS 7/254. Bl. 1.

400 Vgl. Kumm, Vorwärts Prinz Eugen, S. 39. 
zu verhindern, dass noch mehr Familienmitglieder den Dienst in der Waffen-SS antraten. ${ }^{401}$ Doch auch im weiteren Ausbildungsalltag rissen „verbale Misshandlungen“ nicht ab. ${ }^{402}$ In seinen Memoiren hält Umbrich fest, dass sehr bald die Zeit fehlte, „uns über Beleidigungen und ethnische Beschimpfungen aufzuregen“, da die Ausbildung begann und diese brutal gewesen wäre. ${ }^{403}$ Dies war für Umbrich und andere „Volksdeutsche“ aus Rumänien umso enttäuschender, als sie sich nicht zuletzt für den Dienst in deutschen Verbänden entschieden hatten, weil sie den brutalen Methoden in der rumänischen Armee entgehen wollten. ${ }^{404}$

Schonungslose und erniedrigende physische und psychische Gewalt waren in der Division „Prinz Eugen“ oft Teil des Ausbildungsalltags, wie der folgende Fall illustriert: SS-Oberführer Richard Kaaserer, geboren 1896 in Trient in Südtirol, war ein überzeugter Nationalsozialist und seit Dezember 1939 in der Einwandererzentrale Łódź/Litzmannstadt tätig. Von 1940 bis 1943 war er auch Leiter des Sippenamtes im Rasse- und Siedlungshauptamt. Gleichzeitig kommandierte er von Juli bis Dezember 1942 in der „Prinz Eugen“ das I./Rgt. 2 unter Regimentskommandeur Schmidhuber, ${ }^{405}$ wurde dann aber zum Aufstellungsstab der Lettischen SS-Freiwilligen-Legion versetzt. Im Frühsommer 1943 kam er nach Kroatien zum Aufstellungsstab der Division „Handschar“ und wurde schließlich zum SS- und Polizeiführer für den Sandžak ernannt, wo er auch bei der Rekrutierung von albanischen und bosnischen Muslimen aus diesem Raum eine wesentliche Rolle spielte. $^{406}$

Sein Curriculum hatte allerdings einen Makel: Kaaserer wurde im Frühjahr 1943 angeklagt, seine Untergebenen in der „Prinz Eugen“ misshandelt zu haben. In der Anklageverfügung vom 31. Mai 1943 gab er an, sich durch „persönlichen unermüdlichen Einsatz“ bemüht zu haben, aus seiner Truppe einen „schlagkräftigen, einsatzfähigen Verband“ zu machen. Nach seinen Aussagen strengte er sich dabei so sehr an, dass er „nervös“ wurde, abmagerte und schließlich Erholungsurlaub brauchte. Die Richtung, in der die Verhandlung verlief, lässt sich bereits unter dem Punkt „Wesentliches Ermittlungsergebnis“ ablesen: Die aufgestellte Einheit habe aus Rekruten „volksdeutscher“ Herkunft bestanden, die „körperlich in besonde-

\footnotetext{
401 Vgl. Wittmann, Umbrich, Alptraum Balkan, S. 82.

402 Vgl. Milata, Zwischen Hitler, Stalin und Antonescu, S. 242.

403 Vgl. Wittmann, Umbrich, Alptraum Balkan, S. 84.

404 Vgl. Milata, Zwischen Hitler, Stalin und Antonescu, S. 59f. Vgl. Wittmann, Umbrich, Alptraum Balkan, S. 74. Vgl. Casagrande, Volksdeutsche SS-Division, S. 208.

405 Vgl. Kumm, Vorwärts Prinz Eugen, S. 41.

406 Vgl. SS-Personalakte Richard Kaaserer, geb. 21.8.1896, BArchB, ehemals BDC.
} 
rem Maße unbeholfen und schwerfällig, geistig ungeschult und zum Teil vererbt und schlechten Willens" waren. ${ }^{407}$

Obwohl sich der Angeklagte nach Aussagen der Ankläger in neun Fällen schuldig gemacht hatte, hatten die Opfer kaum Aussicht, dass ihnen bei den rassistischen Vorzeichen, die in diesem Fall zutage traten, Gerechtigkeit widerfuhr. Folgende Anklagepunkte werden für die Vorfälle in Bela Crkva/Weißkirchen und nicht näher genannte Orte aufgeführt: Kaaserer habe sich „der Misshandlung von Untergebenen schuldig gemacht, indem er sie vorsätzlich stieß, schlug, misshandelte, an der Gesundheit schädigte, ihnen böswillig den Dienst erschwerte und sie entwürdigend behandelte“. ${ }^{408}$ Weitere Anschuldigungen waren: Schläge mit der Hand und der Faust, Fußtritte gegen Untergebene, Einsatz von Reitpeitschen, als ein SS-Mann erschöpft liegen blieb; den SS-Schützen Baumann habe er absichtlich mit dem Pferd überritten und ihm dabei „nicht unerhebliche“ Verletzungen zugefügt. Die gesamte 3. Kompanie musste bei glühender Hitze so lange in „Stillgestanden“ ausharren, bis einige ohnmächtig wurden. Den SS-Schützen Pavlowitsch, Karl Schmidt, Rudolf Elbel und Adalbert Haag habe er hinterhergeschossen, als sie seiner Meinung nach nicht schnell genug marschierten. Auf einen SS-Mann, der seine Schuhe auszog und barfuß lief, hätte Kaaserer ebenfalls geschossen. $^{409}$

Kaaserer selbst stritt die Vorwürfe nicht ab, sondern führte an, dass er

als Hauptmann im früheren k.u.k. österreichischen Heer nur kroatische, mohammedanische und bosnische Einheiten geführt hätte und es ihm aus dieser Zeit geläufig sei, dass gelegentlich[e] Schläge der Leistungssteigerung dienen würden. Er wäre davon überzeugt gewesen, sich in einem Befehlsnotstand zu befinden. Im Übrigen sei er völlig mit den Nerven fertig gewesen. ${ }^{410}$

Nun wurde aber der Angeklagte nicht etwa verurteilt, sondern der Richter für diesen Fall, SS-Sturmbannführer Kurt Mittelstädt, stellte das Verfahren ein, da Kaaserer „nicht aus unlauteren Motiven“ heraus seine Untergebenen misshandelt habe. Vielmehr habe er ,in der Absicht gehandelt [...], das Beste zu wollen und ein unbedingt einsatzfähiges Bataillon zu schaffen.““11 Kaaserer kam kurz darauf, wie eingangs erwähnt, zum Aufstellungsstab der „Handschar“. ${ }^{412}$ Da er

407 „Anklageverfügung“, 31.5.1943, SS-Personalakte Richard Kaaserer, geb. 21.8.1896, BArchB, ehemals BDC, S. 1.

408 Ebd., S. 1.

409 Ebd., S. 2.

410 Vgl. ebd., S. 3.

411 Vgl. SS-Personalakte Richard Kaaserer, geb. 21.8.1896, „Verfügung“, 6.8.1943, BArchB, ehemals BDC.

412 SS-Personalakte Richard Kaaserer, geb. 21.8.1896, BArchB, ehemals BDC. 
sich aber nicht nur an seinen Soldaten verging, sondern auch die lokale Zivilbevölkerung terrorisierte, wurde er im Januar 1947 in Belgrad hingerichtet. ${ }^{413}$

\subsubsection{Mangel an Bewaffnung und Ausrüstung}

Bereits in der ersten Hälfte 1942 herrschten in der „Prinz Eugen“ für gewisse Bereiche Materialengpässe. So wies etwa SS-Hauptsturmführer Josef Schwörer in einem Schreiben an Berger darauf hin, dass bei der Beschaffung von Tragtieren Schwierigkeiten auftreten würden. ${ }^{414}$ Auch bezüglich der Bewaffnung stiess die Aufstellung im serbisch-kroatischen Raum auf erhebliche Schwierigkeiten. ${ }^{415}$ Um den Mangel an Ausrüstung wettzumachen, wurden unter anderem vom Postschutz 9.000 Karabiner 98k, 1.500 Pistolen 08/38 und 500 Maschinenpistolen 38/40 geliehen. Weiter kamen vor allem Beutewaffen aus tschechischen, polnischen, jugoslawischen, französischen und ab September 1943 aus italienischen Beständen zum Einsatz. $^{416}$

Kumm bestätigt den Mangel an Waffen und Ausrüstung insbesondere für das letzte Kriegsjahr. ${ }^{417}$ Er beschreibt etwa Kommunikationsschwierigkeiten beim Unternehmen „Rösselsprung“, in welchem aufgrund der ständigen Überlastung der knappen Nachrichtenmittel die vereinbarten Stichworte beim Fallschirmbataillon nie angekommen seien oder am zweiten Tag des laufenden Unternehmens ein dringender Befehl erst nach Stunden übermittelt werden konnte. Einen weiteren Mangel sah er in der ungenügenden Ausbildung. ${ }^{418}$ Die sehr knappe Ausbildung von teilweise nur sieben Wochen, sowie extremer Platzmangel und katastrophale sanitäre Zustände etwa in der Divisionsgarnison in Vršac/Werschetz, werden auch von Milata angeführt. ${ }^{419}$

\subsubsection{Mangelnde Geheimhaltung, Dienstverweigerung, Ausfälle und Desertionen}

Schon für die zweite Jahreshälfte 1942 wurden Desertionen gemeldet. Doch nicht alle Deserteure schafften es über die Grenze; so wurden beispielsweise am 27. Au-

\footnotetext{
413 Vgl http://www.olokaustos.org/bionazi/leaders/kaaserer.htm (Stand: 8.11.2019).

414 Vgl. SS-Hauptsturmführer Schwörer an Berger, 13.3.1942, BArchB NS19/319, Bl. 20.

415 Vgl. Klietmann, Waffen-SS: eine Dokumentation, S. 151.

416 Vgl. ebd., S. 151f. Vgl. hierzu auch Vopersal, BArchF, N 756/149b.

417 Vgl. Kumm, Vorwärts Prinz Eugen, S. 209.

418 Vgl. ebd., S. $192 \mathrm{f}$.

419 Vgl. Milata, Zwischen Hitler, Stalin und Antonescu, S. 244.
} 
gust 1942 zehn Flüchtende bei Velika Kikinda von einer nicht identifizierten deutschen Einheit erschossen. ${ }^{420}$ Im August 1943 kam es schließlich zum Eklat: 173 „Volksdeutsche“ des SS-Gebirgsjäger-Regiments 2 unter der Führung Schmidhubers verweigerten den Gehorsam. ${ }^{421}$ Von diesem Vorfall berichtete Phleps Himmler in einem Brief indes erst am 27. Oktober und meldete, dass die renitenten Soldaten nach Dachau gebracht worden seien. ${ }^{422}$ Himmler gab darauf die Hauptschuld den deutschen Vorgesetzten, die die „Volksdeutschen“ als „serbischen und kroatischen Dreck“ bezeichnet hatten. ${ }^{423}$

Dass die Ausbildungsgarnisonen nahe an der rumänischen Grenze lagen, förderte die Bereitschaft zur Desertion zusätzlich: Ebenfalls im Spätsommer 1943 bildete sich auf der anderen Seite der Grenze in Rumänien bereits eine ganze Siedlung aus Deserteuren, darunter auch zahlreiche serbischstämmige „Volksdeutsche“. Sie lag in der Gegend Dinias-Sânnicolau Sârbec im Kreis Temesch-Torontal. Der deutsche Gesandte in Rumänien Killinger berichtete nach Berlin, dass es beinahe täglich zu Desertionen kam, in letzter Zeit wären 50 Fälle gemeldet worden. $^{424}$

Im Januar 1944 mussten schließlich fast 50 Prozent der Division ausgewechselt werden. Schmidhuber schreibt, dass der Ersatz intensiv „weltanschaulich“ geschult werden müsse. ${ }^{425}$ Zwischen dem 21. November 1943 und dem 20. Februar 1944 verzeichnete die Division außerdem 5.000 Krankheitsfälle. Insbesondere das schlechte bzw. beschädigte Schuhwerk machte den Divisionsangehörigen im Winter zu schaffen. ${ }^{426}$

Kumm schreibt rückblickend, dass vor allem die Geheimhaltung zu einem umso größeren Problem wurde, je länger der Krieg andauerte. So wären Titos Partisanen beispielsweise über das bevorstehende Unternehmen „Rösselsprung“ informiert gewesen. Bereits Ende Mai 1944 wäre in Bihać das Gerücht verbreitet worden, dass das wichtigste Ziel dieser Operation die Festnahme oder Ermordung Titos sei. Sogar der Angriffstag soll in Titos Hauptquartier bekannt gewesen sein, wie die Deutschen später in einem Gefangenenverhör erfuhren. ${ }^{427}$

420 Vgl. ebd.

421 Vgl. Schulz, Wegmann, Zinke, Die Generale der Waffen-SS und der Polizei, Bd. 5, S. 49.

422 Vgl. ebd., Bd. 3, S. 510.

423 Vgl. Fußnote 32 in ebd., Bd. 3, S. 510. Vgl. auch Casagrande, Südtiroler in der Waffen-SS, S. 40 .

424 Vgl. Milata, Zwischen Hitler, Stalin und Antonescu, S. 244.

425 Vgl. Casagrande, Volksdeutsche SS-Division, S. 274.

426 Vgl. ebd.

427 Vgl. Kumm, Vowärts, Prinz Eugen, S. 193. 
Dennoch bewährten sich große Teile der „Prinz Eugen“, anders als die übrigen drei hier betrachteten Divisionen, bis zum Schluss. Dies war vor allem der Tatsache geschuldet, dass die „volksdeutschen“ Divisionangehörigen gar keinen Ort mehr besaßen, wohin sie hätten zurückkehren können. Viele ihrer Dörfer existierten nicht mehr oder waren von Angehörigen anderer Ethnien übernommen worden. Ihre Familien wurden am Ende des Krieges vertrieben oder ermordet. ${ }^{428}$ Im Herbst 1944 betrug die Stärke der Division nur mehr 6.000 Mann. Ähnlich wie bei den Schwesterdivisionen „Handschar“, „Kama“ und „Skanderbeg“ sind in den Herbstmonaten 1944 die meisten Desertionen zu finden. Allein im Oktober waren bei den Vermissten 2.610 Mann angegeben; dabei handelte es sich aber oft um Desertionen. ${ }^{429}$

\subsection{Kriegsverbrechen}

Wie keine andere der drei südosteuropäischen Divisionen mordeten die Angehörigen der „Prinz Eugen“ quer durch die Balkanstaaten. Davon betroffen waren die heutigen Gebiete von Serbien, Montenegro, Kosovo, Bosnien, Kroatien bis nach Slowenien. Aufgrund ihres brutalen Auftretens und weil sie an vermeintlichen oder echten Brennpunkten zum Einsatz kamen, wurden sie von Angehörigen anderer Waffen-SS-Formationen auch als „Balkanfeuerwehr“ bezeichnet. ${ }^{430}$ Die Art der Einsätze teilte sich deutlich in zwei Kategorien: einerseits der Schutz kriegswichtiger Rohstoffe und Infrastruktur, so etwa der Bauxitminen bei Mostar ${ }^{431}$ - ein beliebtes Anschlagsziel lokaler Partisaneneinheiten, andererseits die Partisanenbekämpfung, die mit der Ermordung zahlreicher Zivilpersonen einherging. ${ }^{432}$ Hitlers Befehl von Ende 1942, beim Kampf gegen Partisanen rücksichtslos vorzugehen und auch Frauen und Kinder nicht zu schonen, wurde sowohl von Vorgesetzten als auch Soldaten oft als Freibrief interpretiert. Dahingehend lässt sich auch der bereits am 16. Dezember 1942 vom OKW versprochene Straferlaß für alle bei der Partisanenbekämpfung begangenen Verbrechen verstehen. ${ }^{433}$ Bereits im Ja-

428 Vgl. bspw. Janko, Weg und Ende, S. 293-297.

429 Vgl. Michaelis, Die Waffen-SS, S. 135.

430 Vgl. bspw. Brief Fleischer an Vopersal, 24.8.1972, BArchF, N 756/182b. Vgl. zum Narrativ der Waffen-SS-Verbände als „Feuerwehr“ auch Leleu, La Waffen-SS, S. 557-561.

431 Vgl. Böhm, Die deutschen Volksgruppen, S 406.

432 Vgl. Schulz, Wegmann, Zinke, Die Generale der Waffen-SS und der Polizei, Bd. 3, S. 509. Vgl. hierzu auch Stein, Geschichte der Waffen-SS, S. 246.

433 Vgl. Schmider, Partisanenkrieg, S. 182. 
nuar 1943 lautete ein Divisionsbefehl, „Waffenträger kurzerhand zu erschießen“. ${ }^{34}$ Doch selbst Befehle, die zur Sicherung kriegsrelevanter Ressourcen und Abbaugebiete dienten, ließen oft einen großen Interpretations- und somit Handlungsspielraum: So etwa verlangte der Divisionsbefehl vom 16. März 1943 die „Besetzung und Verteidigung des Minengebietes westl[ich] Mostar“ mit dem Ziel, den Bauxitabbau in diesem Gebiet ,vor inneren und äußeren Angriffen zu schützen und die ungestörte Auswertung dieser Gebiete zu gewährleisten. “435 Dieser Befehl konnte als reine Sicherungsaufgabe oder aber als Freipass zur Ermordung von Zivilisten ausgelegt werden.

In eine ähnliche Richtung wies auch ein Schreiben des Panzer-Armee-Oberkommandos 2 an Phleps:

Da bisher die beantragten Sühnemaßnahmen gar nicht oder erst nach langer Zeit vollstreckt wurden, [...] wird es für zweckmäßig gehalten, wenn die Truppe unter Anlegung scharfen Maßstabes und Bewahrung schärfster Disziplin unter der Verantwortung der Kommandeure zur Selbsthilfe schreitet und notwendige Maßnahmen ,im Kampf erledigt ${ }^{436}$

Gefangene Partisaninnen und Partisanen wurden nicht als Kriegsgefangene behandelte, da ihnen der Status, Angehörige einer regulären Armee zu sein, abgesprochen wurde, wie auch Kumm nachträglich bemerkte. ${ }^{437}$ Doch durch „Volksdeutsche“ der „Prinz Eugen“ begangenen Kriegsverbrechen an Zivilpersonen und Partisanen müssen immer auch vor dem Hintegrund bereits schwelender ethnischer Konflikte gesehen werden, wie an einigen Beispielen deutlich wird. ${ }^{438}$

Trotz erdrückender Beweise war Kumm jedoch noch 1978 der Meinung, dass durch seine Division keine Kriegsverbrechen begangen worden wären:

Wir waren es gewohnt, den tapfer kämpfenden Feind zu achten. Der Kranke, Verwundete, Gefangene war für uns nur noch der Mensch und nicht Opfer unseres Hasses. Wohin soll die Weltgeschichte noch abgleiten, wenn solche Verleumdungen und Völkerverhetzungen - 32 Jahre nach dem Kriege in Stein gemeißelt - der Nachwelt überliefert werden? ${ }^{439}$

Er war überzeugt, dass bei fairer Prozessführung keiner der Divisionsangehörigen hätte verurteilt werden können. ${ }^{440}$ Die Archivakten aber sprechen eine an-

434 Divisionsbefehl „Prinz Eugen“, 18.1.1943, VA HEM.OK.BOJCKA, 10/13a/11.

435 Divisionsbefehl SS-Freiwilligen-Division „Prinz Eugen“, Phleps, BArchF, N 756/149b.

436 Pz.Armee.Oberkdo an Phleps, 23.5.1944, BArchF, RS 3-7/14, Dok. 51, nach: Casagrande, Volksdeutsche SS-Division, S. 281.

437 Vgl. Bildüberschrift gefangene Partisaninnen und Partisanen: „Reguläre Truppen?“, in: Kumm, Vorwärts Prinz Eugen, S. 192.

438 Vgl. Casagrande, Volksdeutsche SS-Division, S. 283.

439 Vgl. Kumm, Vorwärts Prinz Eugen, S. 388.

440 Vgl. ebd. 
dere Sprache: In ihrem mehr als dreijährigen Bestehen mäanderte die „Prinz Eugen" mordend quer durch den Balkan. Sundhaussen zitiert Georg H. Stein, der zu den Nürnberger Nachfolgeprozesse schreibt, dass

wohl das entsetzlichste Material gegen die Waffen-SS [...] von der jugoslawischen Delegation vorgetragen [wurde]. Es betraf die verbrecherischen Handlungen der 7. SS-GebirgsDivision ,Prinz Eugen“ und bot anschauliche Beschreibungen der Niederbrennung von Dörfern, der Abschlachtung ihrer Einwohner und der Folterung und Ermordung gefangener Partisanen. ${ }^{441}$

Kumm selbst liefert in seinem apologetischen Werk „Vorwärts Prinz Eugen!“ zahlreiche Hinweise, dass auch gegen unschuldige Zivilisten vorgegangen wurde. So beispielweise in einem Divisionsbefehl während der Operation „Weiß“ Ende 1942: Die Gefechtstruppe Ost sollte dabei „das ganze Gebiet zwischen Kupa und Straße Glina-Virgin Most einschl[ießlich] durchkämmend und von Partisanen und Kampffähigen säubernd“ in westlicher Richtung gegen die Linie Prnjavor-Dugo Selo vorstoßen. Damit wird offensichtlich, dass auch Nicht-Kombattanten und -Kombattantinnen erschossen wurden, falls sie sich in diesem Gebiet aufhielten und als „kampffähig“ erachtet wurden, was dem subjektiven Urteil des Einzelnen vorbehalten blieb. ${ }^{442}$

Ein seltenes Selbstzeugnis liefert der ehemalige Angehörige der „Prinz Eugen“ Heinrich Vonjahr, der erst 1966, nachdem er auf frühere Anfragen von Waffen-SSVeteranen nicht geantwortet hatte, schrieb:

Ich bleibe dabei, dass mir Div[isions]k[ommandeu]r - ich sehe noch seine brennende Zigarre - den Befehl gab, die zusammengetriebenen Zivilisten erschießen zu lassen. Es war eine der schwersten Stunden meines Lebens, weil ich von ihrer Unschuld überzeugt war. Einer der Jünglinge war der Bruder des kroatischen Verbindungsmannes, der dem Div[isions]stab zugeteilt war. Der kam mit dem Nachrichtenoffizier (IIIc?) [sic] zu mir und beschwor mich. Ich wagte die Hinauszögerung und wagte einen Appell an den von hinten zurückgekehrten Div[isions]k[ommandeu]r - nahm einen gewaltigen Anpfiff entgegen und erhielt zu meiner unsäglichen Erleichterung den Befehl, die Gruppe nach gehöriger Vergatterung [Belehrung] zu entlassen. ${ }^{443}$

Leider blieben dieser Vorfall und der Einsatz Vonjahrs, für unschuldige Zivilisten einzustehen, die Ausnahme. Der Normalfall war die Ausführung des Befehls und somit die Erschießung oder Verbrennung tausender unschuliger Zivilisten, oft einhergehend mit dem Niederbrennen ihrer Dörfer. ${ }^{444}$

441 Vgl. Sundhaussen, Waffen-SS in Kroatien, S. 194.

442 Vgl. Kumm, Vorwärts Prinz Eugen, S. 60.

443 Vonjahr an Zimmermann, 5.12.1966, BArchF, N756/149a.

444 Vgl. bspw. Sørlie, Sonnerad und Hakenkreuz, S. 307. 
Im Oktober 1942 kam die frisch aufgestellte Division in den Raum Südserbien, nach Osice, Čačak, Novi Pazar und Mitrovica. ${ }^{445}$ Hier verübten Divisionsangehörige erste Massaker an der Zivilbevölkerung. Bilder vom 29. November 1942 zeigen Artur Phleps in Kraljevo an seiner Geburtstagsfeier umgeben von seinem Divisions-Stab. ${ }^{446}$ Genau hier sowie im benachbarten Kragujevac hatte die 717. Infanterie-Division Anfang Oktober 1941 zwei der schlimmsten Massaker in Südosteuropa überhaupt verübt: In den beiden Städten wurden an die 4.000 Zivilisten ermordet. Dies geschah ein halbes Jahr nach dem Balkanfeldzug und stellte die Weichen für weitere grausame Operationen im „Partisanenkrieg“ in Südosteuropa.

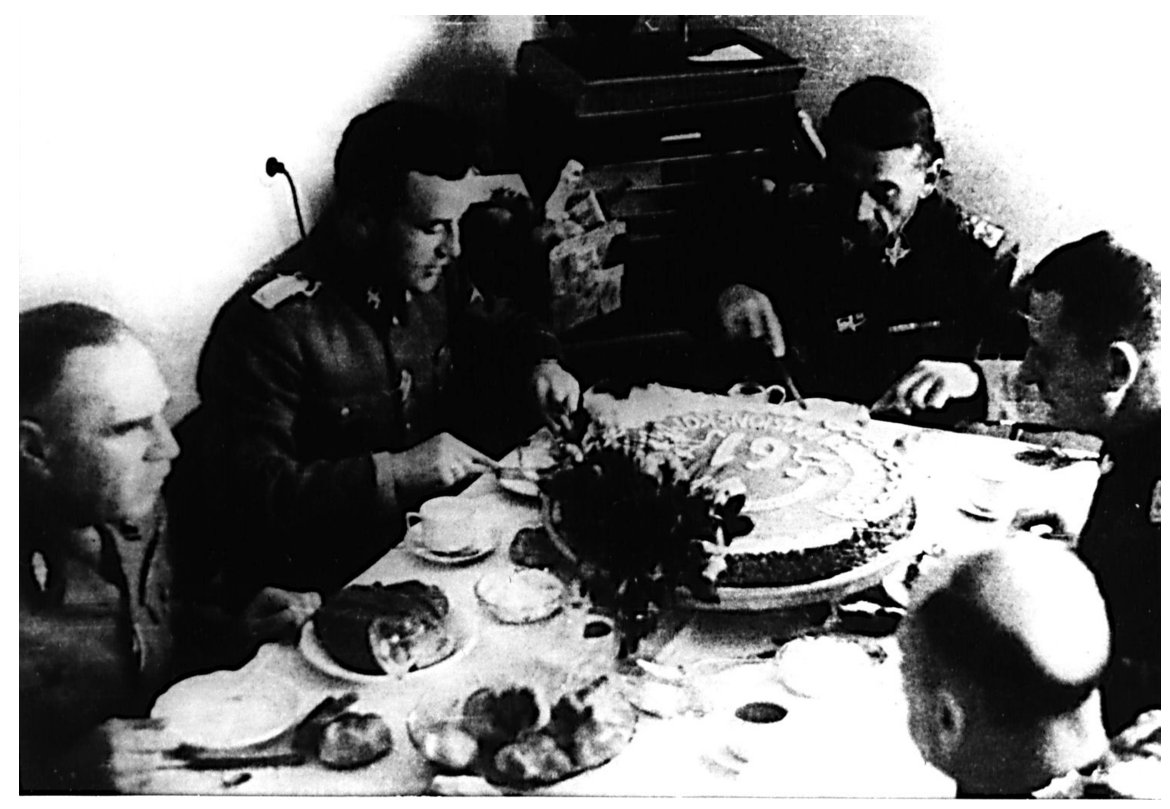

Abb. 14: Phleps‘ Geburtstagsfeier in Kraljevo. ${ }^{447}$

Doch Teile der „Prinz Eugen“ waren auch an der Grenze Sloweniens von Kupa bis nach Zentralkroatien, Slunj, stationiert. Ihr Aktionsradius reichte bis an den äußersten Zipfel Nordwestbosniens nach Bihać, Vrtoče, Petrovac, Grahovo, Livno, Lise, Mostar, Nevesinje, Gacko, Bileća und bis nach Montenegro, nach Nikšić, Gvozd

445 Vgl. Bericht Vopersal, BArchF, N 756/149b.

446 Vgl. Geburtstagsfeier Phleps Kraljevo, BArchF, N 756/149b.

447 BArchF, N 756/149b. 
und Šavnik. ${ }^{448}$ Allein in der Gegend von Knin in Kroatien sollen 22 Dörfer niedergebrannt und rund 1.000 Zivilisten umgebracht worden sein. ${ }^{449}$ Nach dem Unternehmen „Schwarz“ im Frühsommer 1943 kam die „Prinz Eugen“ in den Raum Sarajevo. ${ }^{450}$ Dort kam es zu Übergriffen an Muslimen, so etwa in Rogatica $60 \mathrm{~km}$ östlich von Sarajevo. Im September 1943 verübten Mitglieder der Division Massaker im Raum Dalmatien, in Trilj und benachbarten Ortschaften. ${ }^{451}$ Neben Zivilpersonen gerieten ab September 1943 auch italienische Soldaten ins Visier der „Prinz Eugen“. Heinrich Vonjahr beschrieb nach dem Krieg die Erschießungen von ehemaligen italienischen Soldaten durch die „Prinz Eugen“ mit folgenden Worten:

Bezüglich der ,Erschießung gefangener ital[ienischer] Offiziere‘ bin ich einer Meinung mit Ihnen und habe mit meiner Formulierung nichts Anderes sagen wollen. Die Exekution ist für mich eine unangenehme Erinnerung, weil daran Leute meiner Einheit teilnahmen, die gleiche Einsatzfreudigkeit bei besseren Gelegenheiten vermissen ließen. ${ }^{452}$

Die Blutspur der „Prinz Eugen“ zog sich auch im Frühjahr und Sommer 1944 weiter, wo Angehörige der Division wiederum in der Gegend um Dalmatien, in Split und weiteren benachbarten Ortschaften Massaker verübten. Allein für das Jahr 1944 wurden für die von der „Prinz Eugen“ begangenen Kriegsverbrechen bei den Nürnberger Prozessen 834 zivile Opfer genannt. ${ }^{453}$

Schmidhuber, Regimentskommandeur in der „Prinz Eugen“, für zwei Operationen im Winter 1943/44 ad interim Divisionsführer und späterer Divisionskommandeur der „Skanderbeg“, wurde in erster Linie für seine Kriegsverbrechen, die er während seines Dienstes in der Division „Prinz Eugen“ befohlen hatte, angeklagt. Auch SS-Obersturmbannführer Alfred Graf wurde von Militäranwalt Ilija Djekić in der Anklageschrift Verbrechen während seiner Dienstzeit in der „Prinz Eugen“ bezichtigt, obwohl darin auch Straftaten enthalten sind, die er während seiner Zeit als Kommandeur der „Skanderbeg“ befohlen oder gebilligt haben musste. Doch bereits im Zeitraum zwischen November und Dezember 1943 war er als Kommandeur des I./SS-Freiw.Geb.Jäg.Rgt. 14 der „Prinz Eugen“ an „Säuberungsaktionen“ im Raum um Kosovska Mitrovica beteiligt gewesen. Graf wurde angeklagt,

448 Bildunterschrift einer Bildreihe in Vopersals Nachlass, BArchF, Nachlass Vopersal, N756_149a.

449 Vgl. Schmider, Jugoslawischer Kriegsschauplatz, S. 917.

450 Vgl. Kumm, Vorwärts Prinz Eugen, S. 92.

451 Vgl. bspw. Frano Glavina: Stravican pokolj u cetinskoj krajini, https://kamenjar.com/stra vican-pokolj-u-cetinskoj-krajini/ (Stand: 11.2.2019).

452 Vonjahr an Zimmermann, 5.12.1966, BArchF, N756/149a.

453 Vgl. Casagrande, Schvarc, Spannenberger, Trasca, The Volksdeutsche, S. 247. Die Opferzahlen unterschieden sich stark, so wurden für 1944 auf kroatischer Seite 1.000 zivile Opfer gemeldet, auf deutscher Seite nur 486. Vgl. ebd. 
weil er als Kommandeur des I. Bataillons, 2. Rgt. der verbrecherischen 7. SS-Div. ,Prinz Eugen“ vom Nov[ember] 1942 bis Ende 1943 und später als K[ommandeur] des ersten Versorgungs-R[egiments], später kämpfendes Rgt, mit dem er sich über Kraljevo, Užice, Sarajevo und Zvornik während des Krieges als Organisator und Befehlserteiler die Zivilbevölkerung der Völker Jugoslaviens [sic] zu Todesstrafen verurteilte, verhaftete, in Kzs. abführte, und so: [...] weil er als Kdr des I. Btl des 2. Rgt der verbr. 7-SS-Div. ,Prinz Eugen` an den Geländesäuberungs-Aktionen in Serbien im Raume Kopsonik, Rudnik, Kos[sovska] Mitrovica teilnahm, bei welcher Gelegenheit unsere Bevölkerung ausgeplündert, verhaftet und getötet und der SSW [Serbische Staatswache] übergeben wurde, von wo sie auf Zwangsarbeit nach Deutschland geschickt wurde. [...] Weil er als Kdr. Rgt. [sic] der 21. Geb.Div. ,Skanderbeg“ während des Rückzuges Mitglied des Standgerichtes war und auf diese Art mehrere Straftaten des Kriegsverbrechens aus Art. § 3 Punkt 3 des Gesetzes über Straftaten gegen Volk und Staat beging. ${ }^{454}$

Grafs Anklageschrift liefert einen Einblick in die große Menge verschiedener kleiner und großer Massaker und anderer Kriegsverbrechen, die teilweise bis heute nicht aufgedeckt, und deren Verantwortliche nicht zur Rechenschaft gezogen werden konnten. Als Beispiel soll hier der Fall von Heinrich Schwarz erläutert werden: Josefine Niemroth schrieb am 28. Januar 1965 an das Polizeiamt in Neuwied einen Brief, in welchem sie den „Volksdeutschen“ Heinrich Schwarz, geboren in Martinsdorf in Rumänien, der Kriegsverbrechen in Jugoslawien bezichtigte: „Da ich viele Jahre mit ihm [Heinrich Schwarz] gelebt habe, hat er mir in einer vertraulichen Stunde erzählt, dass er dort Juden und Geiseln erschossen hat. Das Gold, welches er den Leichen weggenommen hatte, ließ er sich in den Mund arbeiten. ${ }^{455}$ Obwohl festgestellt wurde, dass Schwarz in der „Prinz Eugen“ gekämpft hatte, wurde der Fall nicht weiter behandelt. Im Gegenteil, man bezichtigte Niemroth, Schwarz aufgrund von Streitigkeiten schaden zu wollen. ${ }^{456}$ Das Verfahren wurde schließlich am 19. August 1966 mit der Begründung eingestellt: „Auch kann aus der Tatsache, dass der Beschuldigte Goldzähne hatte, nicht gefolgert werden, dass das Gold von ermordeten Juden oder Geiseln stammte.“457

454 Anklageschrift Djekic gegen Graf, 1.9.1948, BArchF, N 756/182b, S. 1.

455 Aussage Josefine Niemroth im Fall Heinrich Schwarz, 28.1.1965, USHMM, BArchL, B162/ 19.145, Bl. 6.

456 Vgl. Weiterführung des Falls Heinrich Schwarz, 19.1.1965, 19.2.1965, 21.5.1965, USHMM, BArchL, B162/19.145, Bl. 4f., 10. Wiedererwähnung des Falls Heinrich Schwarz, 11.1.1980, USHMM, BArchL, B162/19.145, Bl. 12.

457 Vgl. Einstellung des Verfahrens gegen Heinrich Schwarz, 19.8.1966, USHMM, BArchL, B162/19.145, Bl. 13-15. Vgl zu weiteren Einstellungsverfügungen bei Ermittlungen gegen die „Prinz Eugen“: „Einstellungsverfügung“, Staatsanwaltschaft München, Dr. Ludolph, I 116 Js 17/67 gg. Unbekannt vom 12.6.1972, Vgl. USHMM/BArchL, B162/19.144, Bl. 13-16. 
Im Folgenden soll eine Auswahl verschiedener Kriegsverbrechen zeigen, in welch großem Raum und in welchem Umfang Angehörige der „Prinz Eugen“ Massaker und andere Kriegsverbrechen begingen.

\subsubsection{Kriva Reka}

Einer der ersten Einsätze führte die neu aufgestellte „Prinz Eugen“ am 5. Oktober 1942 in den Raum Kriva Reka. ${ }^{458}$ Dieser Angriff Anfang Oktober 1942 im südserbischen Kopaonik-Gebirge, dessen Ausläufer bei Mitrovica enden, ist ein frühes Zeugnis davon, dass die „Prinz Eugen“ in der ersten Zeit ihres Bestehens vor allem gegen Četniks im Einsatz stand. Namentlich erwähnt ist die Gruppe um Dragutin Keserović wie auch eine weitere um Major Keserović, dessen genaue Anzahl von Untergebenen nicht ermittelt werden konnte. Dennoch war sich Phleps sicher, dass „die gesamte Bevölkerung des Raumes als ihm hörig anzunehmen“ sei. ${ }^{459} \mathrm{Zu}$ sammen mit der 9. Infanterie-Division der bulgarischen Armee sollte die „Prinz Eugen“ „diesen Feind zerschlagen“. ${ }^{460}$ Als Ableknungsmanöver war die Besetzung der Höhen Goč und Ljukten bei Trstenik vorgesehen, die von Kumm als illegal betrachtete Četnik-Verbände besetzt hatten. ${ }^{461}$ Beim Versuch, die Četnik-Gruppe um Keserović zu zerschlagen, brannten Angehörige der Division ohne erkenntlichen Grund die Ortschaft Kriva Reka nieder. Schmider schreibt, dass weder der Einsatz von Erfolg gekrönt war, noch das brutale Vorgehen eine abschreckende Wirkung erzielt habe: Nur drei Tage später wurde das ebenfalls im Divisionsbereich gelegene Antimonwerk durch serbische Četniks schwer beschädigt. ${ }^{462}$

\footnotetext{
458 Vgl. Kumm, Vorwärts Prinz Eugen, S. 46-51. Vgl. hierzu den vollständigen Einsatzbefehl an die „Prinz Eugen“, Vgl. Kaltenegger, Totenkopf und Edelweiss, S. 120-124. Kaltenegger erwähnt das mit diesem Einsatz zusammenhängende Massaker in Kriva Reka mit keinem Wort. Vgl. ebd. $124 \mathrm{f}$.

459 Vgl. Kumm, Vorwärts Prinz Eugen, S. 46. Vgl. Schmider, Partisanenkrieg, S. 444. Vgl. zu dieser Ausrichtung der Division auch: August Schmidhuber, Kriegsgefangenenbericht, Juni 1946 (genaues Datum nicht angegeben), VA HEM.OK.BOJCKA, 72/2-1/3.

460 Vgl. Kumm, Vorwärts Prinz Eugen, S. 46.

461 Vgl. ebd.

462 Vgl. Schmider, Partisanenkrieg, S. 444. Kommandeur einer der in Kriva Reka eingesetzten Kampfgruppen war auch der spätere Kommandeur des Regiments 27 und spätere Divisionskommandeur der „Handschar“, zuletzt SS-Brigadeführer und Generalmajor der Waffen-SS Desiderius Hampel. Vgl. Schulz, Wegmann, Zinke, Die Generale der Waffen-SS und der Polizei, Bd. 2, S. 19.
} 


\subsubsection{Erschießungen in Metković}

Am 29. Januar 1963 reichte Ernst August Strupp Strafanzeige gegen seinen ehemaligen Vorgesetzten Rudolf Raff sowie gegen SS-Schütze Kubatscheck [Kubaček?] ein. Zu diesem Zeitpunkt saß Strupp wegen Betrugs in Untersuchungshaft und meldete der Zentralen Stelle der Landesjustiz zur Aufklärung nationalsozialistischer Verbrechen in Ludwigsburg, dass ihm erst im Gefängnis diese Namen wieder eingefallen wären. ${ }^{463}$ In Metković soll Kubatscheck, sowie in einer nahe gelegenen Ortschaft Raff, beide Angehörige des SS-Gebirgspionierbataillon 7 der Division „Prinz Eugen“, willkürlich mehrere Zivilisten ermordet haben. Im Falle Kubatschecks hatte Zugführer Tscherny Strupp erzählt, dass Kubatscheck die Frau, das Kind und den älteren Mann erschossen habe, die er hätte bewachen sollen. Nach Aussagen des Anklägers hatte die Tat für Kubatscheck selbst keine Folgen. Der Vorgesetzte Raffs wurde nach dem Vorfall zu einer Strupp nicht bekannten Einheit versetzt. ${ }^{464}$ An diesem Fall lassen sich gleich drei Sachverhalte aufzeigen, die Michael Okray für den Umgang mit Kriegsverbrechen, die durch Waffen-SS-Angehörige begangen wurden, als symptomatisch bezeichnet: ${ }^{465}$ erstens eine zeitliche Verzögerung von zwei Jahrzehnten, die zwischen den Taten und der Anklage verstrichen waren, zweitens die weitere Verzögerung sowie Absprachen der Beteiligten, möglichst ungenaue Angaben zu Tatorten und -zeiten oder gar die Verneinung der Tatbestände durch weitere Befragte. ${ }^{466}$ Der vernommene Zeuge Herbert Julius Vollmer beispielsweise bestritt mehrmals, auch nur das Geringste von solchen Vorfällen gewusst $\mathrm{zu}$ haben. ${ }^{467} \mathrm{Um}$ von der eigentlichen Tat abzulenken, verwies Vollmer auf eine Vergewaltigung bei Kraljevo und die Ahndung des Vergewaltigers durch ein Militärgericht. Er soll zum Tode verurteilt worden sein. ${ }^{468}$ Drittens ist der Beschluss der Landgerichts Bad Kreuznach vom 22.

463 Vgl. Zeugenaussage Ernst August Strupp, 26.2.1963, USHMM/BArchL, B162/6.252, Bl. 7.

464 Vgl. ebd., Bl. 7.

465 Vgl. hierzu erhellend Michael Okroy, „Nach 26 Jahren nun Mammutprozess gegen Polizisten“. Die justitielle Aufarbeitung von NS-Verbrechen der Ordnungspolizei am Beispiel der Wuppertaler Bialystok-Verfahren, in: Schulte, SS, Himmler und die Wewelsburg, S. 449-469.

466 Vgl. ebd, S. 455-457, 464-466, 459.

467 Vgl. Zeugenvernehmung Herbert Julius Vollmer, gez. Knodel und Fendel USHMM/ BArchL, B162/6.252, Bl. 73. Vgl zur Reaktion auf die zunehmenden Untersuchungen der Zentralen Stelle Ludwigsburg Karsten Wilke, Die Truppenkameradschaften der Waffen-SS 1950-1990, Organisationsgeschichte, Entwicklung und innerer Zusammenhalt, in Schulte, Jan Erik, Lieb, Peter, Wegner, Bernd (Hg.): Die Waffen-SS. Neue Forschungen, S. 426.

468 Vgl. Zeugenvernehmung Herbert Julius Vollmer, gez. Knodel und Fendel USHMM/ BArchL, B162/6.252, Bl. 73. 
Juli 1966 zu nennen, der das Strafverfahren gegen Raff und Kubatschek schließlich einstellte, obwohl keine Zeugen des betroffenen Ortes befragt worden waren. ${ }^{469}$

\subsubsection{Massaker von Trilj, Sinj, Split und Umgebung}

Im September 1943 verübten Mitglieder der „Prinz Eugen“ eine ganze Reihe von Massakern im Raum Dalmatien, in Trilj und Sinj und einer Reihe weiterer Dörfer in ihrer Umgebung. Sie töteten dabei etwa 500 Einwohner von Košute, Brnaza, Garduna, Turjaka, Jabuka/Apfeldorf, Velić, Lećevica und Muć. Diese Verbrechen verübten sie gemeinsam mit Četnik-Einheiten, die sie im Jahr zuvor noch bekämpft hatten. Diese Morde an der Zivilbevölkerung veranlassten den Stellvertreter des kroatischen Gesandten in Berlin, Dr. Tomislav Samugnać, zu einer Protestnote an die deutsche Regierung. ${ }^{470}$ Am 1. Oktober 1943 begingen Angehörige der „Prinz Eugen“ ebenfalls in Trilj ein weiteres Massaker: Eine nicht genannte Anzahl italienischer Offiziere wurde hier erschossen. ${ }^{471}$ Im Folgejahr kam es zu einem weiteren Massaker in dieser Umgebung, wie weiter unten gezeigt wird.

\subsubsection{Massaker von Kosutica und weitere Zwischenfälle}

Solange die „Prinz Eugen“ Kriegsverbrechen gegenüber der serbisch-orthodoxen Bevölkerung beging, waren die Reaktionen von deutscher Seite absehbar und endeten häufig mit der Rechtfertigung des Vorgesetzten für die Tat seines Untergebenen oder mit der Versetzung des Angeschuldigten. ${ }^{472}$ Anders waren die Reaktionen bei Verbrechen gegen muslimische Bevölkerungsteile. Denn seit Frühjahr 1943, mit Beginn der Rekrutierungen für die „Handschar“, vertrugen sich solche Vergehen schlecht mit der offiziellen Politik der Waffen-SS, nämlich die gesamte muslimische Welt für ihre Organisation zu gewinnen.

Anfang September 1943 sollten deshalb mehrere „Zwischenfälle mit Muselmanen im Raume der SS-Division ,Prinz Eugen““ untersucht werden. Phleps berichtete Himmler am 7. September über die vorläufigen Ergebnisse: Am 11. Juli 1943 erreichte ein Spähtrupp der „Prinz Eugen“ unter SS-Obersturmführer Carl

469 Vgl. Beschluss Landgericht Bad Kreuznach UR 2/65 - 213/66 (3 Js 3884/64), 22.6.1966, USHMM/BArchL, B162/6.252.

470 Vgl. bspw. Frano Glavina: Stravican pokolj u cetinskoj krajini, https://kamenjar.com/stra vican-pokolj-u-cetinskoj-krajini/ (Stand: 11.2.2019).

$471 \mathrm{Vgl}$. USHMM/BArchL, B162/6.750.

472 Vgl. Phleps an Reichsführer SS Himmler, 7.9.1943, BarchB NS19/1434, Bl. 16. 
Juels das Dorf Kosutica, wo er durch beidseitiges Flankenfeuer in der Dorfmitte zum Rückzug gezwungen wurde. Dabei wurden zwei Soldaten verwundet. Am nächsten Tag, so berichtete Phleps weiter, hätte die erste Kompanie des SS-Gebirgs-Jäger-Regiments 1 der „Prinz Eugen“ den Befehl erhalten, nicht nur das Dorf, sondern „weit darüber hinaus“ anzugreifen. ${ }^{473}$ Phleps argumentierte bei Himmler, dass Spuren von Tierschlachtungen festgestellt worden wären, und man daher mit Sicherheit davon ausgehen konnte, dass die Bevölkerung die Partisanen mit Nahrung unterstützen würden. Ein einziger älterer Mann wurde mit fünf Schuss Munition erwischt, die er wegzuwerfen versucht hatte. In der Dorfmitte wurde die Kompanie von Juels wieder mit Maschinengewehrfeuer empfangen. Als Racheaktion erschossen Angehörige der 7. SS-Freiwilligen-Gebirgsdivision „Prinz Eugen“ am 12. Juli 194340 Einwohner des Dorfes. ${ }^{474}$

Phleps teilte Himmler Anfang September 1943 mit, dass weder Juels noch der Kompanie ein Vorwurf gemacht werden könnte, da sie nicht gewusst hätten, dass es sich bei der Dorfbevölkerung um Muslime handelte. Juels habe auf Befehl gehandelt und sich und seiner Einheit durch die Erschießung der gesamten Dorfbevölkerung den Rücken freihalten wollen:

Den Obersturmführer Juels kann in dieser Angelegenheit kein Vorwurf treffen, denn 1.) handelte er im Sinne des Führerbefehls vom 16.12.42 betrifft Bandenbekämpfung, sowie des Befehls des Befehlshabers der deutschen Truppen in Kroatien vom 10.7.43 und im Sinne meiner Weisungen, dass die Bevölkerung solcher Ortschaften, die den Partisanen Vorschub leistet niedergemacht wird. ${ }^{475}$

Obwohl Phleps damit einen Teil der Verantwortung auf sich nahm, entbrannte schließlich ein Streit zwischen Divisionskommandeur von Oberkamp und dem Chef der Polizeiverbände in Kroatien, SS-Brigadeführer Konstantin Kammerhofer, in welchen letztendlich Himmler eingriff, weil er befürchtete, das Massaker an der muslimischen Bevölkerung könnte Auswirkungen auf zukünftige Rekrutierungen haben. ${ }^{476}$

Nach dem Krieg wurde durch die Zentrale Stelle Ludwigsburg ein Überprüfungsvorgang betreffend dieser Vergeltungsaktion gegen die Bewohner des Dorfes

473 Vgl. Phleps an Reichsführer SS Himmler, 7.9.1943, BarchB NS19/1434, Bl 15.

474 Vgl. „Aktennotiz über die Besprechung des Reichsführer-SS mit SS-Obergruppenführer Phleps am 28.7.1943», USHMM/BArchL, B162/5.846, Bl. 5. Vgl. „Vergeltungsmaßnahmen der Wehrmacht und Waffen-SS im Polizeigebiet Sarajevo“, 15.7.1943, USHMM/BArchL, B162/5.846, Bl. 7.

475 Vgl. Phleps an Himmler, 7.9.1943, BarchB NS19/1434, Bl 16.

476 Vgl. Casagrande, Unsere Gegner, S. 260 f. 
Kosutica durch Angehörige der SS-Division „Prinz Eugen“ eingeleitet, allerdings ohne Erfolg. 477

\subsubsection{Massaker in Rogatica}

In Rogatica kam es im Herbst 1943 zu „Strafmethoden einer unserer Einheiten“, die selbst die sonst deutschfreundliche Bevölkerung Ostbosniens kritisch stimmte. ${ }^{478}$ Weitere Details sind jedoch hierzu nicht bekannt.

\subsubsection{Massaker in Tulje, Mrkonjići, Drjenjani, Dračevo und Dubljani}

Der Divisionsbefehl vom 11. März 1944 verhieß eine Carte Blanche für Massaker in den Dörfern von Tulje, Mrkonjići, Drjenjani, Dračevo und Dubljani im heutigen Bosnien-Herzegowina. Sämtliche Männer in wehrfähigem Alter sollten festgenommen, die genannten Dörfer wie auch weitere, „aus denen Widerstand geleistet wird“, niedergebrannt werden. ${ }^{479}$ Wie oben genannt, gab es sowohl einen Führerbefehl als auch einen Befehl des obersten Befehlshabers Südost, sowie Weisungen von Phleps selbst, dass solche Dörfer auszulöschen seien. ${ }^{480}$

\subsubsection{Massaker in Otok und der Umgebung von Sinj und Split}

Für die Umgebung von Sinj und Split nennt Sundhaussen weitere Gräueltaten, die von Teilen der „Prinz Eugen“ und angegliederten Četnik-Hilfstruppen begangen wurden, beispielsweise am 28. März 1944 in Otok, wo Frauen und Kinder in Häuser getrieben und in Gruppen von fünf bis fünfzehn erschossen wurden. In einem anderen Dorf, das Sundhaussen nicht näher nennt, sollen 150 Menschen erschossen und danach angezündet worden sein. ${ }^{481}$ Schmider nennt für diesen

477 Vgl. hierzu diverse Vorermittlungen und Ermittlungsverfahren gegen SS-Obersturmführer Carl Juels, USHMM/BArchL, B162/5846, u. a. Bl. 84-91 und Bl. 95-101. Vgl. hierzu auch Vladimir Dedijer, Antun Miletić, Genocid nad Muslimanima, 1941-1945: zbornik dokumenata i svedočenja, Sarajevo: Svjetlost 1990.

478 Vgl. Reisebericht SS-Hauptsturmführer Hasan Bajralitarović [Bajraktarević] an Phleps, 15.11.1943, BArchB, NS19/2601, Bl. 58.

479 BArchF, RS 4/1131, Dok. 4062, nach Casagrande, Volksdeutsche SS-Division, S. 277.

480 Vgl. Phleps an Reichsführer SS Himmler, 7.9.1943, BarchB NS19/1434, Bl 16.

481 Vgl. Sundhaussen, Waffen-SS in Kroatien, S. 195. 
Zeitraum Otok, Gruda und Dolac. ${ }^{482}$ Das Massaker von Otok fand auch in den Nürnberger Prozessen Erwähnung. SS-Obergruppenführer und Generaloberst der Waffen-SS Paul Hausser, der als Zeuge auftrat, wurden dabei Berichte der „Jugoslawischen Kommission zur Feststellung von Kriegsverbrechen“ vorgelegt. In diesen wurde eine etwas andere Version der Vorgänge in Otok beschrieben:

Diese Massenschlächterei wurde in allen Dörfern in derselben schrecklichen Art durchgeführt. Die deutschen Soldaten trieben Frauen, Kinder und Männer auf einem Platz zusammen und eröffneten dann Maschinengewehrfeuer auf die Menge [...]. Nicht einmal die Säuglinge an der Mutterbrust wurden verschont. ${ }^{483}$

Bei diesem Massaker wird offensichtlich, wie stark Partisanentätigkeiten, geplante Umsiedlungen und Gewaltexzesse miteinander verbunden waren. Denn die Bewohner in und um Otok sollten bald in Dörfer gebracht werden, von wo die ursprüngliche „volksdeutsche“ Bevölkerung aufgrund intensiver Partisanentätigkeit umgesiedelt bzw. deportiert worden war. ${ }^{484}$ Auch Kumm nahm zu den Vorfällen in Otok Stellung. Da angeblich eine Nachschubkolonne in diesem Dorf bis auf den letzten Mann niedergemacht worden war, sei der Befehl erteilt worden, das Dorf zu vernichten und sämtliche Bewohner zu töten. In seinem Werk zur „Prinz Eugen“ triumphierte er später, dass „trotz eifrigster Nachforschungen im Militär-Archiv Freiburg“ keinerlei Hinweise hätten gefunden werden können, um die Kommandeure für ein Urteil genügend $\mathrm{zu}$ belasten. Diese wurden allesamt freigesprochen. ${ }^{485}$

Die von der „Prinz Eugen“ in Otok und umliegenden Dörfern begangenen Massaker kosteten verschiedenen Schätzungen zufolge bis zu 2.000 Menschen das Leben. ${ }^{486}$ Insegsamt waren 22 Ortschaften betroffen. ${ }^{487}$ Die Tatsache, dass es sich zumeist um Kroaten handelte, hatte eine Demarche der kroatischen Regierung zufolge, welche der deutsche Gesandte in Kroatien, Kasche, vollumfänglich unterstützte. ${ }^{488} \mathrm{Zu}$ den Massakern in Sinj und Split schrieb Hans Helmas ihm am 11. April 1944

482 Vgl. Schmider, Jugoslawischer Kriegsschauplatz, S. 1030.

483 Nürnberg XX, S. 409, nach Casagrande, Volksdeutsche SS-Division, S. 277.

484 Vgl. Casagrande, Schvarc, Spannenberger, Trasca, The Volksdeutsche, S. 247.

485 Kumm, Vorwärts Prinz Eugen, S. 383, nach: Casagrande, Volksdeutsche SS-Division, S. 282.

486 Vgl. Schmider: Jugoslawischer Kriegsschauplatz. S. 1030.

487 Vgl. Martin Seckendorf, Günter Keber, u. a.; Bundesarchiv (Hg.): Die Okkupationspolitik des deutschen Faschismus in Jugoslawien, Griechenland, Albanien, Italien und Ungarn (1941-1945), Bd. 6 Hüthig: Berlin 1992, S. 321.

488 Vgl. Schmider: Jugoslawischer Kriegsschauplatz. S. 1030. Kasche ging in einem Schreiben an von Ribbentrop am 16.4.1944 von rund 1.000 Opfern aus. Vgl. Seckendorf, Okkupationspolitik des deutschen Faschismus, S. 59, 320 f. 
Exzellenz

Der Minister der kroatischen Befreiungsarmee berichtet der kroatischen Regierung, dass die Tschetniks in Uniformen gekleidet sind, unter Beteiligung der SS-Division ,Prinz Eugen', vor einigen Tagen in der Nähe der Stadt Sinj in Mitteldalmatien sowie in der Nähe von Split (Poljica) 400 kroatische Männer, Frauen und Kinder töteten. Für die Sicherheit der kroatischen Bevölkerung wurden in Split 70 serbische Tschetniks von den kroatischen Behörden festgenommen. ${ }^{489}$

Bei diesem Massaker soll nebst der „Prinz Eugen“ auch eine so genannte „Teufelsdivision“ zum Einsatz gekommen sein. Casagrande geht davon aus, dass dieser Name die angegliederten Četnik-Einheiten bezeichnete. ${ }^{490}$

\subsubsection{Massaker von Vlahovici}

Casagrande erwähnt das Massaker von Vlahovici ohne näher darauf einzugehen. Von Kumm sei dieses später geleugnet worden. ${ }^{491}$

\subsubsection{Niederbrennen von Häusern in Čitluk}

Am 1. Dezember 1966 schrieb Dr. Zimmermann an Heinrich Vonjahr, ehemaliger Kommandeur einer Einheit der „Prinz Eugen“ vom Niederbrennen von Häusern in Čitluk im Süden Bosnien-Herzegowinas. ${ }^{492}$ Vonjahr antwortete ihm nur vier Tage später und bestätigte dieses Verbrechen an bosnischen Zivilisten. ${ }^{493}$

\subsection{Schicksal nach dem Krieg}

Überschriften und Titel wie bei Casagrande, Janko oder Meiser weisen auf die dramatischen Konsequenzen hin, welche ethnische Deutsche in Jugoslawien zu tragen hatten: „Das Ende der deutschen Volksgruppe in Jugoslawien“, „Weg

489 Brief Hans Helmas an die Gesandtschaft in Kroatien, 11. April 1944, V. T 31/44, nach: Frano Glavina: Stravican pokolj u cetinskoj krajini, https://kamenjar.com/stravican-pokolj-ucetinskoj-krajini/ (Stand: 11.2.2019).

490 Casagrande, Volksdeutsche SS-Division, S. 277, 318.

491 Vgl. ebd., S. 282.

492 Zimmermann an Vonjahr, 1.12.1966, BarchF, N756/149c.

493 Vonjahr an Zimmermann, 5.12.1966, BArchF, N756/149a. 
und Ende der deutschen Volksgruppe in Jugoslawien“, „Ausgelöscht! Der Untergang der Deutschen in Südostmitteleuropa“. 494

Im September 1944 plante die „Volksgruppenführung“ im Banat die Ausarbeitung eines Evakuierungsplans für die „volksdeutsche“ Bevölkerung. Obwohl der HSSPF Serbien, Montenegro und Sandžak, Hermann Behrends, diesen Plan ablehnte, ordnete die VoMi dennoch die Evakuierung dieser „Volksdeutschen“ an. Der Aufforderung folgten etwa 300.000 von rund 500.000 „Volksdeutschen“ aus der Region. ${ }^{495}$ In einem Verzweiflungsakt wurde noch versucht, eine lokale Formation aus bislang für die Rekrutierung $\mathrm{zu}$ jungen und $\mathrm{zu}$ alten Soldaten bis 65 Jahren, die Batschka-Division, aufzustellen, um die von „Volksdeutschen“ bewohnten Gebiete zu verteidigen. Doch dieses Vorhaben scheiterte rasch. ${ }^{496}$

Vielen „volksdeutschen“ Funktionären gelang es, sich ins Ausland abzusetzen. Obwohl eine Evakuierung von Teilen der „volksdeutschen“ Bevölkerungen Südosteuropas geplant war, blieben zahlreiche weniger vermögende bzw. arme Leute in ihren Heimatgebieten und wurden Opfer grausamer Racheaktionen. Sie wurden nun nicht mehr als Angehörige eines der Völker Jugoslawiens wahrgenommen, sondern als Fremdkörper. ${ }^{497}$ Aufgrund der teilweise intensiven Zusammenarbeit mit den Deutschen, insbesondere aber wegen den zahlreichen durch die „Prinz Eugen“ begangenenen Massaker wurden die „Volksdeutschen“ nach Kriegsende kollektiv als Kriegsverbrecher und fünfte Kolonne abgestempelt. ${ }^{498}$ Entsprechend wurden nicht nur die ehemaligen SS-Angehörigen, sondern auch „volksdeutsche“ Zivilisten nach dem Einmarsch der kommunistischen Partisanen in ihre Dörfer misshandelt, interniert und erschossen. ${ }^{499}$

Nach dreijährigem Einsatz gerieten viele Divisionsangehörige schließlich im Frühjahr 1945 in Slowenien im Raum Celje/Cilli und Brežice/Rann in Slowenien selbst in Gefangenschaft. ${ }^{500}$ Wer nicht sofort erschossen oder in eine der zahlreichen Karstschluchten gestürzt wurde, ${ }^{501}$ verblieb in Celje/Cilli oder kam in das Internierungslager nach Teharje/Tüchern. Dort wurden neben „volksdeutschen“ und

494 Vgl. Casagrande, Volksdeutsche SS-Division, S. 298. Vgl. Janko, Weg und Ende der deutschen Volksgruppe. Vgl. Meiser, Ausgelöscht! Der Untergang der Deutschen in Südostmitteleuropa. Tübingen: Hohenrain-Verlag 2015.

495 Vgl. Calic, Geschichte Jugoslawiens, S. 179.

496 Vgl. Janko, Weg und Ende der deutschen Volksgruppe, S. 293.

497 Vgl. Casagrande, Volksdeutsche SS-Division, S. $299 \mathrm{f}$.

498 Vgl. Böhm, Die deutschen Volksgruppen, S. $261 \mathrm{f}$.

499 Vgl. Janko, Weg und Ende der deutschen Volksgruppe, S. 295.

500 Vgl. Tessin, Verbände, Bd. 3, S. 83.

501 Vgl. Janko, Weg und Ende der deutschen Volksgruppe, S. 295. 
reichsdeutschen Soldaten auch Domobranzen ${ }^{502}$ interniert. Etwas weiter südöstlich gerieten rund 1.800 Soldaten der „Prinz Eugen“ aus den Gemeinden Lazarfeld, Ernsthausen, Setschan und Molidorf in Brežice/Rann in die Hände von Partisanen und wurden dort erschossen. ${ }^{503}$ Laut Zeugen geschah dies am 18. Mai 1945, ungefähr 1.600 Soldaten sollen von Partisanen der I. Armee, II. Partisanen-Brigade im Ort Sveti Jurij/Sankt Georg, das zwischen Celje/Cilli und Zagreb liegt, erschossen worden sein. Ein Überlebender kam später ins Lager Kragujevac. Auch aus Kruševac wurden Erschießungen von Angehörigen der „Prinz Eugen“ und anderer deutscher oder kollaborierender Einheiten gemeldet. Nach Einnahme der Stadt sollen dort 2.000 Mann erschossen worden sein, davon etwa 400-500 Deutsche. Die Toten wurden westlich der Stadt auf dem Hügel Bagdala begraben. ${ }^{504}$ In einem der größten bisher entdeckten Massengräber in der Region Brešice/Rann konnten auch Angehörige der „Prinz Eugen“ identifiziert werden. ${ }^{505}$ Im Lager Obrovac und anderen kam es zu Misshandlungen, insbesondere von ehemaligen Soldaten der „Prinz Eugen“ wie auch „Handschar“-Soldaten. ${ }^{506}$

Zwischen Spodnje Hoče/Unterhötsch und Maribor/Marburg gab es einen 6 km langen Panzergraben, in dem einige Nächte lang SS-Männer, Wehrmachtssoldaten und Zivilisten, rund 20.000 Personen, erschossen wurden. In Novo Celje/Neu Cilli wurden 20 bis 25 verwundete SS-Männer an Titos Geburtstag aus den Betten geholt und erschossen. ${ }^{507}$

Eine Schätzung, wie viele der ehemaligen „volksdeutschen“ Waffen-SS-Soldaten insgesamt bei den Massentötungen oder durch unmenschliche Haftbedingungen zu Tode kamen, ist kaum möglich, zumal die jeweiligen Opferzahlen sowohl in Titos Jugoslawien als auch in der „volksdeutschen“ Nachkriegsliteratur sehr einseitig dargestellt wurden..$^{508}$

502 Slovensko Domobranstvo, antikommunistische, katholisch-konservative Slowenische Landwehr oder Slovenische Heimwehr genannt.

503 Vgl. Böhme, Die Geschichte der deutschen Kriegsgefangenen in Jugoslawien 1941-1949, Bd. I/1, München: Verlag Ernst und Werner Gieseking 1962, S. 107.

504 Vgl. ebd., S. 108.

505 Karl Peter Schwarz, Eine eineinhalb Meter starke Schicht von Skeletten, in: http://www.faz. net/aktuell/politik/ausland/massengrab-in-slowenien-entdeckt-eine-eineinhalb-meter-starkeschicht-von-skeletten-11070164.html.

506 Vgl. Böhme, Geschichte der deutschen Kriegsgefangenen, I/1, S. 107.

507 Vgl. ebd., S. 108.

508 Für eine ausführliche Auflistung verschiedenster Beispiele von Zwangsmaßnahmen gegen und Massakern an der „volkdeutschen“ Bevölkerung in Südosteuropa sowie Lagern aus „volksdeutscher“ Perspektive vgl. Hans Meiser, Ausgelöscht! Der Untergang der Deutschen in Südostmitteleuropa, S. 77-260. Für eine objektivere Darstellung vgl. Mirna Zakić, Ethnic Germans and National Socialism in Yugoslavia in World War II, Cambridge: Cambridge University Press 2017, S. 256-262. 
Insgesamt wurden im Frühjahr 1945 rund 50.000 Kollaborateure, darunter auch zahlreiche ehemalige Soldaten der „Prinz Eugen“, von den Briten nach Jugoslawien abgeschoben und von der Odjeljenje za Zaštitu Narodna (OZNA), der späteren jugoslawischen Geheimpolizei, ermordet. ${ }^{509}$ Portmann und Suppan gehen von 6.000 umgebrachten „Volksdeutschen“ allein in der Vojvodina aus. ${ }^{510}$ Die Erschießungen erfolgten ohne Gerichtsurteile, basierend allein auf der ethnischen Zugehörigkeit zur „volksdeutschen“ Volksgruppe. Das heute in Serbien liegende Jabuka/ Apfeldorf soll als Beispiel dienen: Im Spätherbst 1944 weigerte sich der serbische Ortsrichter, „volksdeutsche“ Dorfbewohner ohne Urteil erschießen zu lassen. ${ }^{511}$ Trotz seiner Intervention wurden am 14. November 194415 „Volksdeutsche“ verhaftet und getötet. Insgesamt wurden schließlich sogar 440 „Volksdeutsche“ aus Jabuka ermordet. ${ }^{512}$ In und um Jabuka sollen 32 Massengräber ausgehoben worden sein. ${ }^{513}$

Wer nicht erschossen wurde, dem drohten Deportation, Lagerhaft und Zwangsarbeit, beispielsweise in der Sowjetunion. ${ }^{514}$ Sowjetische Truppen brachten im Oktober 1944 rund 30.000 „volksdeutsche“ und deutsche Kriegsgefangene als Zwangsarbeiter nach Russland. Diese wurden, soweit sie nicht vorher starben, erst 1949 wieder aus den Lagern entlassen. ${ }^{515}$ Das Vermögen von vermeintlichen und echten Kollaborateuren wurde konfisziert. Über eine kollektive Aussiedlung verbliebener „Volksdeutscher“ wurde zumindest diskutiert. Nachdem die jugoslawische Regierung 1948 die Internierungslager auflöste, schob sie die Überlebenden nach Ungarn und Österreich ab. Weitere rund 62.000 „Jugoslawiendeutsche“ kamen im Zuge der Familienzuführung in den 1950er Jahren in die Bundesrepublik Deutschland. ${ }^{516}$

509 Brunnbauer, Politische Entwicklung Südosteuropas, S. 605.

510 Vgl. Portmann, Suppan, Serbien und Montenegro, S. 292.

511 Josef Beer (Hg.), Weißbuch der Deutschen aus Jugoslawien. Ortsberichte 1944-1948, München: Universitas 1992, S. 131.

512 Beer, Weißbuch der Deutschen aus Jugoslawien, S. 132.

513 Vgl. Heimatbuch der Ortsgemeinde Jabuka, S. 175, 312f., 319, 381, 388, 390, 408.

514 Vgl. Janko, Weg und Ende der deutschen Volksgruppe, S. 294-297.

515 Vgl. Calic, Geschichte Jugoslawiens, S. 179. Vgl. Janko, Weg und Ende der deutschen Volksgruppe, S. 297. Vgl. hierzu die etwas abweichenden Zahlen bei Arnold Suppan, Zwischen Hitler, Beneš und Tito. Deutsch-tschechoslowakische und deutsch-jugoslawische Konfliktgeschichte als Beispiele für Aufgaben der Mittel- und Südosteuropa-Forschung, in: Michael Gehler, Imke Scharlemann, Zischen Diktatur und Demokratie. Erfahrungen in Mittelost- und Südosteuropa, Hildesheim: Olms 2012, S. 319.

516 Vgl. Calic, Geschichte Jugoslawiens, S. 179f. 